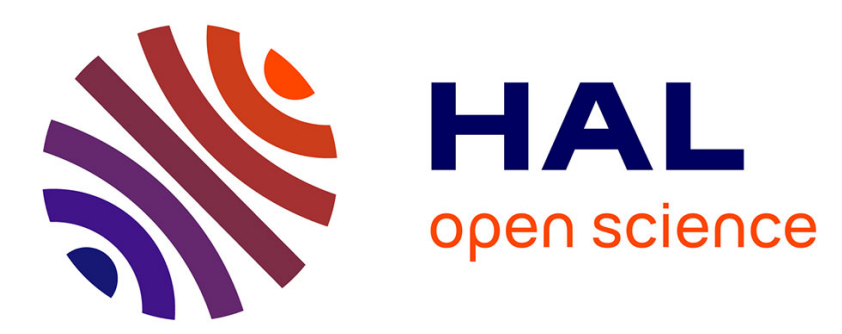

\title{
Emergence of Hemicryptophanes: From Synthesis to Applications for Recognition, Molecular Machines, and Supramolecular Catalysis
}

Dawei Zhang, Alexandre Martinez, Jean-Pierre Dutasta

\section{- To cite this version:}

Dawei Zhang, Alexandre Martinez, Jean-Pierre Dutasta. Emergence of Hemicryptophanes: From Synthesis to Applications for Recognition, Molecular Machines, and Supramolecular Catalysis. Chemical Reviews, 2017, 117 (6), pp.4900 - 4942. 10.1021/acs.chemrev.6b00847 . hal-01682799

\section{HAL Id: hal-01682799 \\ https://hal.science/hal-01682799}

Submitted on 14 Apr 2018

HAL is a multi-disciplinary open access archive for the deposit and dissemination of scientific research documents, whether they are published or not. The documents may come from teaching and research institutions in France or abroad, or from public or private research centers.
L'archive ouverte pluridisciplinaire HAL, est destinée au dépôt et à la diffusion de documents scientifiques de niveau recherche, publiés ou non, émanant des établissements d'enseignement et de recherche français ou étrangers, des laboratoires publics ou privés. 


\title{
Emergence of Hemicryptophanes: From Synthesis to Applications for Recognition, Molecular Machines, and Supramolecular Catalysis
}

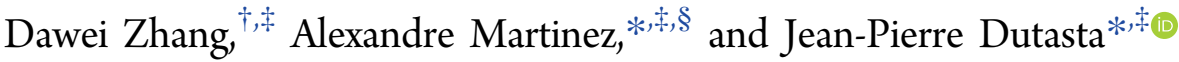 \\ ${ }^{\dagger}$ Shanghai Key Laboratory of Green Chemistry and Chemical Processes, School of Chemistry and Molecular Engineering, East China \\ Normal University, 3663 North Zhongshan Road, Shanghai 200062, People's Republic of China \\ ${ }^{\ddagger}$ Laboratoire de Chimie, École Normale Supérieure de Lyon, CNRS, UCBL, 46, Allée d’Italie, F-69364 Lyon, France \\ ${ }^{\S}$ Aix-Marseille University, CNRS, Centrale Marseille, iSm2, Av. Escadrille Normandie-Niemen, F-13397 Marseille, France
}

\begin{abstract}
In the wide area of host-guest chemistry, hemicryptophanes, combining a cyclotribenzylene (or cyclotriveratrylene CTV) unit with another different $C_{3}$-symmetrical moiety, appears as a recent family of molecular cages. The synthesis and recognition properties of the first hemicryptophane were reported in 1982 by Collet and Lehn, but the very little attention received by this class of host compounds in the 20 years following this first promising result can account for their apparent novelty. Indeed, in the last 10 years hemicryptophanes have aroused growing interest, and new aspects have been developed. Thanks to the rigid shaping unit of the north part (CTV) and also the variable and easily functionalized south moiety, hemicryptophanes are revealed to be inherently chiral ditopic host compounds, able to encapsulate various guests, including charged and neutral species. They also enter the field of stimuli-responsive supramolecular systems exhibiting controlled functions. Moreover, endohedral functionalization of their inner cavity leads to supramolecular catalysts. The confinement of the catalytic center affords nanoreactors

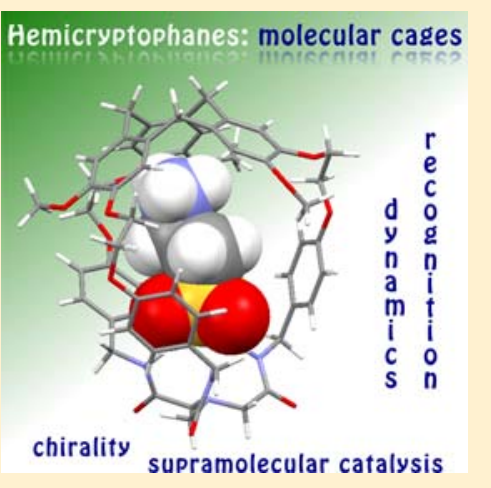
with improved catalytic activities or selectivities when compared to model systems without a cavity. The current trend shows that reactions in the confined space of synthetic hosts, mimicking enzyme behavior, will expand rapidly in the near future.
\end{abstract}

\section{CONTENTS}

1. Introduction

2. Synthesis of Hemicryptophanes

2.1. Synthesis of Covalent Hemicryptophanes

2.1.1. Triamide- and Tren-Hemicryptophanes

2.1.2. Trialkanolamine Hemicryptophanes

2.1.3. Hemicryptophanes Based on a Tripodal Benzenic Platform

2.1.4. Hemicryptophanes Based on a Macrocyclic Platform

2.1.5. Hemicryptophanes Based on Heteroatomic Pivot

2.1.6. Hemicryptophanes Formed from a Covalent $\mathrm{CTV}-\mathrm{C}_{60}$ Adduct

2.1.7. Hemicryptophanes Constructed from a Diphenylglycoluril Unit

2.1.8. Hemicryptophanes Obtained by Metal Coordination

2.2. Formation of Hemicryptophane Capsules by Reversible Bonds/Interactions

2.2.1. Formation by Boronate Esterification

2.2.2. Formation by lonic Interactions

2.3. Functionalization of Hemicryptophanes

2.3.1. Water-Soluble Hemicryptophanes

2.3.2. Endohedral Functionalization of Hemicryptophanes

3. Host-Guest Chemistry of Hemicryptophanes
3.1. Guest Inclusion in the Solid State: X-ray Molecular Structures

3.2. Complexation in Solution

3.2.1. Recognition of Ammonium Guests

3.2.2. Recognition of Ion Pairs

3.2.3. Recognition of Zwitterions

3.2.4. Recognition of Carbohydrates

3.2.5. Recognition of Fullerenes

4907

4908

4911

4912

4912

4912

4914

4915

4916

4917

4917

4. Hemicryptophanes in Motion: Toward Molecular Machines

4.1. Molecular Gyroscope

4.2. Molecular Propeller

4.3. Molecular Breathing

5. Hemicryptophanes: Supramolecular Catalysts

5.1. Hemicryptophanes as Organocatalysts

5.1.1. Encaged Verkade's Superbases: Catalysts for Diels-Alder Reactions

5.1.2. Encaged Azaphosphatrane Catalysts for $\mathrm{CO}_{2}$ Conversion

4921

4923

4923

4925

4926

4928

4929

4930

4930

4930

4931

4931

4932

4932

4932

5.2. Metal-Hemicryptophane Complexes as Catalysts

5.2.1. Encaged Vanadium(V) Catalysts for Sulfoxidation Reactions

5.2.2. Encaged Zinc(II) Catalysts for Carbonate Hydrolysis

4933

4933

4934

4918

4921 


\subsubsection{Encaged Ruthenium(II) Catalysts for the Oxidation of Alcohols \\ 5.2.4. Encaged Copper(II) Catalysts for Cyclo- alkane Oxidation \\ 6. Conclusions}

4935

4936

Acknowledgments References

\section{INTRODUCTION}

Molecular cages, defined as hollow structures delineating a three-dimensional cavity, are attracting considerable attention in modern supramolecular chemistry due to their possible applications in molecular recognition, catalysis, drug delivery, biosensing, separation, and storage. ${ }^{1-8}$ Among the classes of molecular containers, such as crown ethers, ${ }^{9,10}$ cryptands, ${ }^{10}$ calixarenes, ${ }^{11-13}$ resorcinarenes, ${ }^{14,15}$ curcurbiturils, ${ }^{16-18}$ cyclodextrins, ${ }^{19,20}$ or pillararenes, ${ }^{21-23}$ cryptophanes and hemicryptophanes based on a cyclotribenzylene core, most of the time identified to a derivative of the cyclotriveratrylene (CTV) unit (Figure 1), have recently received growing interest. (a)

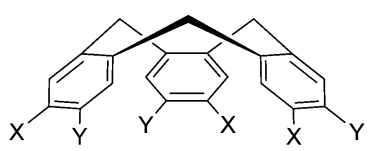

Cyclotribenzylene (CTV: $\mathrm{X}=\mathrm{Y}=\mathrm{OCH}_{3}$ ) (b)

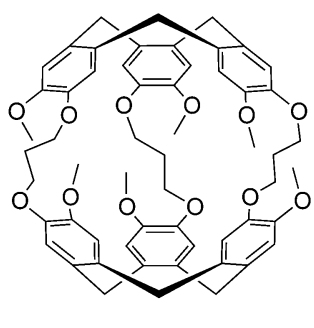

Cryptophane-E

Figure 1. (a) Cyclotribenzylene and cyclotriveratrylene (CTV, $\mathrm{X}=\mathrm{Y}$ $\left.=\mathrm{OCH}_{3}\right)$. (b) Cryptophane-E. ${ }^{24}$

Cryptophanes are homotopic host compounds built from two CTV units, which can efficiently encapsulate small molecules such as methane or epoxides, cations, anions, and xenon or radon noble gases. ${ }^{24,25}$ A previous comprehensive review on cryptophanes by Brotin and Dutasta highlighted the synthesis methods, their binding and chiroptical properties, and their potential applications as biosensors and chiral agents. ${ }^{24}$ In contrast, the related hemicryptophanes combining a CTV unit with another $C_{3}$-symmetrical moiety via covalent bonds or noncovalent interactions are heteroditopic hosts able to recognize various charged or neutral guests, such as ion pairs, zwitterions, ammoniums, carbohydrates, and fullerenes. Currently, hemicryptophanes are mainly used as molecular receptors, supramolecular catalysts, and functional molecules anticipating molecular machines.

The chemistry of hemicryptophane was developed quite slowly before $2005 .^{26}$ In 1982, Lehn and Collet described the first two members of a new type of molecular cages called speleands ( $\mathbf{1}$ and $\mathbf{2}$ in Figure 2a), which associated a CTV and a crown ether unit, showing potential recognition properties toward methylammonium cations. ${ }^{27}$ Then in 1989 Nolte et al. reported the synthesis of a molecular host derived from CTV and diphenylglycoluril units presenting potential catalytic a)
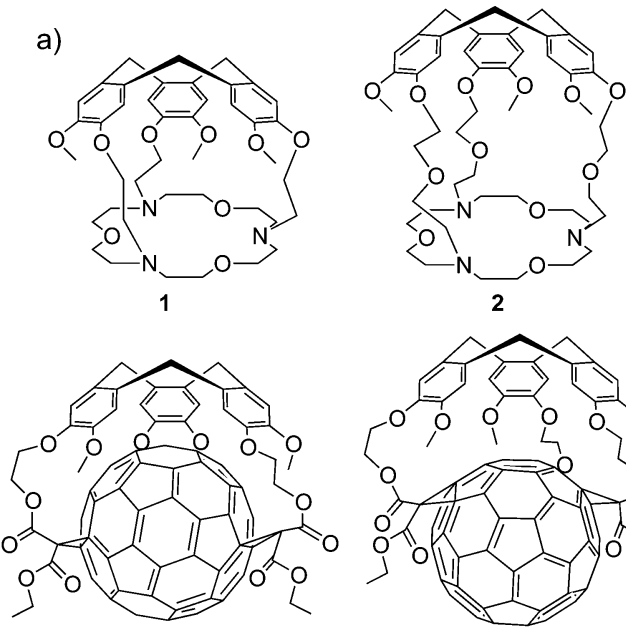

3

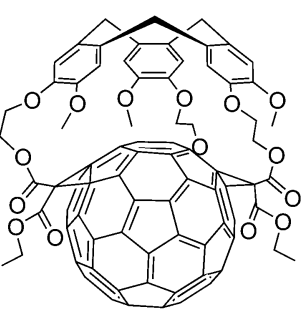

4
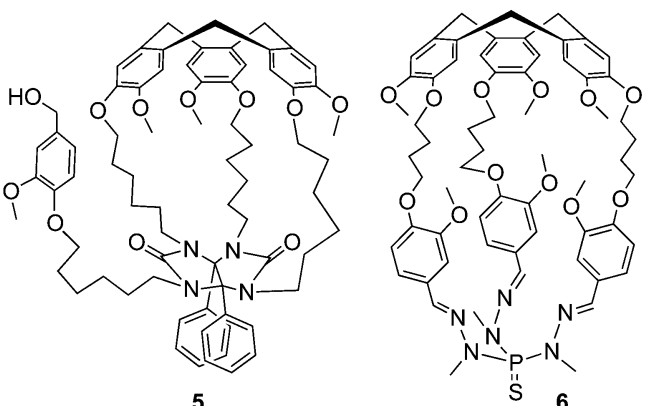

b)
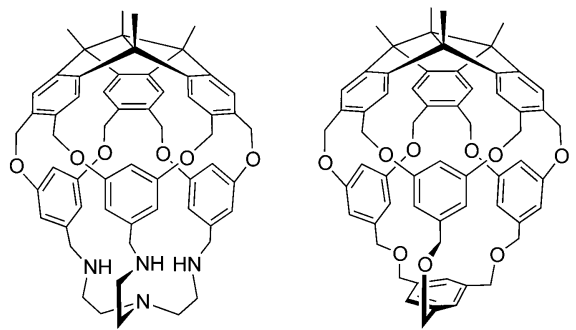

Figure 2. (a) Hemicryptophanes 1-6 synthesized between 1982 and 2005. (b) Structures of Kuck's hemicryptophanes based on the TBTQ unit.

properties related to its easily functionalized arm ( 5 in Figure $2 a) .{ }^{28}$ Ten years later, Diederich and Echegoyen described the synthesis of the two covalent $\mathrm{CTV}-\mathrm{C}_{60}$ adducts 3 and 4 (Figure $2 \mathrm{a}$ ) prepared by the tether-directed Bingel reaction. ${ }^{29}$ The $C_{3}$ symmetry of the two cage adducts was evidenced by NMR spectroscopy. Nevertheless, it is obvious that the free space in the cavity of the two compounds is quite restricted due to the interactions between the electron-rich aromatic rings of the CTV and the electron-poor $\mathrm{C}_{60}$, limiting their applications as receptors. The same year Dutasta and co-workers reported the synthesis and crystal structure of the thiophosphorylated molecular cage 6 (Figure 2a) based on the CTV unit and proposed the term hemicryptophane for this type of molecular cages, which has been widely used thereafter. ${ }^{30}$ Last, based on suitably functionalized CTVs, metal complexes were obtained that possess the hemicryptophane structure. In some specific cases, the CTV cap was used as ligand platform for iron(II) and iron(III) coordination. ${ }^{31}$ Hence, it can be seen that this class of host compounds received little attention before 2005 since only a few relevant papers were reported during this period and even 
less have really focused on their applications. Unexpectedly, after 2005, this chemistry received growing interest leading to a blossoming field of research, particularly for molecular recognition. For instance, a series of sophisticated enantiopure hemicryptophanes has been synthesized benefitting from the inherent chirality of the CTV unit and used for stereoselective recognition of chiral guest molecules. They have also entered the field of controlled molecular motions, exhibiting solventresponsive properties. Moreover, confinement of catalytic sites in the inner space of the cavity of hemicryptophanes resulted in supramolecular organic and organometallic catalysts with remarkable properties. We should mention herein the important contribution of Kuck et al., who synthesized cryptophane and hemicryptophane-like molecular cages based on the tribenzotriquinacene (TBTQ) scaffold. Recently, they reported the synthesis of hemicryptophanes where the CTV part is replaced by the TBTQ unit. This type of molecular receptor does not strictly belong to the CTV-based derivatives, but their closely related structures deserve to be pointed out in this review (Figure 2b). ${ }^{32}$

In this review, we will first introduce the general synthetic methods (section 2) to obtain racemic, enantiopure, watersoluble, and metalated hemicryptophane hosts. Next, the applications of hemicryptophanes in molecular recognition (section 3) as molecules with controllable motions (section 4) and as supramolecular catalysts (section 5) will be presented. Finally, we will conclude and present perspectives on the future development of hemicryptophanes and highlight the key challenges in this emerging area of research (section 6).

\section{SYNTHESIS OF HEMICRYPTOPHANES}

Hemicryptophane hosts can be classified into two main families according to the method of preparation used: covalent hemicryptophanes and self-assembled hemicryptophane capsules. Covalent hemicryptophanes refer to compounds, where the two main $\mathrm{C}_{3}$-symmetrical units defining the ditopic character of these hosts are connected by covalent bonds. Access to covalent cages most of time needs multistep syntheses, and often the main drawback of these syntheses is a low overall yield. Although some cage compounds are only accessible on a milligram scale, a range of laboratory-scale synthesis schemes has been developed to afford hemicryptophanes with various functionalities that can be obtained easily on gram scale, allowing wider applications. The different approaches to the syntheses of covalent hemicryptophane hosts will be presented in section 2.1. The formation of self-assembled hemicryptophane capsules is currently attracting great attention due to the developments in self-assembling strategies and will be described in section 2.2. For instance, hemicryptophanes formed of two interacting molecular subunits have been reported using reversible dynamic covalent interactions such as the reversible formation of boronate esters or supramolecular ionic interactions between charged moieties. Finally, section 2.3 is devoted to the functionalization of hemicryptophanes to develop specific properties and to investigate their applications in catalysis and sensing in organic or aqueous media.

An important aspect of hemicryptophanes is their inherent chirality arising from the CTV unit. A greatly growing demand for chiral hosts exists, and consequently, the production of enantiopure hemicryptophanes should be considered as a significant breakthrough for applications in chiral recognition or catalysis. Particular attention will be paid to this aspect throughout this section. The $C_{3}$ symmetry of the CTV moiety confers to the hemicryptophanes an inherent chirality with $P$ or $M$ configuration. ${ }^{33}$ When associated with other stereogenic centers the hemicryptophane molecules exist as diastereomers. Thus, the synthesis of enantiopure compounds leads to either enantiomers or diastereomers, and it is essential to determine their absolute configuration. A convenient method relies on determination of the X-ray crystal structure of the enantiopure compounds. However, obtaining crystals suitable for X-ray analysis is not always easy and successful. ${ }^{34}$ The use of electronic circular dichroism (ECD) spectroscopy has been widely described in the literature and is particularly suitable to determine the absolute configuration of compounds bearing the CTV unit. ${ }^{35}$ Indeed, the spectra can be interpreted as the result of the excitonic coupling of the three aromatic rings of the CTV unit, which gives a specific ECD signature. ${ }^{35-38}$ This method is relatively easy and reliable but may also fail in some specific cases when the ECD signals of the CTV overlap with those of other aromatic groups. In such cases, chemical correlation methods were developed and successfully applied to hemicryptophane molecules.

When compared to racemic hemicryptophanes, enantiopure cages are more useful since chirality plays a crucial role in most of the biological events, and chiral synthetic bioinspired supramolecular systems can be designed to mimic and understand these processes. ${ }^{39-41}$ However, the easy synthesis of this type of enantiopure molecular cages is a difficult challenge because of the high complexity of such molecules. Two main strategies can be followed to prepare enantiopure hemicryptophanes. (i) One is the resolution of racemic mixtures using chiral semipreparative high-performance liquid chromatography (HPLC). The major drawbacks of this method are the necessity of a chiral HPLC and the difficulty in providing sizable amounts of compounds. (ii) Another is introduction of additional stereocenters to form diastereomers. This second strategy needs more complex synthesis pathways, and in most cases, the separation of two diastereomers is tedious but affords more sizable amounts of enantiopure cages. Both methods appear in the literature and will be discussed in the following sections. Throughout this review, without specific indications, the chiral compounds described are racemates.

\subsection{Synthesis of Covalent Hemicryptophanes}

Covalent hemicryptophanes can be obtained by three main pathways. The first one is a cage-closing reaction to form the CTV unit (arbitrarily named the north part) and is related to the "template method" used for the synthesis of cryptophanes (Figure 3a). ${ }^{24}$ The Friedel-Crafts condensation of the veratryl precursors is a convenient and common approach for the synthesis of cryptophanes and hemicryptophanes. The acidcatalyzed cyclization reaction using mainly $\mathrm{HCOOH}$ or $\mathrm{Sc}(\mathrm{OTf})_{3}$ gives rise to the CTV moiety leading to the desired hemicryptophanes. The performance of this intramolecular cyclodehydration to generate the CTV in the last step, in terms of yield and difficulty in their purification, usually depends on the structures of the hemicryptophane precursors.

The second way is the $[1+1]$ coupling between the north part and the other $C_{3}$ unit (arbitrarily named the south part), which is very effective in many cases and is particularly well suited for the preparation of enantiopure hemicryptophanes (Figure $3 \mathrm{~b}$ ). Moreover, this strategy allows the preparation of a wide range of ditopic molecules thanks to the numerous and versatile available southern moieties and involves different approaches such as reactions of acyl chloride with primary or 


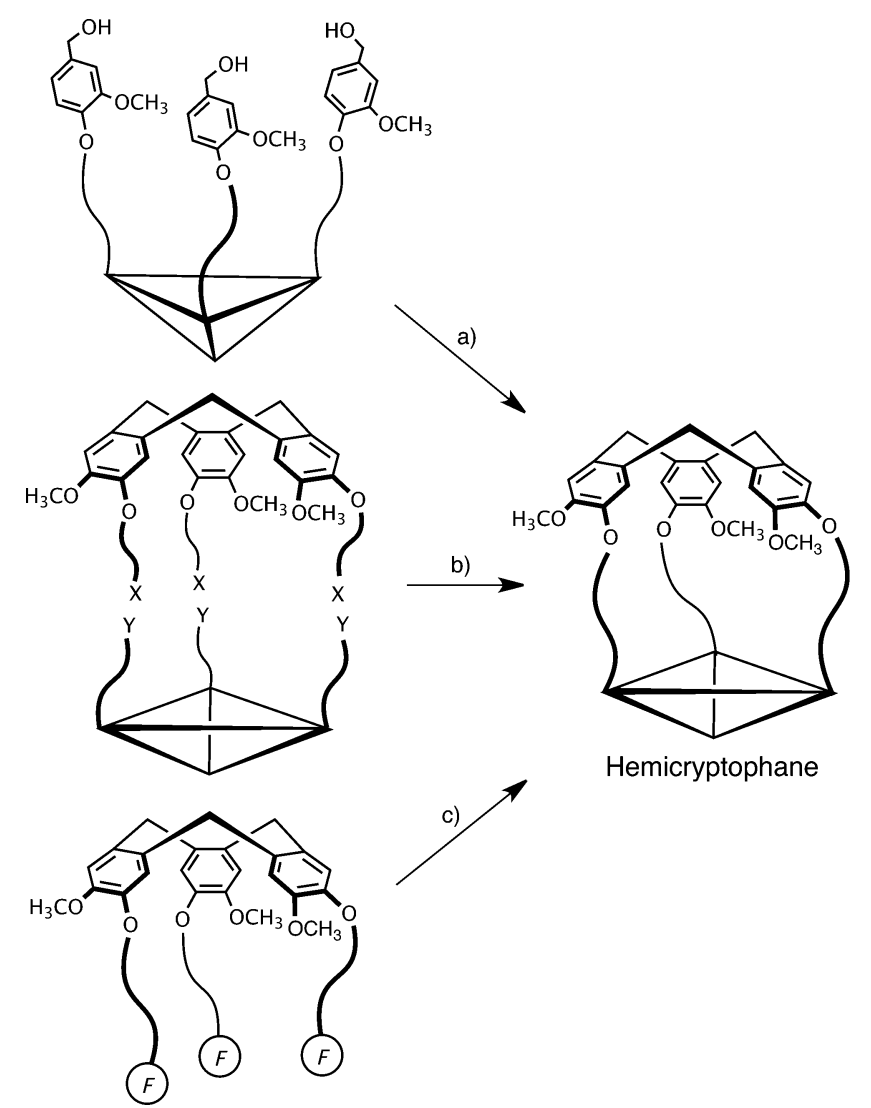

Figure 3. Synthesis strategies for the preparation of hemicryptophane hosts: (a) by formation of the CTV unit; (b) by $[1+1]$ coupling of north and south parts; (c) by closure reaction at the south part (X, Y, and $\mathrm{F}$ are suitable functions).

secondary amine, carboxyl with primary amine, Ugi reaction type, and disulfide-bond formation most commonly. For instance, sophisticated structures such as crown ethers, calixarenes, and cyclodextrins were combined with the CTV cap to afford ditopic hosts with fairly good yields. This method usually requires high-dilution conditions to avoid formation of polymeric compounds.

The third way is to introduce the southern $C_{3}$ unit from the suitably functionalized CTV scaffold (Figure $3 \mathrm{c}$ ). In this way hemicryptophanes are formed by appending on the CTV three linkages bearing suitable functions for an intramolecular reaction that leads to the cage structure. This approach has been seldom used compared to strategies based on the cageclosure reaction at the north part or the $[1+1]$ coupling presented above.

For a given compound, the authors often used either of the methods described above to increase the yields and/or produce sizable amounts of enantiopure compounds. For instance, the $[1+1]$ coupling between two modules has been often advantageously applied to the synthesis of hemicryptophanes already obtained by formation of the CTV cap according to the first synthetic pathway. In the following sections we thus emphasize the various approaches reported in the literature for the synthesis of racemic and enantiomerically pure hemicryptophanes according to the nature of the southern units.

2.1.1. Triamide- and Tren-Hemicryptophanes. The triamide and the tris(2-aminoethyl)amine (tren) structures have been used to build receptors for complexation of anionic $^{42,43}$ and cationic species. ${ }^{44}$ In particular, transition metal ions such as cobalt, zinc, ${ }^{45}$ and copper ${ }^{46}$ form complexes with these ligands, presenting interesting catalytic or recognition properties. Different heteroelements have been also trapped into a tren moiety, leading, in the case of phosphorus, to pro-azaphosphatrane compounds, which constitute a remarkable class of basic and nucleophilic organocatalysts. ${ }^{47}$

The racemic triamide- and tren-hemicryptophanes 14 and 15a were first synthesized following the first method (Figure 3a) as depicted in Scheme $1 .^{48}$ The reaction of vanillyl alcohol 7 with dibromoethane in $\mathrm{EtOH}$ at $80{ }^{\circ} \mathrm{C}$ affords compound 8, which is protected with THP to give 9 with an overall yield of $27 \%$. The $C_{3}$ symmetry precursor of the south part of the host is obtained from the nitrilotriacetic acid $\mathbf{1 0}$ that reacts with 3 equiv of $p$-methoxy benzylamine in the presence of $\mathrm{P}(\mathrm{OPh})_{3}$ to give the tripodal triamidoamine derivative 11. The methoxy groups in $\mathbf{1 1}$ are then removed using $\mathrm{BBr}_{3}$ to give the triphenol derivative 12. Reacting 9 and 12 in DMF in the presence of $\mathrm{Cs}_{2} \mathrm{CO}_{3}$ affords the hemicryptophane precursor 13 . The cyclization is then performed in $\mathrm{HCOOH}$ to give the desired hemicryptophane $\mathbf{1 4}$ in $30 \%$ yield. Finally, the reduction of the amide functions is achieved with $\mathrm{BH}_{3}$ in THF to give the trenhemicryptophanes $\mathbf{1 5 a}$ in $30 \%$ yield. Similar to the synthesis of 14, the hemicryptophanes 16 and 17 (Scheme 1b) bearing fluorinated aromatic rings in the three linkages were also obtained. ${ }^{49}$ The racemic triamide-hemicryptophane $\mathrm{rac}-14$ was resolved by chiral semipreparative HPLC, leading to the enantiopure compounds $M-14$ and $P-14{ }^{50}$ Applied to rac-15a the resolution is unsuccessful, underlining the limitation of the method.

The convenient and efficient modular approach of the $[1+$ 1] coupling reaction (Figure 3b) was developed for the synthesis of the tren-based hemicryptophanes 15a-i (Scheme 2). ${ }^{51}$ The alkyl-brominated CTV $\mathbf{1 8 a}$ is first synthesized in two steps from vanillyl alcohol and dibromoethane according to the procedure described by Dmochowski et al. ${ }^{52}$ The preparation of the hemicryptophane precursor 20a is then conducted under standard conditions by reacting $\mathbf{1 8 a}$ with 4 -hydroxybenzaldehyde (19a) in DMF in the presence of $\mathrm{Cs}_{2} \mathrm{CO}_{3}$ with excellent yields and without purification by column chromatography. The condensation of $20 \mathrm{a}$ with tris (2-aminoethyl)amine in $\mathrm{CHCl}_{3} / \mathrm{CH}_{3} \mathrm{OH}$ mixture, followed by a reduction step with $\mathrm{NaBH}_{4}$, affords $15 \mathrm{a}$ in $77 \%$ yield. Hemicryptophane 15 a is thus obtained in $8 \%$ overall yield via a four-step synthetic route, which improves the previous seven-step procedure (3\% overall yield; Scheme 1) and allows the synthesis of 15a on a gram scale. Moreover, the size, shape, and functionalities of the molecular cavity are easily modified by changing the nature of the aromatic linkages (Scheme 2 ). For instance, the cavity size was modified by changing the relative position of the aldehyde and the hydroxy groups on the aromatic rings (hemicryptophanes $\mathbf{1 5 b}$ and $\mathbf{1 5 c}$ ). An electron-donating group was also incorporated in the aromatic part of the linkages at different positions, leading to hemicryptophanes $15 \mathrm{~d}$ and $15 \mathrm{e}$, and the chlorine electron-withdrawing group was successfully integrated in the aromatic wall of the hemicryptophane $\mathbf{1 5 f}$. Hemicryptophanes $\mathbf{1 5 g} \mathbf{- i}$ with larger aromatic walls (naphthyl moieties) were obtained and showed fluorescent properties. Thus, this synthetic pathway constituted an important step in the chemistry of hemicryptophanes as it allowed production of larger amounts of compounds, which helped in further applications as receptors or supramolecular catalysts.

Dutasta and Martinez et al. followed the pathway shown in Scheme 2 to develop the gram-scale preparation of enantiopure 
Scheme 1. (a) Synthesis of Hemicryptophanes 14 and 15a; (b) Structure of Hemicryptophanes 16 and 17

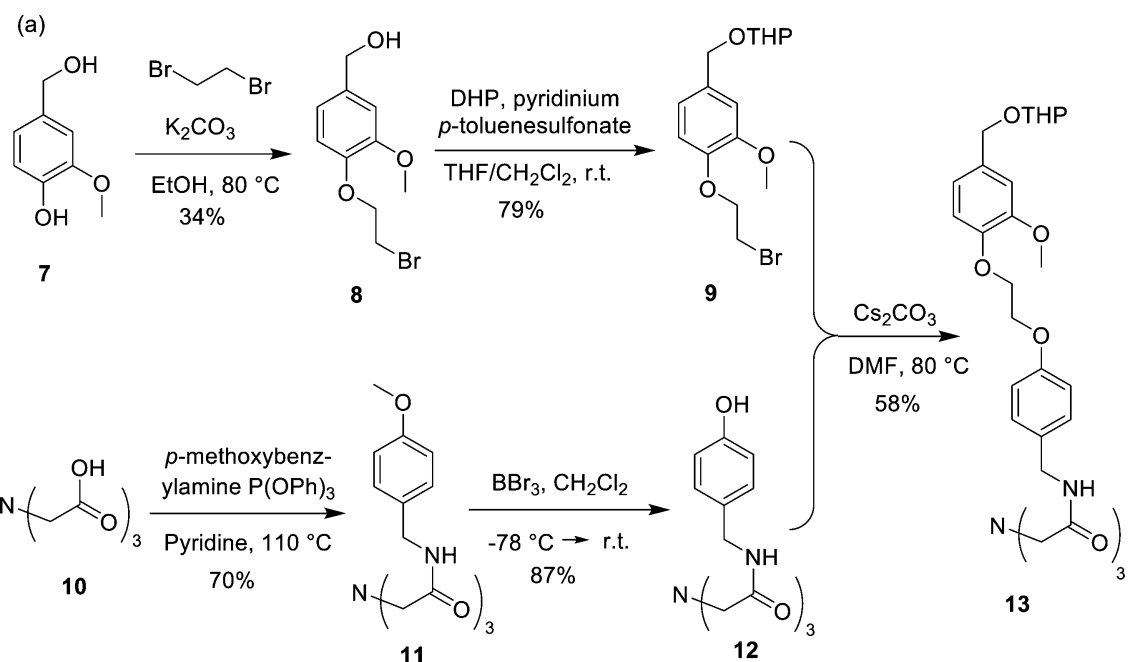

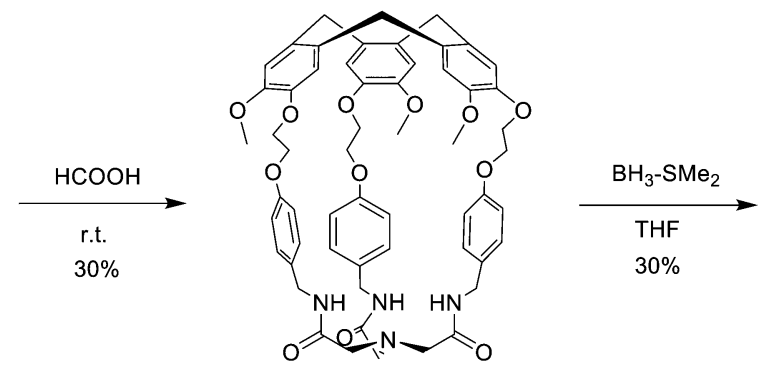

14

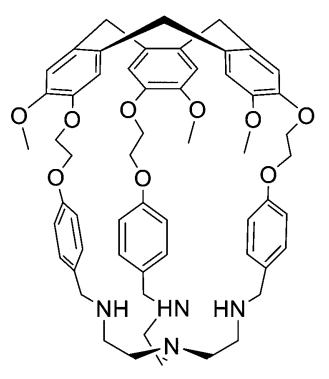

$15 a$

(b)

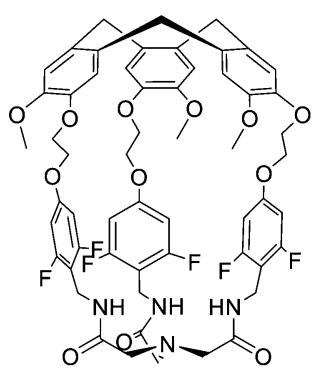

16

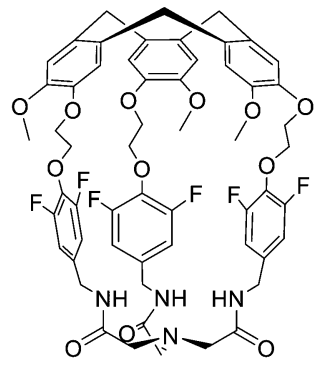

17

Scheme 2. Synthesis of Hemicryptophanes $15 a-i$
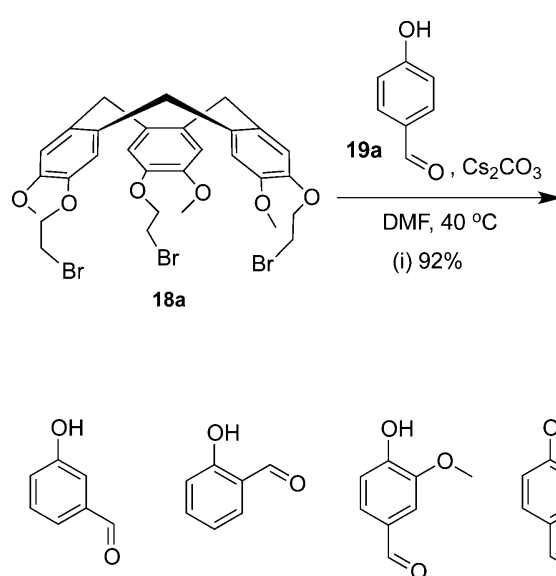

$19 b$
$19 c$

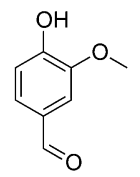

19d

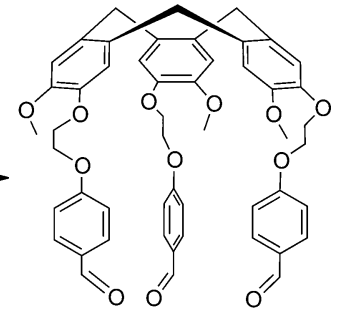

20a

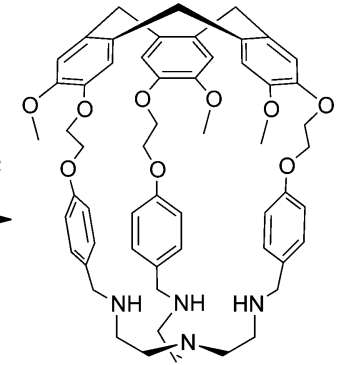<smiles>COc1cc(O)ccc1C=O</smiles><smiles>O=Cc1cccc(O)c1Cl</smiles>

$19 f$<smiles>O=Cc1ccc(O)c2ccccc12</smiles>

$19 \mathrm{~g}$
$15 a$ $\mathrm{NH}_{2} \curvearrowright \mathrm{NH}_{2}$ $\underset{\mathrm{CHCl}_{3} / \mathrm{MeOH} \text {, r.t. }}{\stackrel{\mathrm{NaBH}_{2}}{\longrightarrow}}$ (ii) $77 \%$<smiles>O=Cc1ccc2cc(O)ccc2c1</smiles>

$19 \mathrm{~h}$
$19 i$ 
hemicryptophanes M-15a and P-15a. ${ }^{53}$ The synthesis starts from the enantiopure CTV-18a obtained by resolution of its racemates by chiral HPLC. To prevent the racemization of the enantiopure 18a and 20a, the two subsequent steps were performed at $25{ }^{\circ} \mathrm{C}$, affording the expected product with good yields and excellent enantiomeric excess for the final cages (ee $\geq 98 \%$ ). Moreover, the enantiopure hemicryptophanes 15d, 15f, and 15i were also prepared from the corresponding phenols 19d, 19f, and 19i, respectively, highlighting the modularity of this strategy.

Makita and co-workers followed a similar strategy to synthesize the tren-hemicryptophane rac-22 and triamidehemicryptophane rac-24 having smaller cavities (Scheme $3)^{54,55}$ It is noteworthy that hemicryptophane $\mathbf{2 2}$ was obtained

Scheme 3. Synthesis of Hemicryptophanes 22 and 24
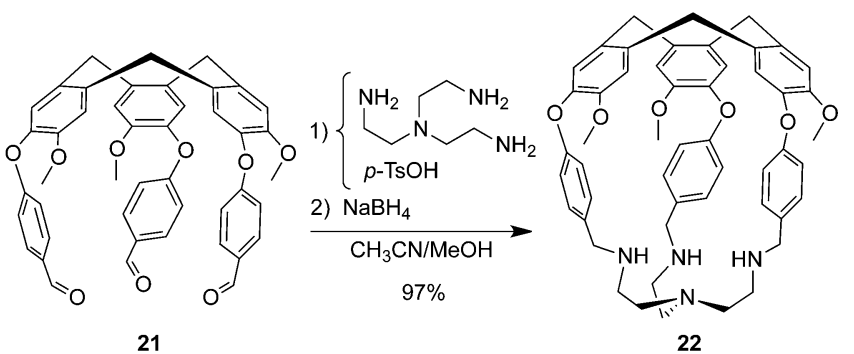

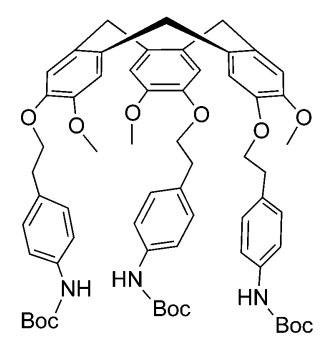

23
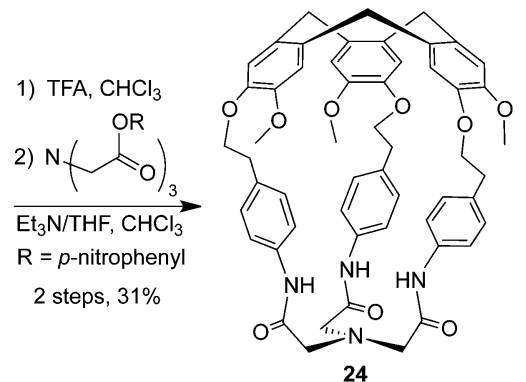

in $97 \%$ yield from precursor $\mathbf{2 1}$, $^{54}$ demonstrating the high efficiency of this synthetic method. The triamide derivative $\mathbf{2 4}$ was obtained in a two-step synthesis. Removal the tri-tertbutoxycarbonyl (Boc) protecting groups from precursor 23 and subsequent coupling with nitrilotriacetic acid tris ( $p$-nitrophenyl ester) afforded hemicryptophane $\mathbf{2 4}$ in $31 \%$ overall yield. Hemicryptophane $\mathbf{2 4}$ was able to bind tetraalkylammonium salts and exhibited a strong affinity for acetylcholine neurotransmitter.

Compared to 14 and $15 \mathrm{a}$, hemicryptophane stereoisomers $M-(S, S, S)-29 / 30, P-(S, S, S)-29 / 30, M-(R, R, R)-29 / 30$, and $P$ $(R, R, R)-29 / 30$ possess three additional stereogenic centers (Scheme 4). ${ }^{5,57}$ Interestingly, introducing these new chiral centers in $\mathbf{2 9}$ avoids chiral HPLC to separate the enantiomers and also makes this class of hosts more promising for stereoselective recognition experiments. A synthetic pathway similar to that used for $\mathbf{1 4}$ afforded hemicryptophanes 29 starting from the chiral $(S / R)-4$-methoxy- $\alpha$-benzylamine. The two diastereomers $M-(S, S, S)-29$ and $P-(S, S, S)-29$ were separated by preparative achiral TLC. Direct reduction of the amide functions of the mixture of the two diastereomers 29 gives the two stereoisomers of $\mathbf{3 0}$, which are readily separated by column chromatography on silica gel. ${ }^{57}$

An easy synthesis of enantiopure hemicryptophanes $31 \mathrm{a}-\mathrm{c}$ via the thermodynamic resolution of the racemic CTV 20a
(Scheme 2), leading to enantiomerically pure compounds, was reported (Scheme 5). ${ }^{58}$ It was found that when using enantiopure tren derivative as the other modular compound, only one diasteromeric cage was formed whatever the nature of the substituents located on tren's stereogenic centers. This route provides an original access to enantiopure hemicryptophanes, avoiding the separation of two diastereomers.

Rivera et al. developed a very efficient and straightforward method, featuring the one-pot assembly of molecular architectures by Ugi-type multiple multicomponent macrocyclization of trifunctional building blocks, for synthesis of the hemicryptophane 33 bearing Ugi-peptoid backbones. ${ }^{59}$ In this approach, four components, i.e., CTV-tricarboxylic acid 32, a primary amine, an oxo compound, and an isocyanide, are required for the 3-fold Ugi reaction (Scheme 6). A methanol solution of the tetra- $n$-butyl ammonium salt of CTVtricarboxylic acid 32 is gradually added to a solution of paraformaldehyde and amine, followed by slow addition of tris(2-isocyanoethyl)amine. The hemicryptophane 33 is thus obtained with acceptable yields after purification by flash column chromatography. Apart from the simplicity of this approach for constructing complex molecules, another key feature is the variability of the tris-functionalized scaffolds with defined geometries to build various molecular cages.

2.1.2. Trialkanolamine Hemicryptophanes. Hemicryptophanes combining CTV and triethanolamine groups such as compound 41 (Scheme 7) are particularly interesting for their potential as ligands for endohedral metal coordination. The synthesis of the enantiopure hemicryptophanes 41 was reported in 2005 and facilitated by introduction of additional stereocenters to form diastereomers. ${ }^{60}$ As shown in Scheme 7, allyloxyphenol 34 reacts with compound 9 in the presence of $\mathrm{Cs}_{2} \mathrm{CO}_{3}$ in DMF to give 35 , which is subsequently deprotected to generate the phenol derivative 36 . The epoxide 37 is synthesized by a regioselective nucleophilic substitution reaction of 36 on $(R)-(-)$-glycidyl nosylate in DMF. Then an excess of ammonia is added to the methanol solution of $\mathbf{3 7}$ to give the primary amine 38 . The hemicryptophane precursor 39 is obtained by a trimerization reaction of 38 with 2 equiv of the epoxide 37 in methanol followed by an acetylation reaction to decrease the polarity and facilitate purification. An intramolecular cyclization of 39 is then accomplished using $\mathrm{Sc}(\mathrm{OTf})_{3}$ as Lewis acid in $\mathrm{CH}_{3} \mathrm{CN}$ to produce hemicryptophanes $M-(R, R, R)-\mathbf{4 0}$ and $P-(R, R, R)-\mathbf{4 0}$ in their diastereomerically pure form with yields of $22 \%$ and $17 \%$, respectively, after separation by column chromatography. Finally, the synthesis of hemicryptophanes $M-(R, R, R)-41$ and $P-(R, R, R)$ 41 is achieved quantitatively from the corresponding hemicryptophane $\mathbf{4 0}$ by hydrolysis with methanolic $\mathrm{NaOH}$. Starting from the $(S)-(+)$ enantiomer of glycidyl nosylate, the other diastereoisomeric pair, $P-(S, S, S)-41$ and $M-(S, S, S)-41$, were also successfully prepared using the same synthetic pathway.

Determination of the absolute configuration of the four stereoisomers of $\mathbf{4 1}$ was achieved using ECD spectroscopy. The $P$ configuration of the enantiopure hemicryptophane gave rise to a characteristic positive-negative bisignate (from low to high energies, $270-230 \mathrm{~nm}$ ). In turn, the $M$ configuration is assigned to the hemicryptophane that gives a negative-positive bisignate, as observed in Figure $4 .^{60}$

A new class of enantiopure hemicryptophanes (46, Scheme 8 ) bearing the trialkanolamine group was also synthesized. ${ }^{61}$ However, the structures of the stereoisomers of 46 are more complicated than those of $\mathbf{4 1}$ since there are three types of 

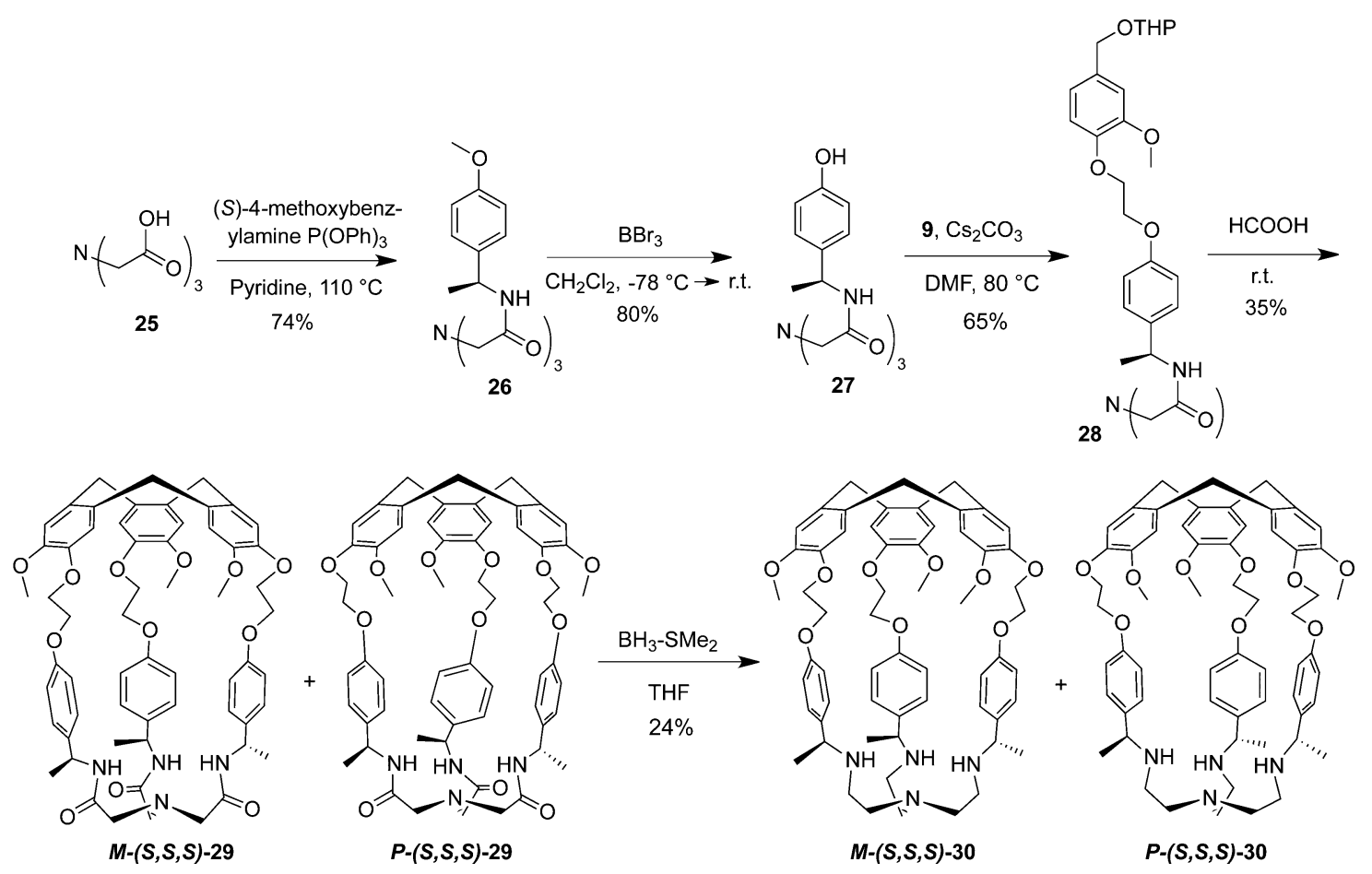

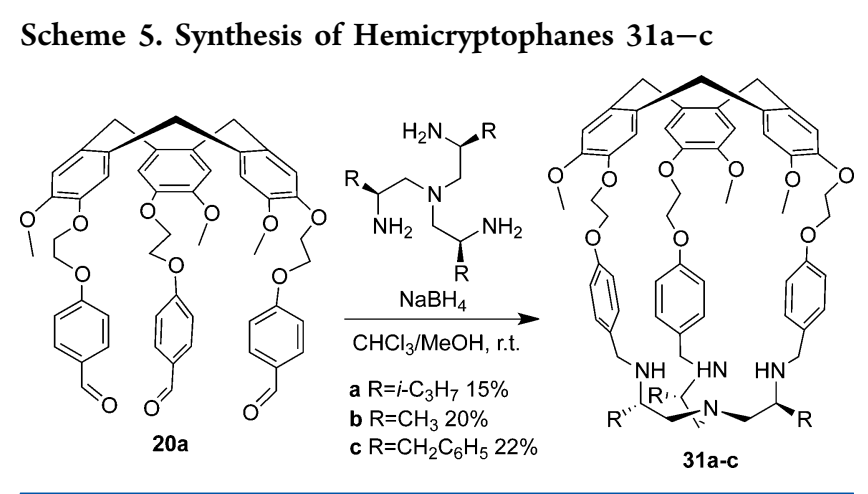

Scheme 6. Synthesis of Hemicryptophane 33

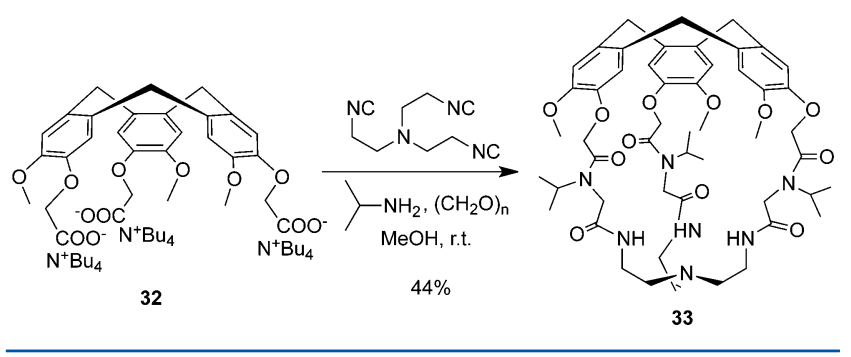

chiral elements simultaneously in one molecule with seven stereogenic units, i.e., a helically chiral CTV unit, three axially chiral binaphthol linkages, and three centrally asymmetric carbons on the trialkanolamine group affording eight stereoisomers. Following the synthetic strategy depicted in Scheme 8, the first pair of diastereomers of hemicryptophane 46, $M$ $(S, S, S)-(S, S, S)-46$ and $P-(S, S, S)-(S, S, S)-46$, was obtained by condensation of $(S)-(-)-1,1^{\prime}$-bi(2-naphthol) (BINOL) with compound 9 to give the BINOL derivative 42 and subsequent reaction with $(S)$-glycidyl-nosylate in DMF to provide the epoxide 43 . The primary amine 44 was obtained by treating 43 with an excess of ammonia in methanol. The trimerization reaction led to the hemicryptophane precursor 45 , which was then treated with $\mathrm{Sc}(\mathrm{OTf})_{3}$ in $\mathrm{CH}_{3} \mathrm{CN}$ to generate the enantiopure hemicryptophanes $M-(S, S, S)-(S, S, S)-46$ and $P$ $(S, S, S)-(S, S, S)-46$ in moderate yields $(30 \%$ and $13 \%$, respectively) after preparative thin-layer chromatography (TLC). Following the same synthetic scheme and using the enantiopure BINOL and glycidyl-nosylate with the suitable configuration, the other three pairs of hemicryptophane diastereomers 46 were obtained with a moderate diastereoselectivity in the last synthesis step. Noteworthy is the fact that the incorporation of binaphthyl groups into the cage structures not only introduces an additional stereogenic element and fluorescent properties but also avoids the protectiondeprotection steps required in the synthesis of 41 . In addition, it was later reported that in solution and in the solid state the trisalkanol-amine unit presents a concave form twisted by the three binaphthol linkages, and the cavities of these diastereomeric cages exhibit unexpected "imploded" structures, which give rise to different physical/chemical and binding properties. $^{62}$

The assignment of the absolute configuration of the eight stereoisomers of hemicryptophane 46 by ECD spectroscopy failed because of the overlap of the signals of CTV and binaphthyl groups. ${ }^{61}$ In this particular case the authors developed a chemical correlation method based on the $[1+$ $1]$ coupling of north and south parts. The enantiopure cage 46, such as $P-(S, S, S)-(S, S, S)-46$, can also be prepared from the enantiopure CTV-tribromide $P$-18, successfully resolved by chiral HPLC, ${ }^{53}$ and the BINOL derivative $(S, S, S)-(S, S, S)-47$, synthesized from enantiopure starting materials (Scheme 9). The $[1+1]$ coupling between the two units afforded the hemicryptophane 46 with controlled chirality. In this work, the authors underline the importance of the reaction conditions, especially temperature and concentration, to avoid racemization of the enantiopure CTV 18a and polymerization or low reaction rate. Furthermore, one single chemical correlation 
Scheme 7. Synthesis of Hemicryptophanes $M-(R, R, R)-41$ and $P-(R, R, R)-41$
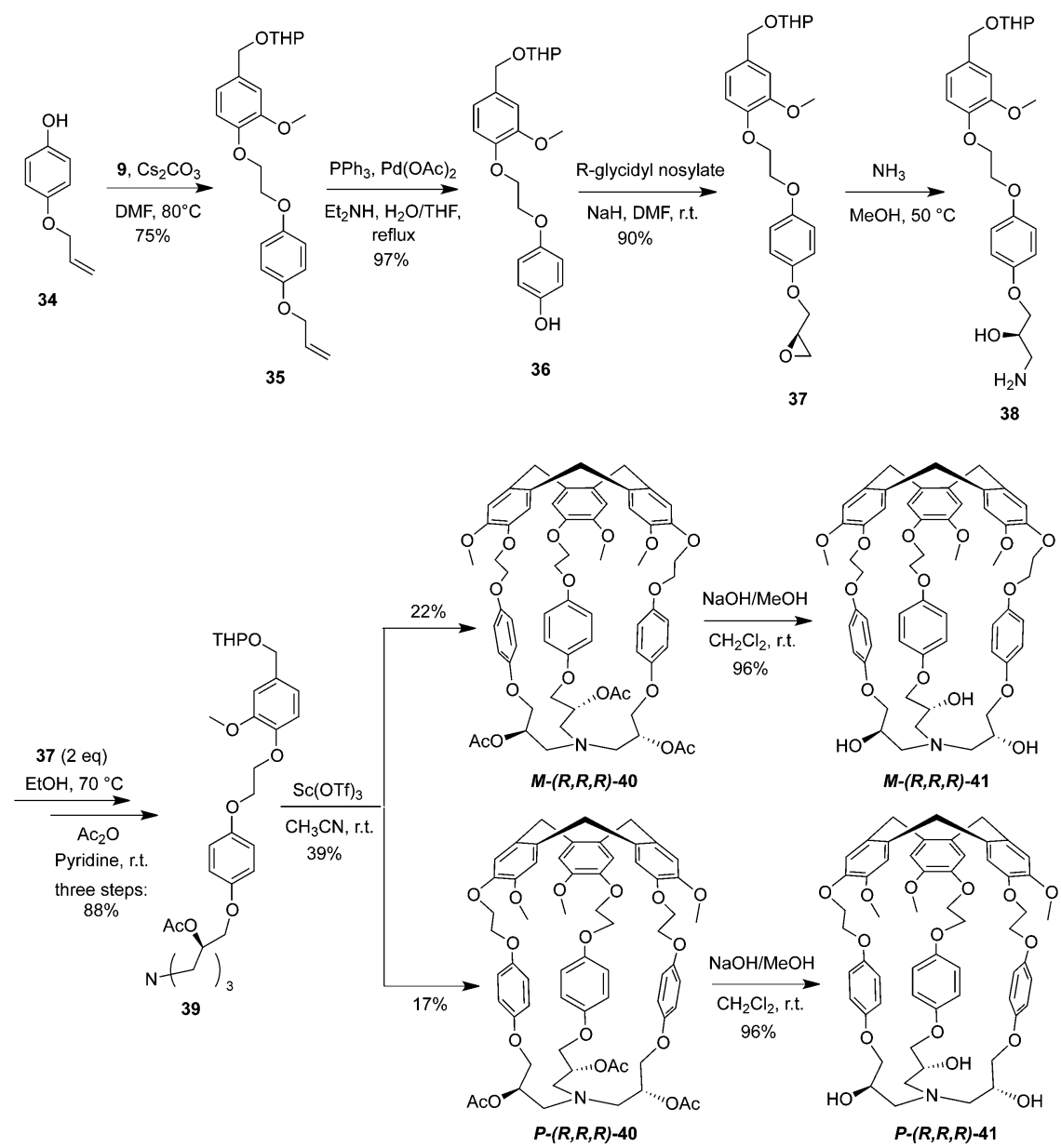

experiment provides the information about the absolute configuration for four stereoisomers, and two experiments are enough to assign all eight isomers. Interestingly, despite the low yield of the reaction depicted in Scheme 9 (15\%), it also provides a new way to directly obtain enantiopure hemicryptophanes, avoiding the tedious separation of diastereomers.

2.1.3. Hemicryptophanes Based on a Tripodal Benzenic Platform. The benzenic ring is a simple and attractive unit to close a covalent cage because of its high modularity. Indeed, depending on the nature of the substituents attached to this moiety (withdrawing or electro-donating groups) it can interact with anions, cations, or neutral guests by anion $-\pi$, cation $-\pi$, or $\mathrm{CH}-\pi$ interactions, respectively. The following examples are representative of the variety of strategies used for construction of hemicryptophanes from a tripodal benzenic platform.

Rivera et al. applied the Ugi-type multiple multicomponent macrocyclization to the synthesis of hemicryptophane $49 .{ }^{59}$ Following the same synthesis pathway described for hemicryptophane 33 (section 2.1.1; Scheme 6) and adding the triisocyanide 48 to CTV 32, they obtained the cage compound 49 bearing a $C_{3}$ symmetry tricarboxamide aromatic platform (Scheme 10).

Another example of tris amido-aromatic hemicryptophane was also synthesized from CTV derivative $\mathbf{5 3}$ and benzene1,3,5-tricarbonyl trichloride, still using the $[1+1]$ coupling reaction, to give compound $\mathbf{5 4}$ (Scheme 11 ). ${ }^{63}$ Vanillyl alcohol 7 reacts with chloroacetic acid $\mathbf{5 0}$ in the presence of $\mathrm{NaI}$ and
$\mathrm{NaOH}$ in EtOH to give compound 51. Formation of the CTV 52 is performed by a one-pot synthesis by first adding 1 equiv of $\mathrm{HCl}$ to $\mathbf{5 1}$ and then a catalytic amount of $p$-toluenesulfonic acid in $\mathbf{M e O H}$. The resulting compound $\mathbf{5 2}$ is then condensed in pure ethylenediamine to give 53. Finally, the $[1+1]$ coupling between $\mathbf{5 3}$ and 1,3,5-benzenetricarbonyl trichloride generates the hemicryptophane $\mathbf{5 4}$ in four steps and with $4 \%$ overall yield from vanillyl alcohol without any chromatography.

Hemicryptophanes bearing three BINOL groups in the linkages and a 1,3,5-trisubstituted aromatic ring at the south part were also synthesized and afforded the four hemicryptophane stereoisomers of 56 (Scheme 12). ${ }^{64}$ Starting from the $(S)$-BINOL derivative 42, the hemicryptophane precursor $\mathbf{5 5}$ was obtained in one step by reaction of $\mathbf{4 2}$ with tris(bromomethyl)benzene in DMF using $\mathrm{Cs}_{2} \mathrm{CO}_{3}$ as base. The macrocyclization of the precursor 55 in $\mathrm{CH}_{3} \mathrm{CN}$ catalyzed by $\mathrm{Sc}(\mathrm{OTf})_{3}$ gave the first pair of diastereomers of hemicryptophane 56 with a moderate diastereoselectivity. The other pair of stereoisomers was synthesized using the same way starting from the $(R)$-BINOL derivative.

The absolute configurations of the stereoisomers $M-(S, S, S)$ 56, $P-(S, S, S)-56, \quad M-(R, R, R)-56$, and $P-(R, R, R)-56$ were assigned using the chemical correlation method described above for hemicryptophane 46 (section 2.1.2). ${ }^{61}$ For this the authors synthesized the stereoisomers of 56 by the $[1+1]$ coupling of diastereomerically and enantiomerically pure CTV 57 suitably substituted with BINOL arms with 1,3,5-tris- 

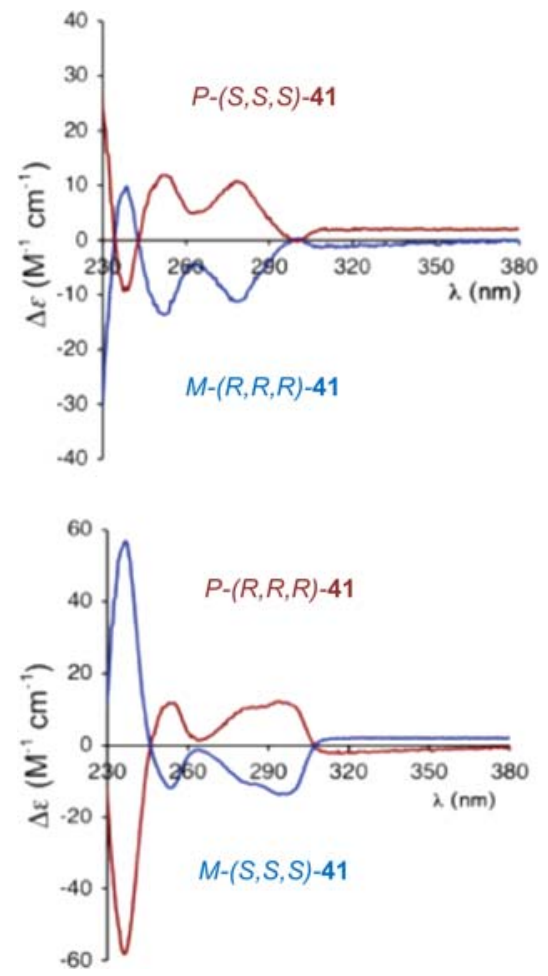

Figure 4. ECD spectra of the four stereoisomers of hemicryptophane 41 in $\mathrm{CH}_{2} \mathrm{Cl}_{2}$ at $20{ }^{\circ} \mathrm{C}$. Reproduced with permission from ref 60 . Copyright 2010 American Chemical Society.

(bromomethyl)benzene as shown in Scheme 13 for $M-(S, S, S)$ 56. ${ }^{64}$

2.1.4. Hemicryptophanes Based on a Macrocyclic Platform. Macrocyclic units like calixarenes or cyclodextrins have been linked to CTV units in order to combine in a single hemicryptophane molecule the recognition properties of both compounds. The syntheses of the resulting heteroditopic hosts are presented below.
Scheme 9. Synthesis of Hemicryptophane P-(S,S,S)-(S,S,S)46 Using the $[1+1]$ Coupling Reaction

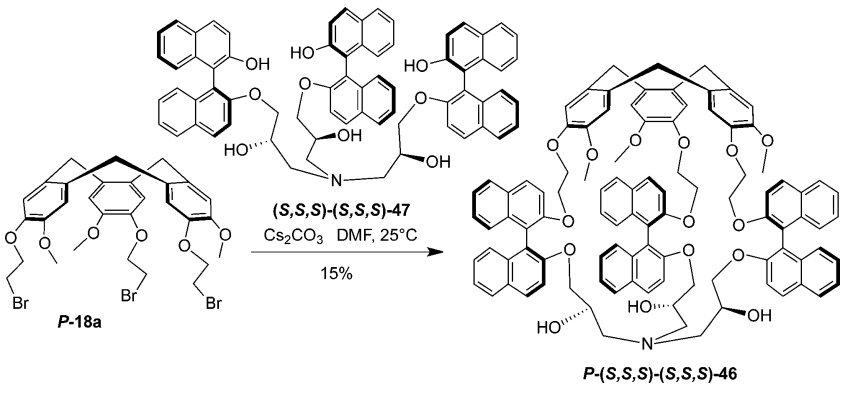

Scheme 10. Synthesis of Hemicryptophane 49

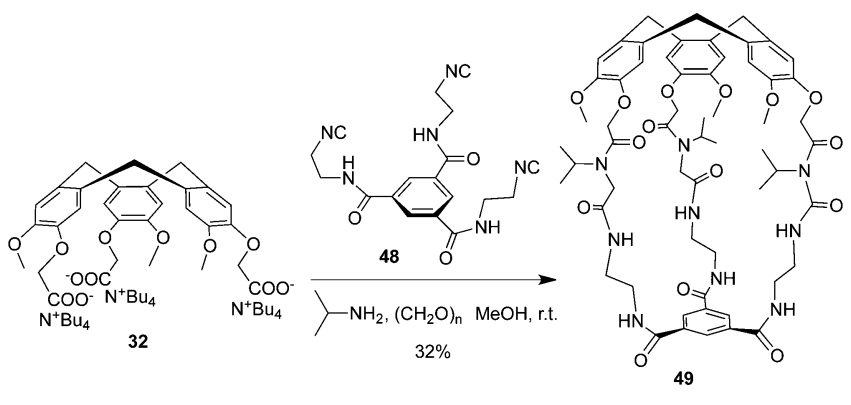

2.1.4.1. Hemicryptophanes Based on Aza-Crown Ether: Speleands. The synthesis of the first two hemicryptophane derivatives (speleands 1 and 2) developed by Collet and Lehn was achieved using the $[1+1]$ coupling method. ${ }^{27}$ As shown in Scheme 14, condensation of the trichloride $\mathbf{5 8}$ with the azacrown ether [18]- $\mathrm{N}_{3} \mathrm{O}_{3}$ under high dilution conditions afforded the tricarboxamide hemicryptophane $\mathbf{5 9}$ in 35\% yield. Then reduction of $\mathbf{5 9}$ with diborane gave the hemicryptophane 1 in $85 \%$ yield. Starting from the trichloride 60 and following the same reaction sequence, the hemicryptophane 2 with a larger cavity was synthesized with an overall yield of $26 \%$.

Scheme 8. Synthesis of Hemicryptophanes $M-(S, S, S)-(S, S, S)-46$ and $P-(S, S, S)-(S, S, S)-46$
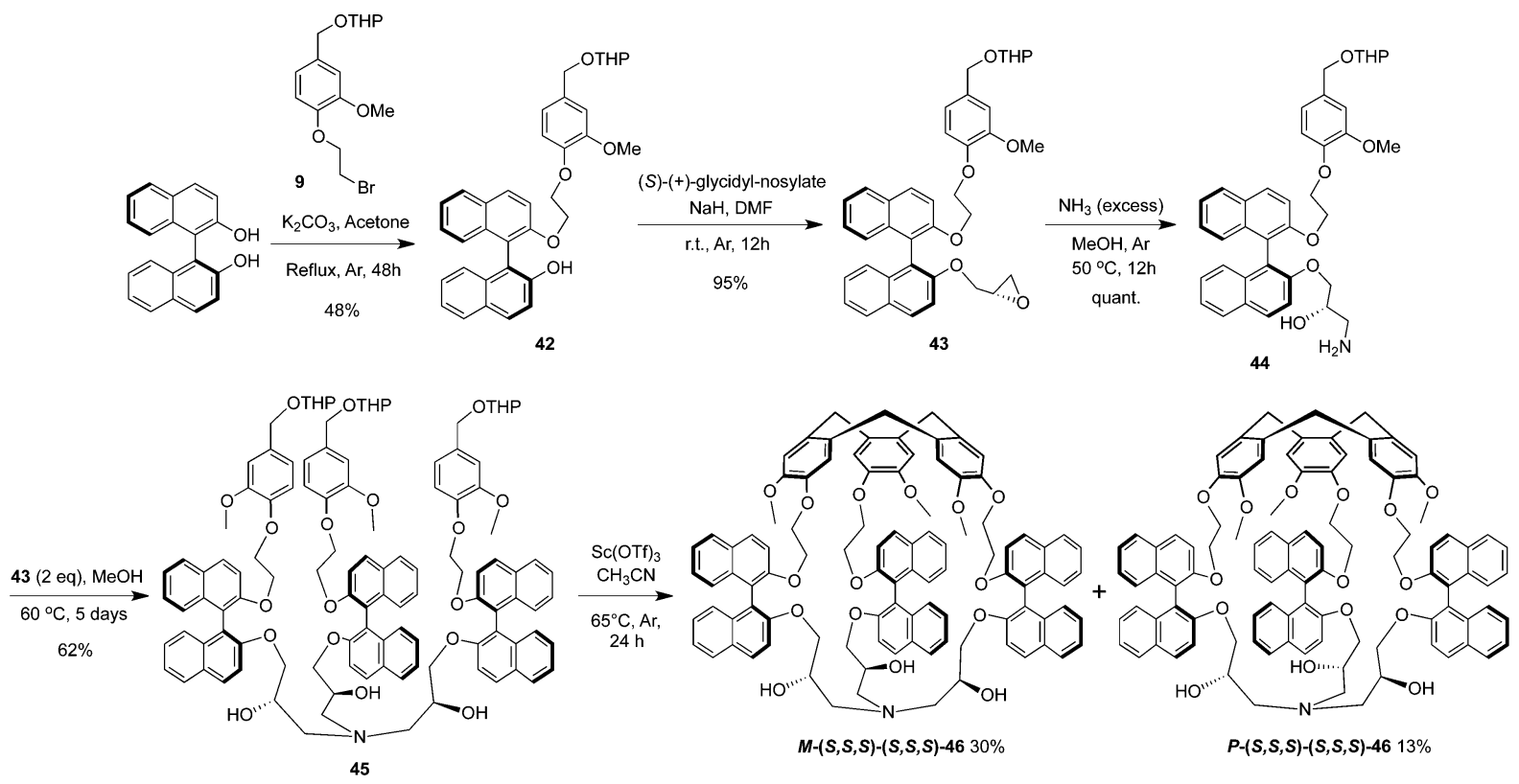
Scheme 11. Synthesis of Hemicryptophane 54
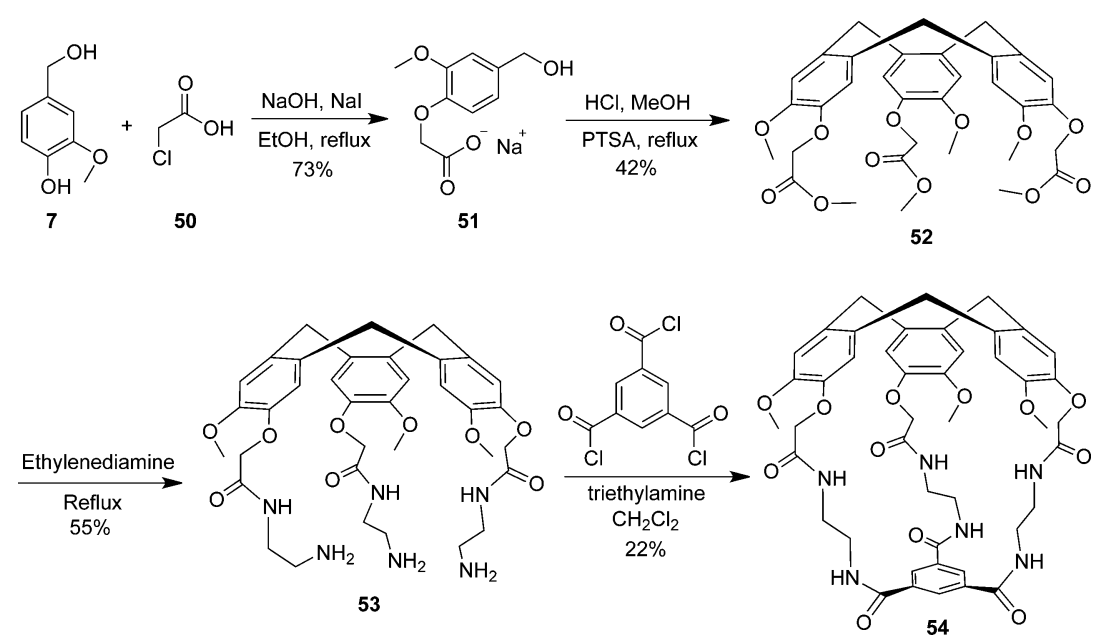

Scheme 12. Synthesis of Hemicryptophanes $M-(S, S, S)-56$ and $P-(S, S, S)-56$

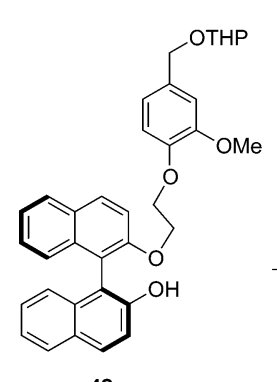

42

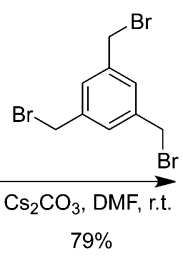

$79 \%$

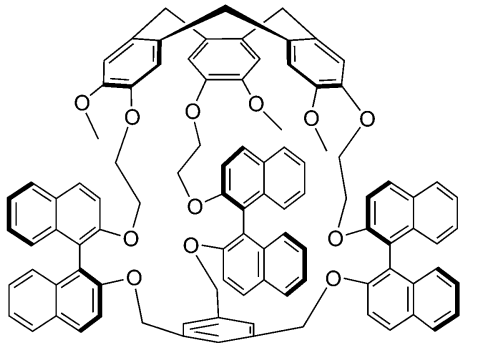

$M-(\mathrm{S}, \mathrm{S}, \mathrm{S})-56$

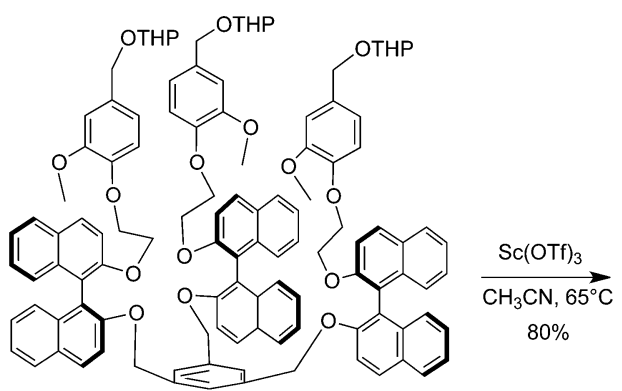

55

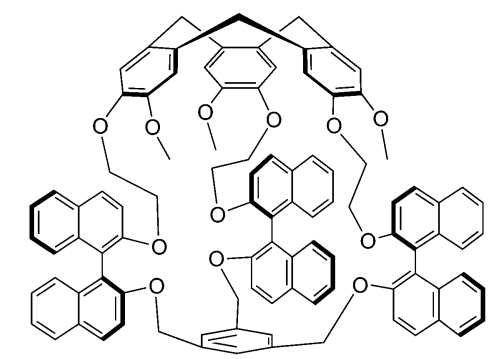

P-(S,S,S)-56

Scheme 13. Synthesis of Hemicryptophane $M-(S, S, S)-56$ Using the $[1+1]$ Coupling Reaction

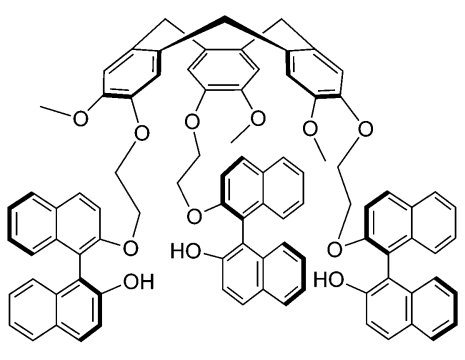

$M-(\mathrm{S}, \mathrm{S}, \mathrm{S})-57$
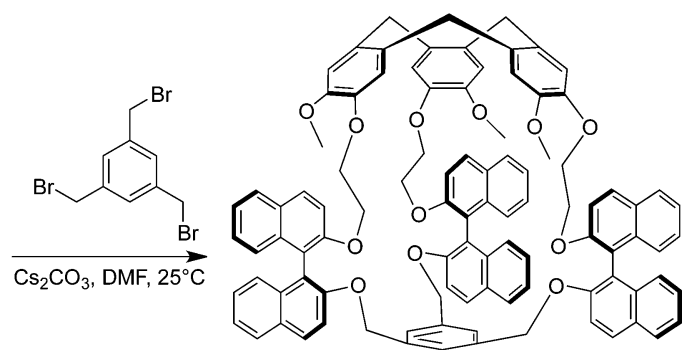

$M-(\mathrm{S}, \mathrm{S}, \mathrm{S})-56$
2.1.4.2. Hemicryptophanes Based on a Cyclopeptide Platform. Hutton et al. synthesized a new class of enantiopure cyclic peptide-containing hemicryptophanes $P L-67$ and $M L-67$ (Scheme 15) able to recognize the biologically relevant carnitine zwitterion. ${ }^{65}$ Three tyrosine residues provide a hydrophobic "wall" to the cavity, and glycine was chosen for the alternate residues to facilitate the synthesis of the cyclic peptide and to minimize steric bulk within the cage. First, cleavage of the hexapeptide from the resin with 5\% TFA gives the unprotected linear peptide 63. The cyclization of compound 63 generates the cyclic peptide 65 in quantitative yield after $1 \mathrm{~h}$. Compound 65 can also be prepared starting 
Scheme 14. Synthesis of Speleands 1 and 2
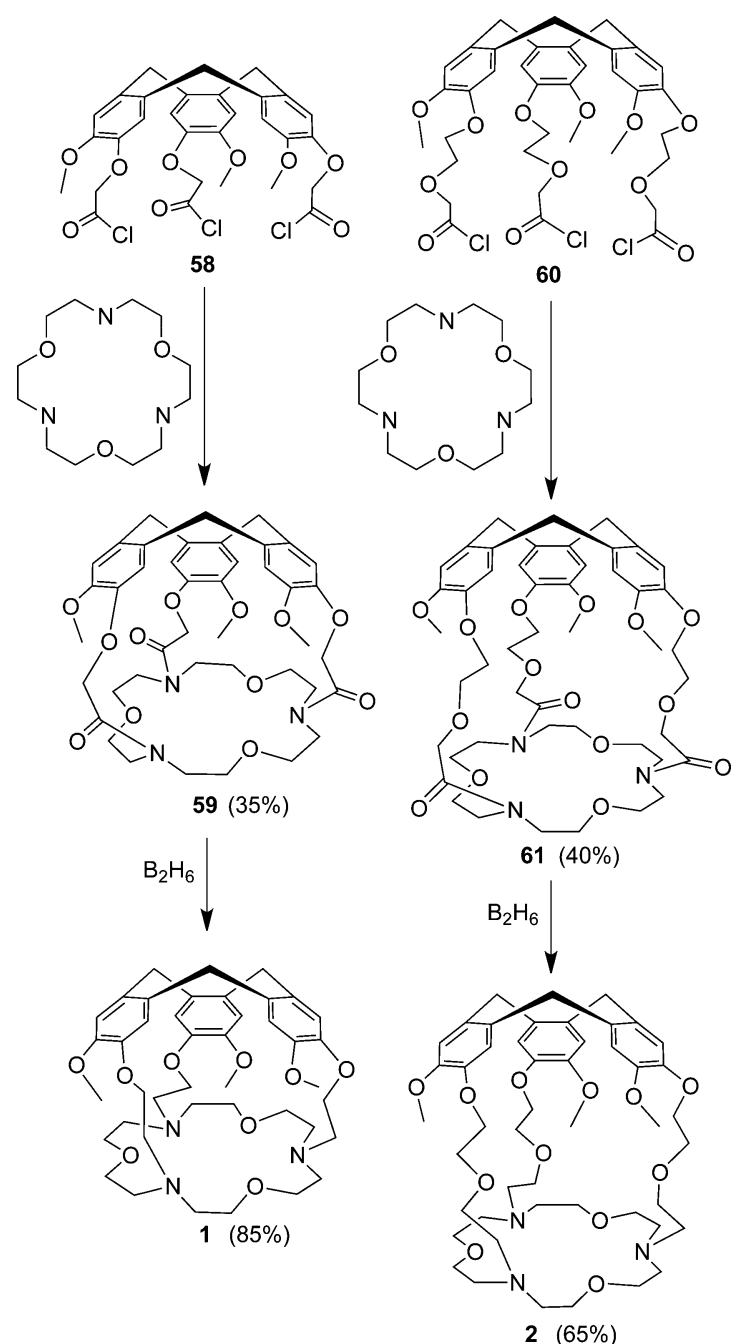

from cleavage of the hexapeptide from the resin with 1\% TFA; however, an additional deprotection step is required (see Scheme 15). The cyclic hexapeptide $\mathbf{6 5}$ is then triply alkylated with bromoethyl vanillyl alcohol 9 to give hemicryptophane precursor 66 in 55\% yield. Finally, the CTV unit was generated by treatment of 66 with $\mathrm{HCOOH}$, providing hemicryptophane 67 in good yield (64\%) as a mixture of two diastereomers. The $P$ and $M$ isomers were formed in a 2:1 ratio and readily separated by column chromatography.

2.1.4.3. Hemicryptophanes Based on a $\alpha$-Cyclodextrin Platform. Chambron et al. synthesized a pair of hemicryptophane diastereomers based on permethylated $\alpha$-cyclodextrin. ${ }^{66}$ As shown in Scheme 16, $\alpha$-cyclodextrin triol $\mathbf{6 8}$ is treated with a 4-fold excess of $\mathrm{NaH}$ in $\mathrm{DMF}$ at room temperature followed by addition of the same amount of the iodo compound 69 to give the hemicryptophane precursor 70 in $49 \%$ yield. The last cyclization reaction for the hemicryptophane precursor has been tested with $\mathrm{HCOOH}$ or $\mathrm{Sc}(\mathrm{OTf})_{3}$ as catalyst; however, both of them gave very low yields for a mixture of the two diastereomers of $71,8 \%$ and $5 \%$, respectively. The separation by column chromatography of the two diastereomers obtained in a 6:1 ratio allowed the authors to isolate the main diastereomer in pure form. Interestingly, hemicryptophane $\mathbf{7 1}$ acts as a solvent-sensitive NMR and ECD probe. Inclusion of a solvent molecule in the $\alpha$-CD component of the hemicryptophane induces conformational changes that result in the shielding of the primary methoxy $\left(6^{\prime}-\mathrm{OMe}\right)$ protons of the $\alpha$-CD unit, which increases with the size of the chloroalkane solvent. ${ }^{67}$

Formation of disulfide bonds was also used for constructing hemicryptophanes based on a $\alpha$-cyclodextrin scaffold following the $[1+1]$ coupling strategy (Scheme 17). ${ }^{68}$ The trimesylate $\alpha$-cyclodextrin 72 reacts with potassium thioacetate in DMF to give compound 73 in quantitative yield after column chromatography. Subsequently, methanolysis of 73 in the presence of $\mathrm{K}_{2} \mathrm{CO}_{3}$ in $\mathrm{MeOH}$ followed by acidification of the mixture with $\mathrm{HCl}$ affords the tris-methylthiol $\alpha$-cyclodextrin $\mathbf{7 4}$. Addition of a solution of $\mathrm{I}_{2}$ in $\mathrm{MeOH}$ to a methanol solution of 74 and racemic cyclotrithiophenolene 75 in the presence of $\mathrm{KI}$ and triethylamine generates the final hemicryptophane 76 in $11 \%$ yield as a 5:3 mixture of two diastereomers that could not be separated.

2.1.4.4. Hemicryptophanes Based on a Macrocyclic Arylamide Platform. Wang et al. synthesized hemicryptophanes 85a and 85b starting from the CTV tribromides 18a and $\mathbf{1 8 b}$ (Scheme 18). ${ }^{69}$ This synthesis follows the seldom-used strategy consisting in preparing a cyclotribenzylene bearing suitably functionalized pendant arms that react together to form the hemicryptophane derivative (Figure $3 \mathrm{c}$ ). The authors first treated 18a or $18 b$ with an excess of $\mathrm{NaN}_{3}$ in DMF to form the triazide derivatives $77 \mathbf{a}$ and $77 \mathbf{b}$, respectively. Then the alkynylmethylbenzoate derivative 80 was prepared from 78 and 79 in $\mathrm{DMF}$ in the presence of $\mathrm{K}_{2} \mathrm{CO}_{3}$ at $80{ }^{\circ} \mathrm{C}$ and further hydrolyzed with $\mathrm{LiOH}$ to give $\mathbf{8 1}$ quantitatively. The acid $\mathbf{8 1}$ was then coupled with $\mathbf{8 2}$ in $\mathrm{CHCl}_{3}$ to generate compound $\mathbf{8 3}$, which then reacts with $77 \mathbf{a}$ or $77 \mathbf{b}$ in the presence of $\mathrm{CuI}$ to give the hemicryptophane precursors $84 a$ or $84 b$. Finally, the hemicryptophanes $\mathbf{8 5 a}$ and $\mathbf{8 5 b}$ are assembled quantitatively by forming three imine bonds from arylamide-derived foldamer segments after adding TFA to the $\mathrm{CHCl}_{3}$ solution of $\mathbf{8 4 a}$ and $\mathbf{8 4 b}$. In principle, each of the two hemicrytophanes should have four stereoisomers, two pair of enantiomers, because of the relative orientation of the CTV and triimine macrocyclic units. However, only one set of signals is observed in the ${ }^{1} \mathrm{H}$ NMR spectra, suggesting that only one isomer (or a pair of enantiomers) was formed in the final step. Molecular dynamic simulations demonstrated that isomers, where the methoxy of the CTV moiety and the imine groups are arranged in anti orientation with respect to one another, are more energetically favorable and probably the observed products in solution. Hemicryptophanes $\mathbf{8 5} \mathbf{a}$ and $\mathbf{8 5} \mathbf{b}$ turned out to be good receptors for $\mathrm{C}_{60}$ and $\mathrm{C}_{70}$ fullerenes (see section 3.2.5).

2.1.4.5. Hemicryptophanes Based on Calixarene. On the basis of the reaction between tris-acyl chloride and tris-amino compounds, Jabin and co-workers synthesized hemicryptophane 90 with a calix[6]arene platform (Scheme 19). ${ }^{70}$ The $[1$ $+1]$ macrocyclization reaction between calix[6] arene 86 and CTV 87 was first performed under high dilution conditions, giving the hemicryptophane 90 in $15 \%$ yield after flash chromatography purification. With the aim of improving the yield, they also tested and optimized the reaction between calix[6]trisamine 86 and CTV tris-acid 88 in the presence of peptide-coupling reagents such as PyBOP ((benzotriazol-1yloxy)tripyrrolidinophosphonium hexafluorophosphate) to produce 90 with a much better yield (46\%). Under the same reaction conditions they also obtained the hemicryptophane 91 containing a wider cavity and a larger number of hydrogenbond donors in $33 \%$ yield (Scheme 19). 
Scheme 15. Synthesis of Hemicryptophanes $M L-67$ and $P L-67^{a}$

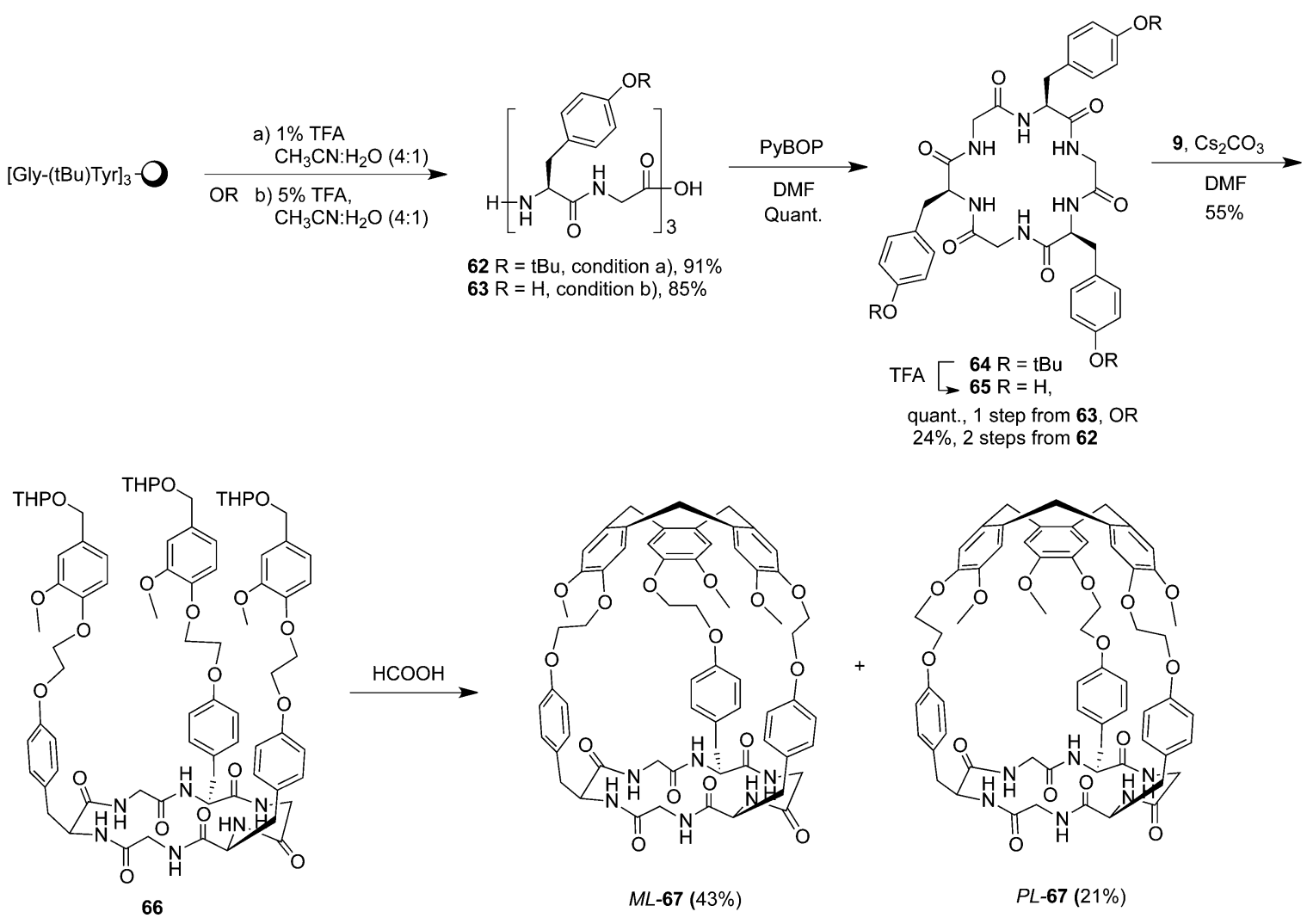

${ }^{a}$ Adapted from ref 65 . Copyright 2013 The Royal Society of Chemistry.

Scheme 16. Synthesis of Hemicryptophanes M-71 and P-71

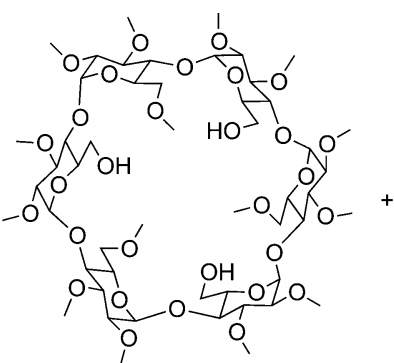

68

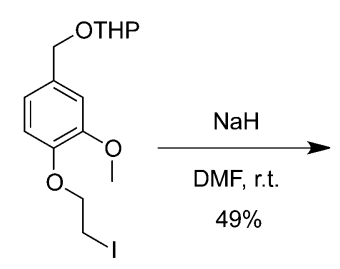

69

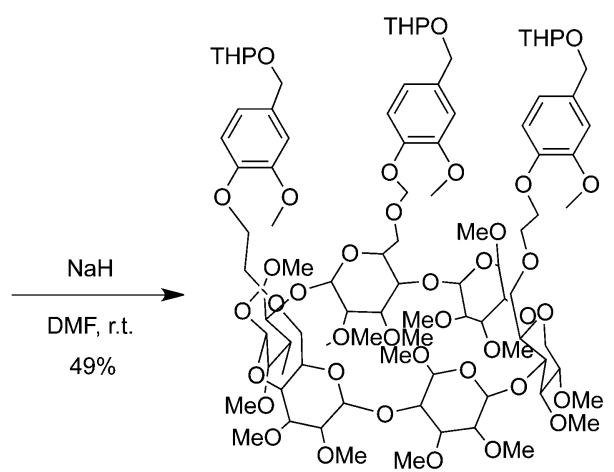

70

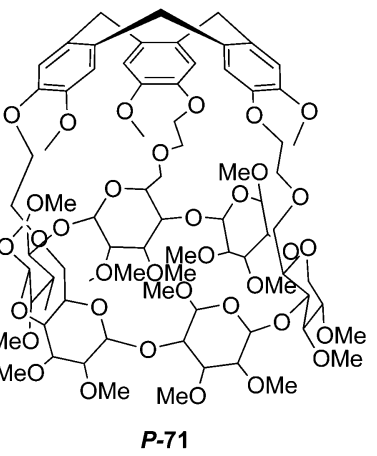

2.1.5. Hemicryptophanes Based on Heteroatomic Pivot. 2.1.5.1. Hemicryptophanes with a Phosphotrihydrazone Core. Following the $[1+1]$ strategy, the racemic hemicryptophane 6 was successfully obtained (Scheme 20a). ${ }^{30}$ The trisallyl CTV 93 was first prepared from the allyl-protected vanillyl alcohol 92 in perchloric acid and methanol. The Pd- 
Scheme 17. Synthesis of Hemicryptophanes M-76 and P-76
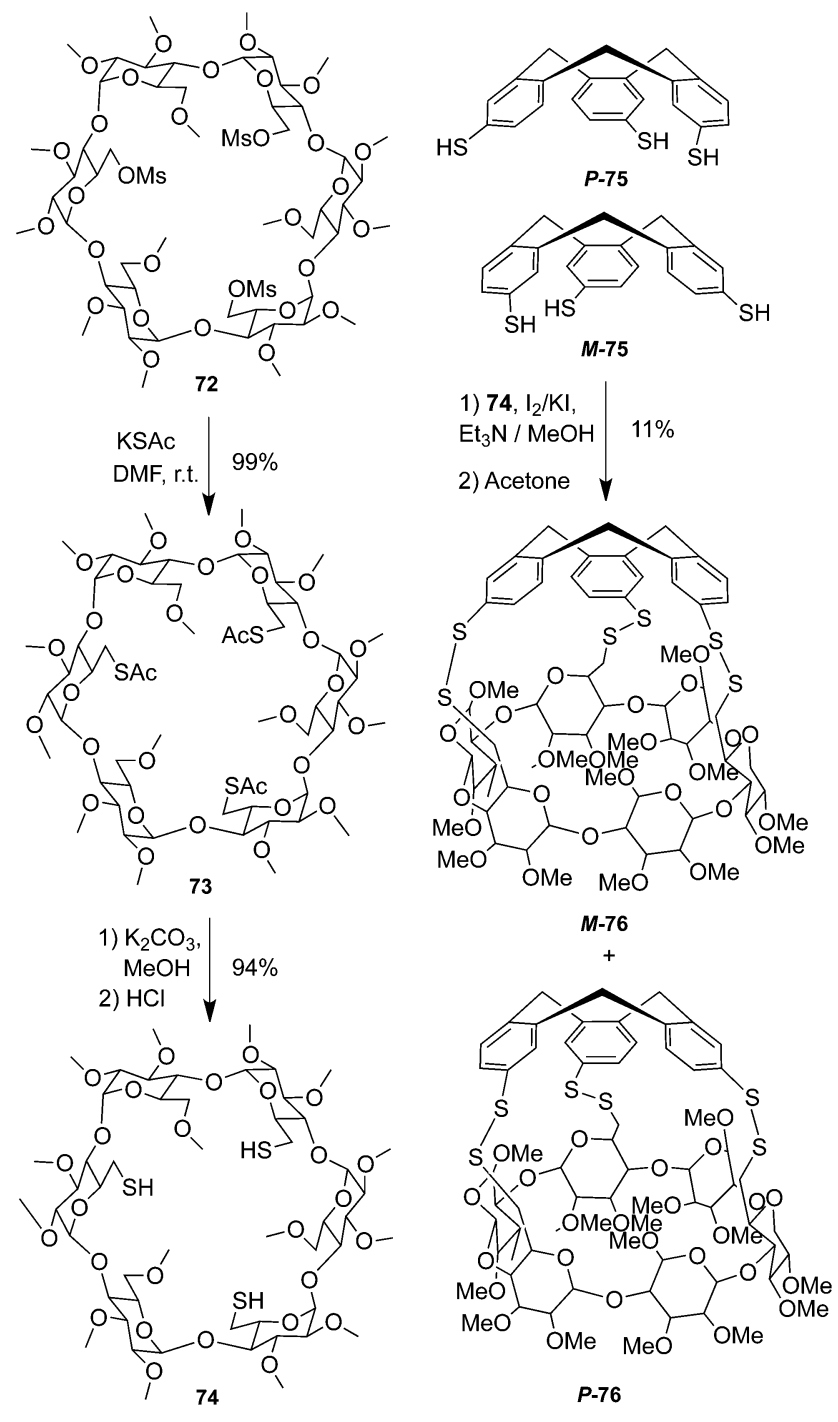

catalyzed deprotection of 93 in the presence of $\mathrm{Et}_{2} \mathrm{NH}$ in $\mathrm{THF} / \mathrm{H}_{2} \mathrm{O}$ led to the cyclotriguaiacylene 94, which reacted with the brominated derivative 95 in the presence of aqueous $\mathrm{NaOH}$ in DMF-HMPA to give the precursor 96 bearing three benzaldehyde moieties. Finally, 96 reacted with phosphotrihydrazide 97 in THF under high dilution conditions affording the hemicryptophane 6 in $23 \%$ yield. It was proposed that the success of the last reaction is partly attributed to the rather rigid conformation of the phosphorus derivative.

A similar synthetic scheme led to hemicryptophane 101, which was specifically designed to complex iron and gallium ions (section 2.3.2.2). The reaction of the cyclotriguaiacylene platform 94 with allyl-protected benzaldehyde 98 afforded the precursor 99. The subsequent deprotection step led to compound 100, which was allowed to react with phosphotrihydrazide 97 to give hemicryptophane 101 (Scheme 20b). ${ }^{71}$

2.1.5.2. Hemicryptophanes with an Amine Core. The synthesis of hemicryptophane $\mathbf{1 0 5}$ was reported by Dmochowski et al., 52 where vanillyl alcohol 7 reacted with dibromo-pxylene 102 in the presence of $\mathrm{K}_{2} \mathrm{CO}_{3}$ to form compound 103, which was treated with a catalytic amount of $\mathrm{Sc}(\mathrm{OTf})_{3}$ in $\mathrm{CH}_{3} \mathrm{CN}$ to afford the hemicryptophane precursor 104 (Scheme 21). In the last step, compound 104 reacted with $7 \mathrm{~N} \mathrm{NH}_{3}$ in
$\mathrm{MeOH}$ at high temperature to give the hemicryptophane 105 in $67 \%$ yield. It can be noted that this short, streamlined synthetic scheme utilizes mild conditions and results in a fairly good overall yield (13\%).

2.1.6. Hemicryptophanes Formed from a Covalent CTV- $\mathrm{C}_{60}$ Adduct. The concave electron-donor aromatic surface of the CTV scaffold is known to interact favorably with electron-acceptor fullerenes $\mathrm{C}_{60}$ or $\mathrm{C}_{70} \cdot{ }^{72-74}$ Diederich et al. used this property to build a covalent $\mathrm{CTV}-\mathrm{C}_{60}$ assembly that led to a hemicryptophane-like architecture. The tetherdirected Bingel reaction of $\mathrm{C}_{60}$ with the tris-malonate CTV derivative 106 led in one step to $\mathrm{C}_{3}$-symmetrical CTV $-\mathrm{C}_{60}$ trisadducts 3 and $\mathbf{4}$ (Scheme 22). ${ }^{29,75}$ Although no available cavity is observed in $\mathbf{3}$ and $\mathbf{4}$, these adducts can be considered as hemicryptophane structures. Many regioisomers are expected that complicate the determination of the stereochemistry of the isolated compounds. ${ }^{76}$ In their former work, Diederich and colleagues isolated the trans-3,trans-3,trans-3 and e,e,e regioisomers, which were characterized by their FAB-mass spectra and UV-vis and NMR spectroscopies. Later, the authors performed a new synthesis from the enantiomerically pure CTV units $P-106$ and $M-106$ to get more insights into the structure and configuration of the CTV $-\mathrm{C}_{60}$ adducts. In this work, they observed the exclusive formation of only four CTV$\mathrm{C}_{60}$ adducts among the $2^{3}=8$ expected ones according to the combination of trans-3,trans-3,trans-3 or e,e,e with the $P$ or $M$ configurations of the CTV units. The ECD and VCD spectra allowed the assignment of the tris-adducts and their absolute configuration based on the known absolute configuration of the enantiopure CTV units $P-106$ and $M-106$. These results revealed that only the trans-3,trans-3,trans-3 tris-adducts were formed underlining the complete regioselectivity of the addition reaction of 106 with $\mathrm{C}_{60}{ }^{77}$

2.1.7. Hemicryptophanes Constructed from a Diphenylglycoluril Unit. Nolte et al. reported in 1989 the preparation of one of the first hemicryptophane structures. The cage molecule (5) was constructed from the CTV scaffold and a diphenylglycoluril southern unit that did not satisfy the expected $C_{3}$ symmetry, giving rise to a molecular cage with a free functionalized arm. The strategy used is depicted in Scheme 23: vanillin reacts first with 1,6-dibromohexane to give 107, which then reacts with diphenylglycoluril to give the precursor 108a with four $n$-hexyl arms terminated with vanillyl groups. Reduction with $\mathrm{NaBH}_{4}$ affords the corresponding benzylic alcohol derivative $\mathbf{1 0 8 b}$, which is treated in formic acid to produce the expected hemicryptophane $5^{28}$

2.1.8. Hemicryptophanes Obtained by Metal Coordination. Although they are not strictly covalent hemicryptophane hosts, several CTV metal complexes gave rise to original hemicryptophane structures. Functionalized CTVs with three pendant arms have been prepared as new $C_{3}$-symmetrical ligands for metal coordination. For example, by incorporating thiol groups on the arms, the cyclotriveratrylene derivatives thus obtained were able to complex iron-sulfur clusters. Collet et al. reported in 1994 the formation of complexes 109 and $\mathbf{1 1 0}$ (Figure 5). ${ }^{78}$ The same year the group of Nolte synthesized very similar ligands, which reacted with various [4Fe-4S] clusters affording complexes such as $\mathbf{1 1 1}$ and $\mathbf{1 1 2}$ presented in Figure 5. It was shown that for hemicryptophane 111 with a $\mathrm{Fe}-\mathrm{Cl}$ bond, the chloro ligand was pointing toward the cavity, whereas the $\mathrm{Fe}-\mathrm{SR}$ group in $\mathbf{1 1 2}$ is oriented outside the cavity. $^{79}$ 
Scheme 18. Synthesis of Hemicryptophanes 85a and 85b

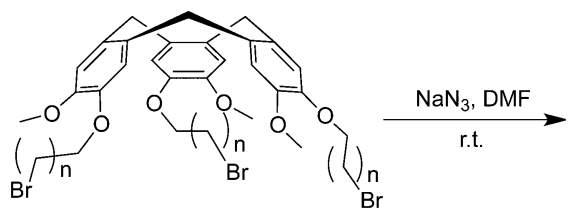

18a: $\mathrm{n}=1$

18b: $n=3$

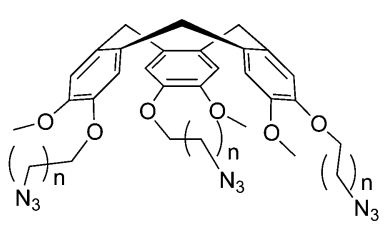

77a: $n=1 ; 91 \%$ $77 \mathbf{a}: \mathrm{n}=1 ; 91 \%$
$\mathrm{n}=3 ; 90 \%$

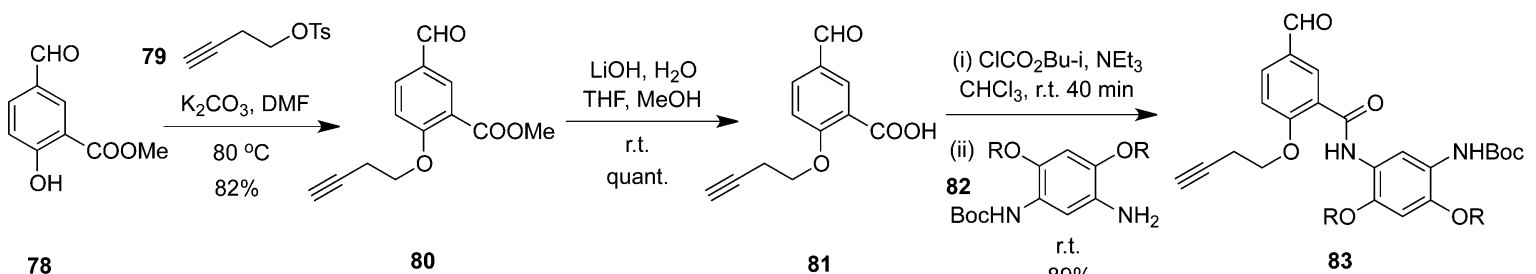

78

80

81

$89 \%$

83

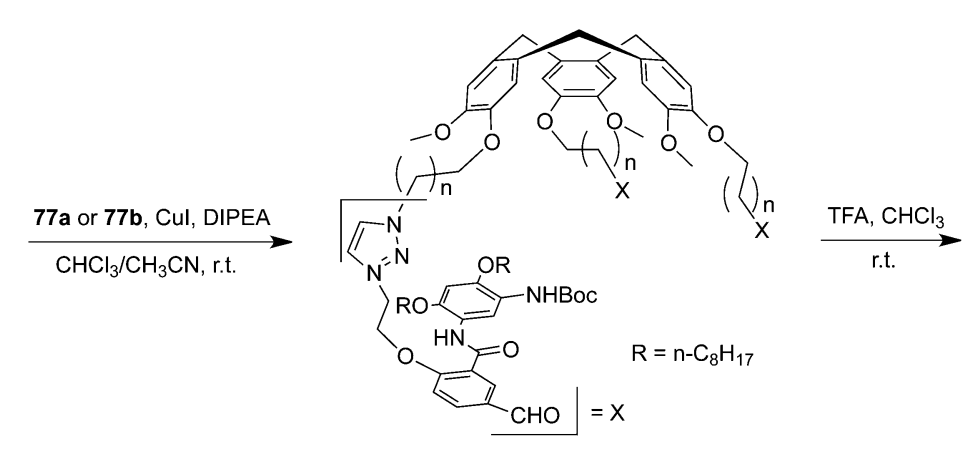

84a: $n=1 ; 74 \%$ 84b: $n=3 ; 76 \%$

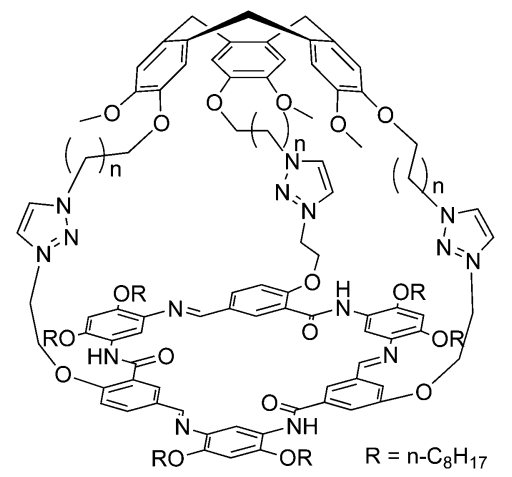

85a: $n=1$; quant. $85 \mathrm{~b}: \mathrm{n}=3$; auqnt.

Scheme 19. Synthesis of Hemicryptophanes 90 and 91

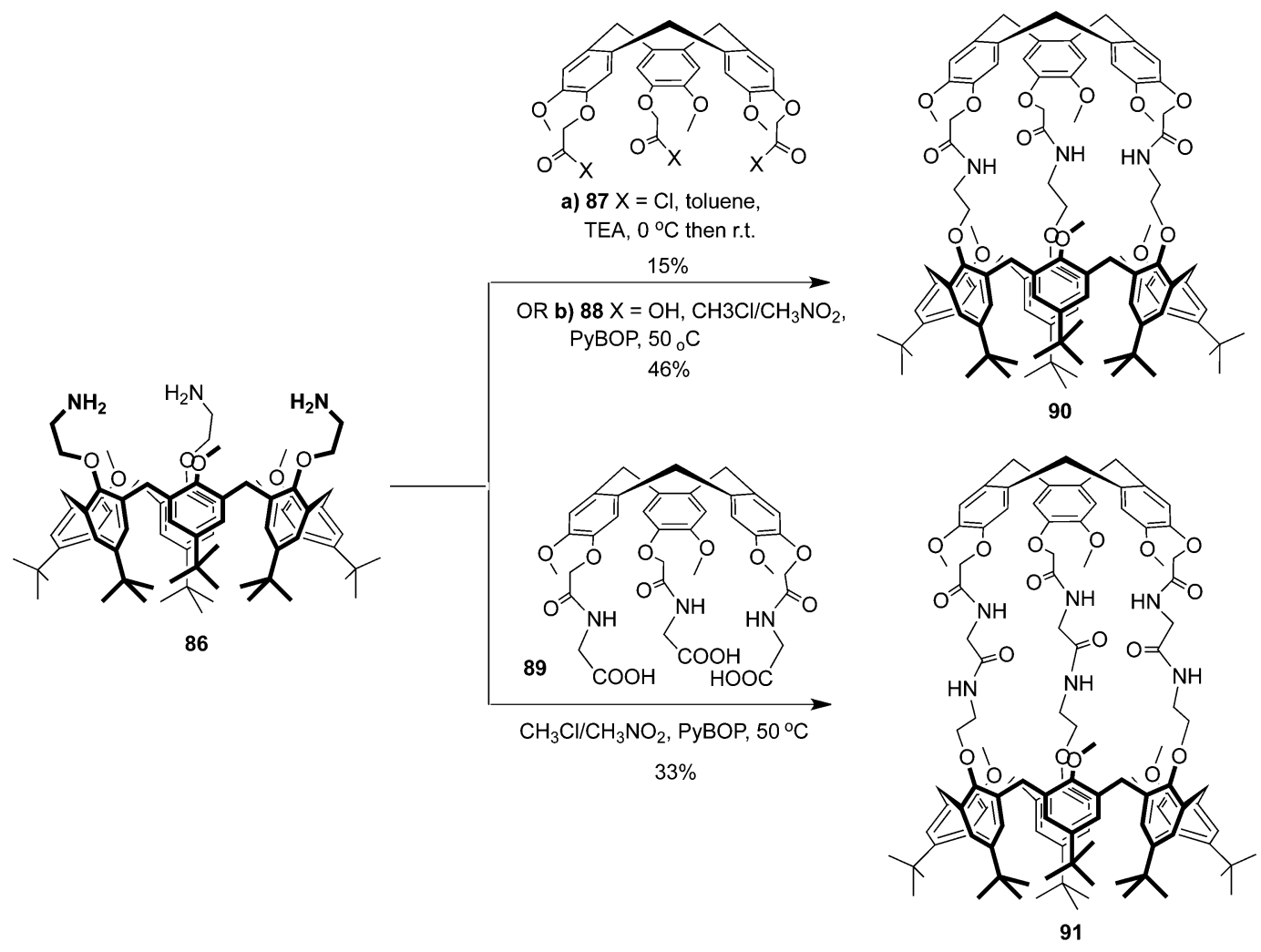


Scheme 20. Synthesis of Hemicryptophanes 6 (a) and 101 (b)
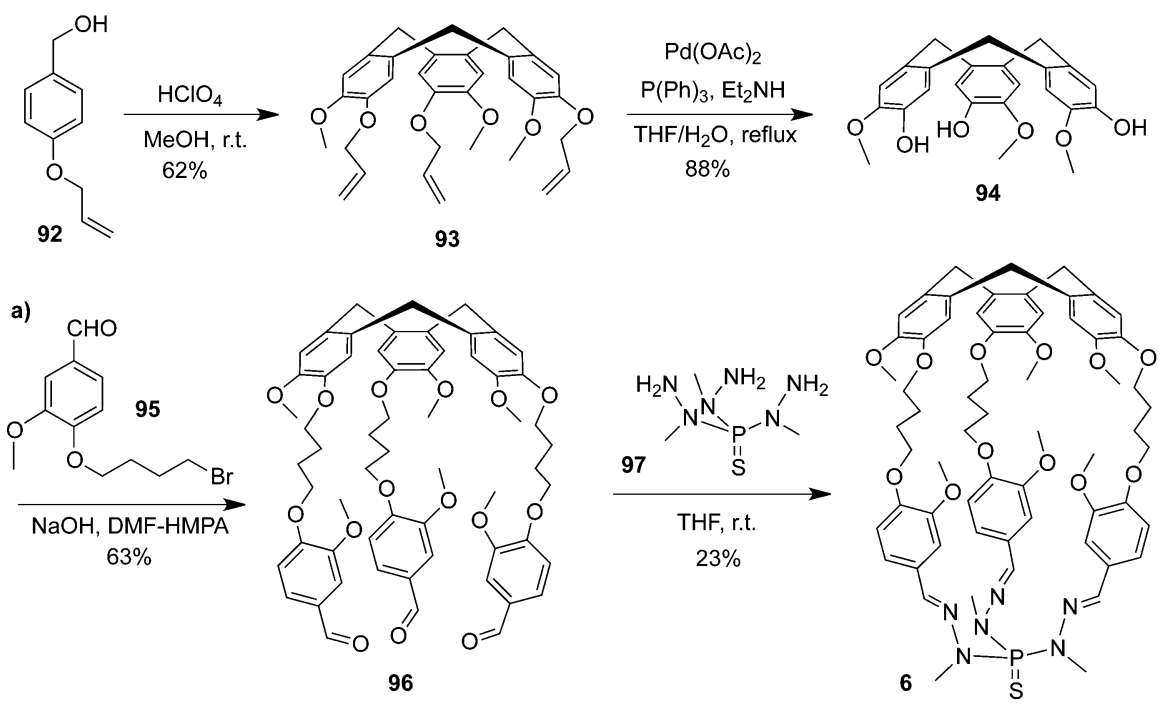

b)
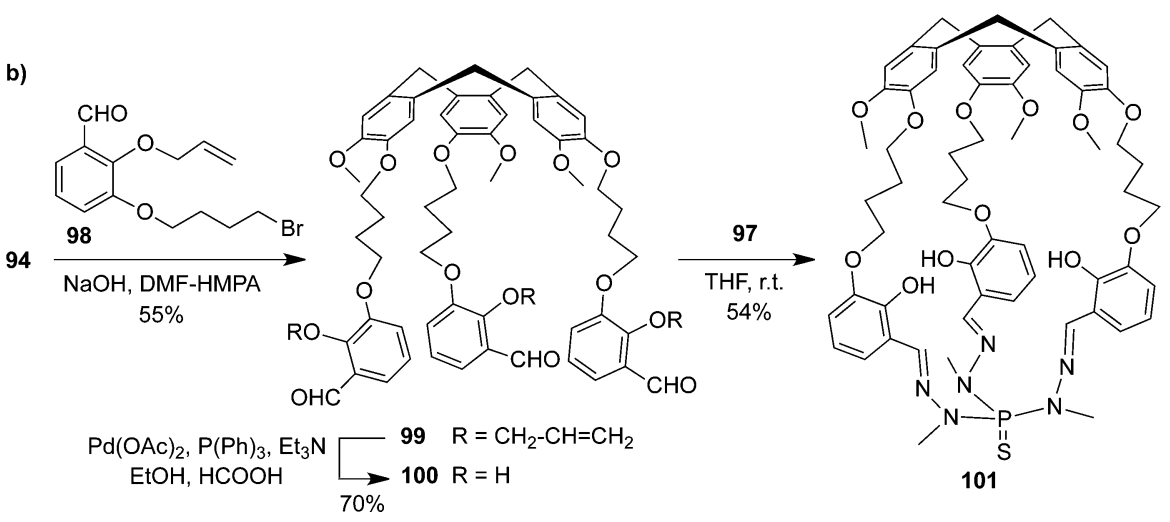

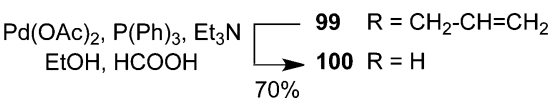

101

\section{Scheme 21. Synthesis of Hemicryptophane 105}

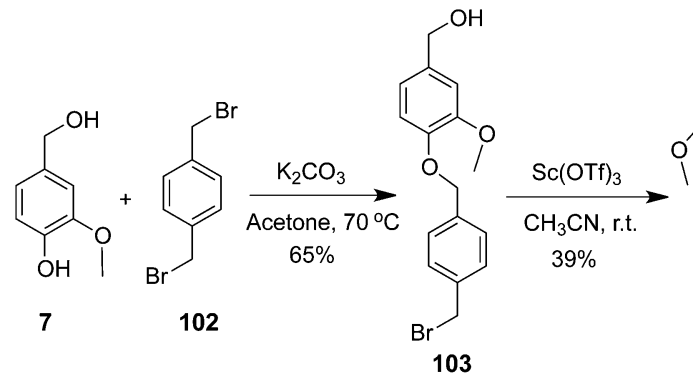

103
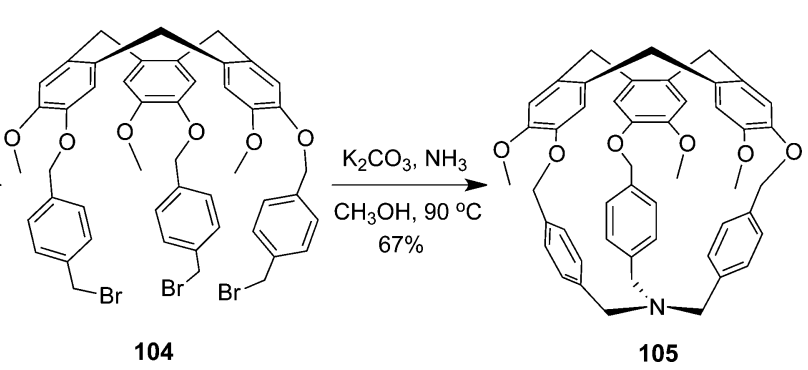

Several $C_{3}$ cyclotriveratrylene ligands featuring three arms ending with catecholate, hydroxamate, bipyridine, or iminopyridine moieties were synthesized for the octahedral coordination of iron(II) and iron(III) (Figure 6). Ligands bearing various pendant arms $(\mathrm{a}-\mathrm{h}$ in Figure 6) were generally obtained by reaction of CTV precursors such as 52, 53, or 88 with the corresponding suitable reagents. ${ }^{31}$ Magnetic and electrochemical properties of iron(II) complexes $113 \mathbf{e}-\mathbf{h}$ were investigated. As an example, compound $113 \mathrm{~g}$ was characterized by X-ray diffraction and Mössbauer spectroscopy, and it has been shown that both low-spin and high-spin states coexist in the solid. These iron complexes contain two stereogenic elements, possibly leading to the two diastereomeric racemates $(M \Delta / P \Lambda)$ and $(M \Lambda / P \Delta)$. Interestingly, in the X-ray molecular structure of $113 \mathrm{~g}$ only the $(M \Delta / P \Lambda)$ pair of enantiomers was found. ${ }^{80}$

In 1995 Nolte and co-workers published also a rhodium complex of a CTV ligand bearing three arms terminated by triphenyl phosphite functions. The hemicryptophane complex thus obtained is quite flexible, and the cavity is occupied by the spacer arms. ${ }^{81}$

\subsection{Formation of Hemicryptophane Capsules by Reversible Bonds/Interactions}

The association of two or more CTV units has led to interesting self-assembled supramolecular systems, which present a molecular cavity. We will not report on these cage structures, which are out of the scope of this review. They are more like reversible capsules with $C_{3}$ symmetry when two cyclotribenzylene caps self-arranged to form a cryptophane-like 
Scheme 22. Synthesis of C60-CTV Tris-Adducts 3 and 4

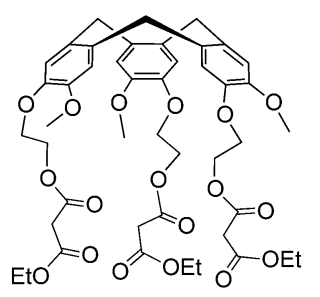

106

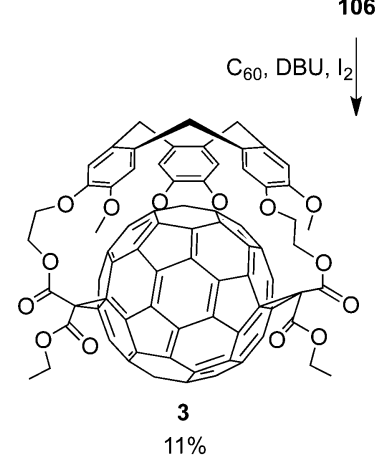

$\left(\right.$ trans $_{3}$, trans $_{3}$, trans $\left._{3}\right)$

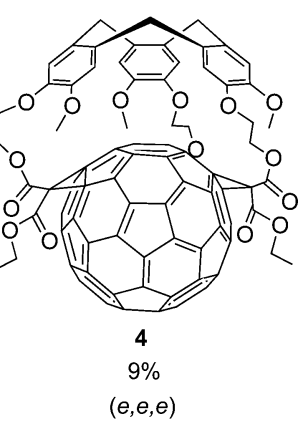

Scheme 23. Synthesis of Hemicryptophane 5
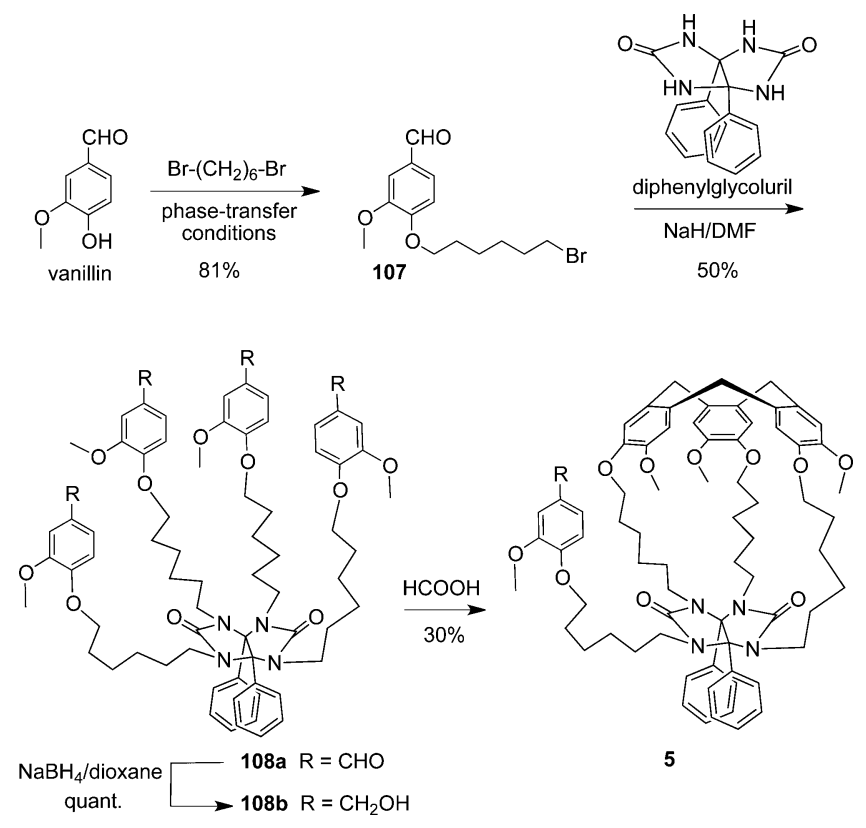

structure. $^{82-85}$ Some can also form MOF-type structures ${ }^{86}$ when several cyclotribenzylene units are held together through metal coordination. ${ }^{87-92}$ However, besides the covalent synthesis of hemicryptophane cages, reversible covalent bonds, such as dynamic boronate esterification, ${ }^{93,94}$ and reversible supramolecular interactions, such as ionic interaction, ${ }^{95}$ have also been developed for construction of hemicryptophane capsules. Compared to the covalent synthesis, the self-assembling is straightforward and can avoid tedious purification procedures. However, the lower stability of the resulting cages can be a main drawback, as mentioned for self-assembled architectures using reversible bonds/interactions. ${ }^{96-99}$ Furthermore, the assemblies are usually driven by external template molecules, which may go inside the cavity of the hemicryptophane capsules, preventing access to their inner cavities to other guest molecules. ${ }^{100}$
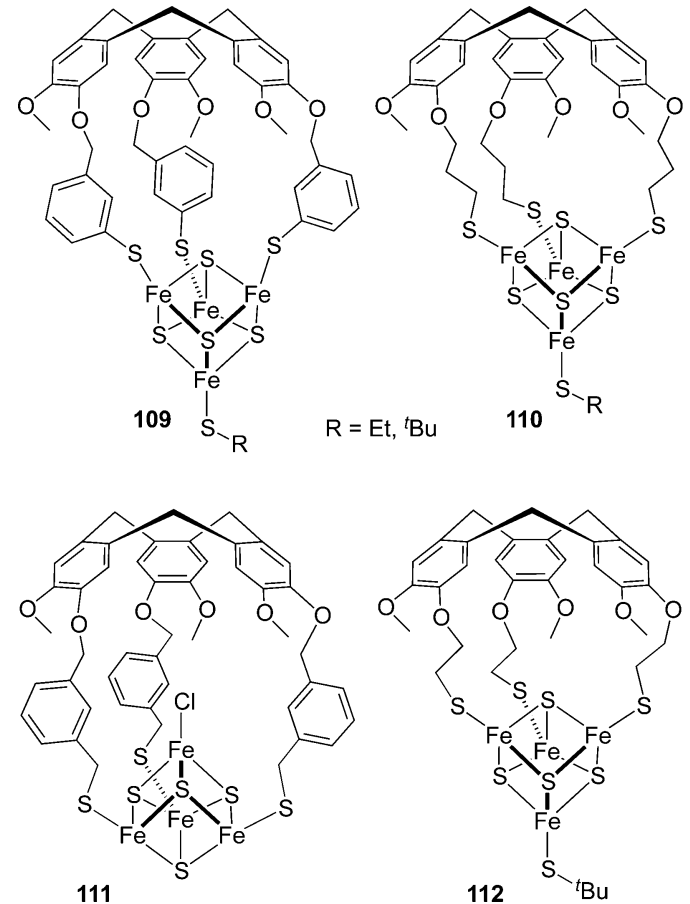

Figure 5. Structures of hemicryptophanes built on [4Fe-4S] clusters.
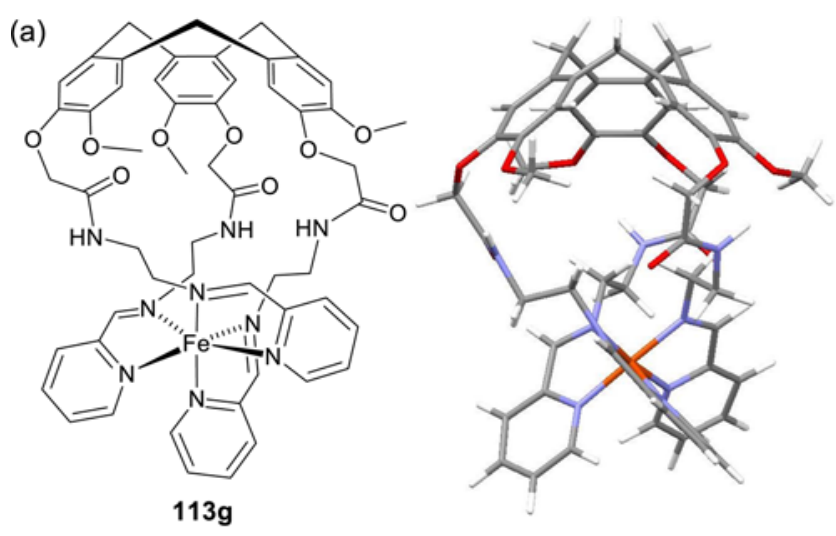

(b)
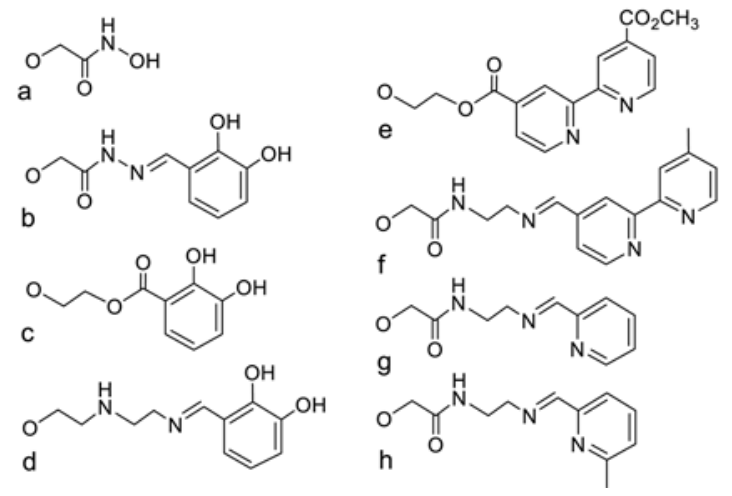

Figure 6. Hemicryptophane $113 \mathrm{~g}$ obtained by complexation of iron ion: (a) X-ray molecular structure (stereoisomer $\left(P_{\Lambda}\right)$ is shown); (b) different linkages used in the construction of complexes 113a-h.

2.2.1. Formation by Boronate Esterification. Boronic acids can rapidly and reversibly form cyclic boronate esters with diols showing great promise for developing self-assembled hemicryptophane capsules. ${ }^{101,102}$ For example, Kataoka et al. described the ion-pair-driven hemicryptophane self-assembled 

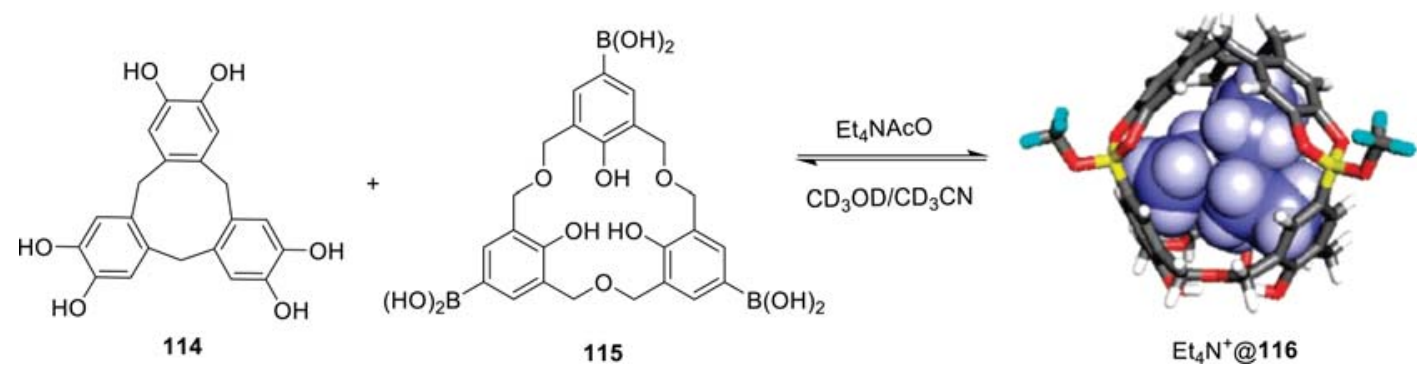

${ }^{a}$ Adapted from ref 93. Copyright 2007 American Chemical Society.

\section{Scheme 25. Formation of Hemicryptophane Capsules 116 and $\mathrm{Et}_{3} \mathrm{NH}^{+} @ 116^{a}$}

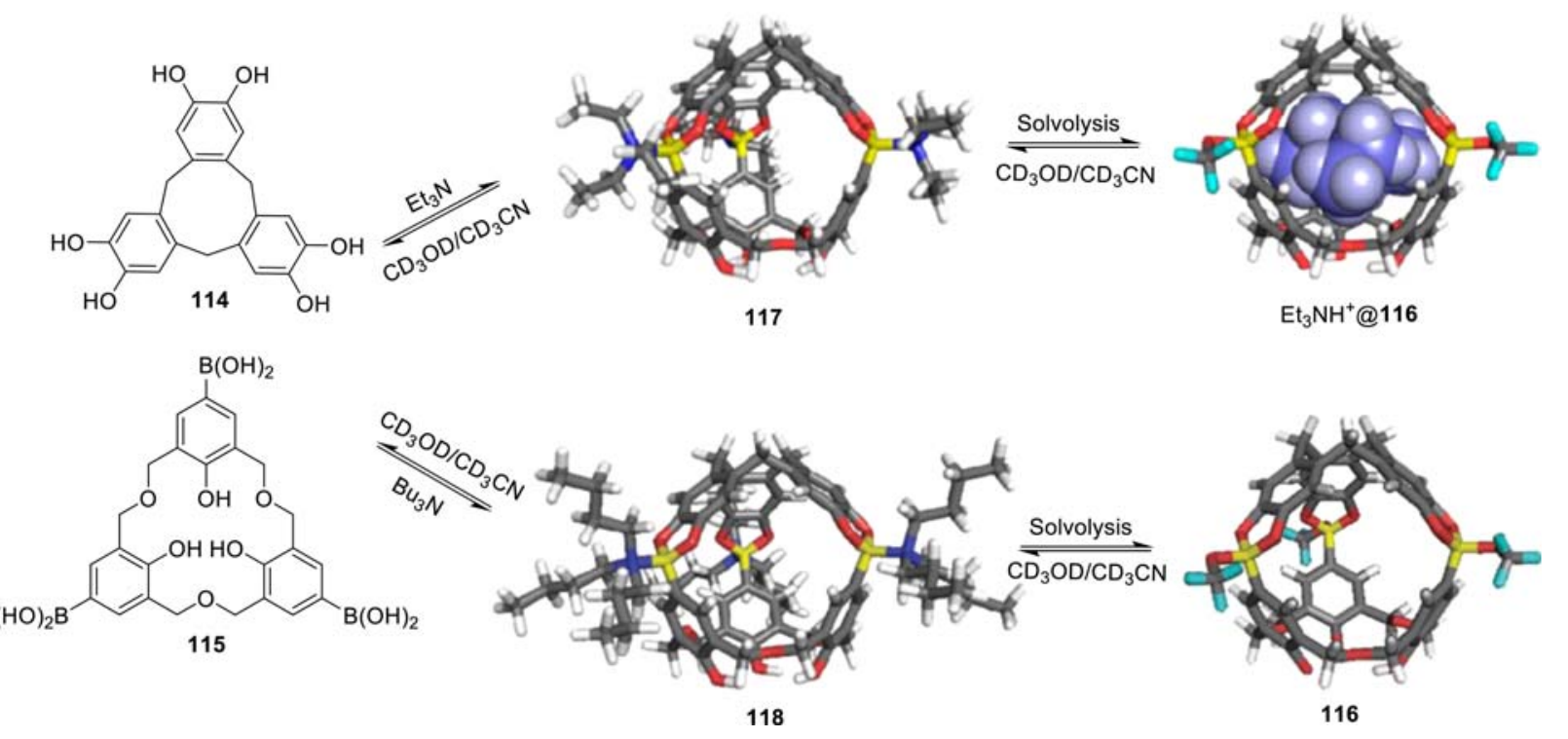

${ }^{a}$ Adapted with permission from ref 94 . Copyright 2009 The Royal Society of Chemistry.

capsule 116 using cyclotricatechylene 114 and boronic acidappended hexahomotrioxacalix[3]arene 115 via boronate esterification (Scheme 24). ${ }^{93}$ Individually, 114 exhibits a bowl-shaped structure, whereas $\mathbf{1 1 5}$ presents a flexible conformation. No assembled capsule is formed when mixing 114 and 115 in $\mathrm{CD}_{3} \mathrm{OD} / \mathrm{CD}_{3} \mathrm{CN}$ since no change of the ${ }^{1} \mathrm{H}$ NMR chemical shifts of 114 and 115 is observed. However, when 3 equiv of $\mathrm{Et}_{4} \mathrm{~N}^{+} \mathrm{AcO}^{-}$is added to this solution, the ${ }^{1} \mathrm{H}$ NMR spectrum changed significantly; in particular, the ethereal protons in $\mathbf{1 1 5}$ become a doublet, suggesting that the conformation of $\mathbf{1 1 5}$ is frozen into a cone conformation. In addition, the encapsulated $\mathrm{Et}_{4} \mathrm{~N}^{+}$species is also detected at low chemical shift, demonstrating formation of a molecular capsule induced by $\mathrm{Et}_{4} \mathrm{~N}^{+} \mathrm{AcO}^{-}$. The authors also use ROESY, DOSY, and ESI-MS techniques to investigate the $\mathrm{Et}_{4} \mathrm{NAcO}$-triggered self-organization. The decomposition-reconstruction process of 116 is reversible and could be controlled by the $\mathrm{pH}$. Nevertheless, it cannot be neglected that $\mathrm{Et}_{4} \mathrm{~N}^{+}$plays an important role as template in formation of the cage, preventing exploration of the recognition capacities of the inner space.

Subsequently, the authors reported the assembled hemicryptophane capsule 116 with the same modules 114 and 115 triggered by amine using dynamic boronate esterification. ${ }^{94}$ As shown in Scheme 25, upon addition of $\mathrm{Et}_{3} \mathrm{~N}$ to the $\mathrm{CD}_{3} \mathrm{OD} /$ $\mathrm{CD}_{3} \mathrm{CN}$ solution of 114 and 115 , the $\mathrm{N}-\mathrm{B}$ bonds are first formed together with the association of two modular compounds to generate the intermediate 117. Then the cage 117 is subjected to a solvolysis reaction to produce the $\mathrm{CD}_{3} \mathrm{O}$ attached 116 with encapsulation of $\mathrm{Et}_{3} \mathrm{NH}^{+}$. Addition of $\mathrm{Bu}_{3} \mathrm{~N}$ also follows the same sequence, first giving intermediate 118 . However, only the capsule $\mathbf{1 1 6}$ with an empty cavity is obtained in the solvolysis reaction because of the larger size of $\mathrm{Bu}_{3} \mathrm{NH}^{+}$ compared with $\mathrm{Et}_{3} \mathrm{NH}^{+}$. This result is quite appealing since an empty assembled hemicryptophane capsule is obtained, of which properties and applications, such as molecular recognition, could be investigated.

2.2.2. Formation by lonic Interactions. Ionic interactions between anion and cation have also been utilized for constructing self-assembled hemicryptophane cages. ${ }^{95}$ Jabin et al. combined the trisamine-calix[6] arene 86 with the CTVtricarboxylic acids $\mathbf{8 8}$ or $\mathbf{8 9}$ to generate $[1+1]$ hemicryptophanes (Scheme 26). In a first experiment addition of 1 equiv of calix[6]trisamine 86 to a suspension of CTVtriscarboxylic acid 88 in $\mathrm{CDCl}_{3}$ did not generate $[1+1]$ hemicryptophane capsule, and instead, various aggregated species were formed probably because of the flexibility of the calix[6] arene structure. However, subsequent addition of 3 equiv of neutral polar molecules, such as imidazolidin-2-one (IMI), to this $1: 1$ mixture led to a discrete $[1+1+1]$ selfassembled ternary hemicryptophane capsule IMI@119 composed of 86, 88, and encapsulated IMI. Futhermore, other polar molecules, such as imides, alcohols, amides, sulfoxides, 


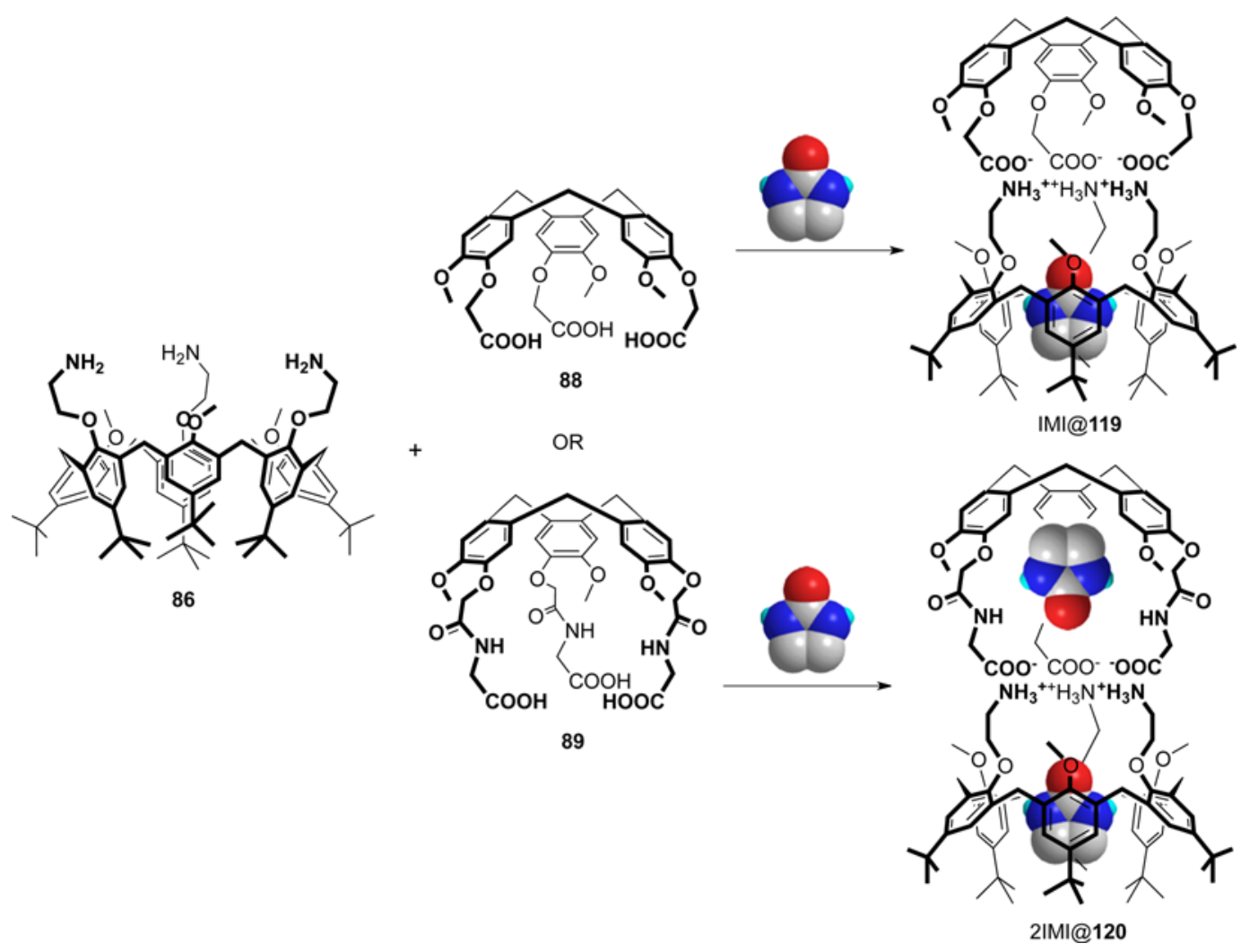

${ }^{a}$ Adapted with permission from ref 95. Copyright 2007 Elsevier.

carbamates, or ureas, could also induce the formation of the hemicryptophane capsules through an induced-fit process. These polar molecules can go inside the cavity of the calix[6] tris-ammonium via hydrogen-bonding, $\mathrm{CH}-\pi$ interactions with the aromatic walls, and charge-dipole interactions, leading to the expulsion of the methoxy groups from the calix cavity, rigidification of the calixarene core, and preorganization of the ammonium arms, which are necessary for assembly of the $[1+1]$ ion-paired complex. Interestingly, when using the CTV building block 89, a new self-assembled ditopic hemicryptophane capsule 2IMI@120 including simultaneously two IMI molecules, one in the calixarene cavity and one in the CTV cavity, was formed thanks to the larger size of the building block 89 and the flexibility of $\mathbf{8 6}$.

\subsection{Functionalization of Hemicryptophanes}

2.3.1. Water-Soluble Hemicryptophanes. Effective molecular recognition or catalysis in water is especially meaningful and attractive since it can mimic more accurately biological systems. ${ }^{103,104}$ Accordingly, supramolecular events should take place in water at physiological $\mathrm{pH}$ without addition of organic solvent, requiring water-soluble molecular hosts. The design of water-soluble hemicryptophanes is a real challenging task that mainly relies on introduction of hydrosoluble functions on the CTV unit. Two strategies that address this issue have been reported, where hydrosoluble groups allow solubilization of the host in strong basic aqueous solution ${ }^{105}$ or in water at physiological $\mathrm{pH}^{106}$ The two strategies that either introduce phenol functions or incorporate carboxylate groups on the CTV units originate from the synthesis of water-soluble cryptophanes. ${ }^{107-109}$
The tren-hemicryptophane $\mathbf{1 2 3}$ bearing three phenol functions on the CTV cap was synthesized from hemicryptophane 15a (Scheme 27). ${ }^{105}$ The tren unit in 15a was first protected by tert-butyloxycarbonyl groups (BOC) to give compound 121, avoiding the difficult and tedious purification

Scheme 27. Synthesis of the Water-Soluble Hemicryptophane 123
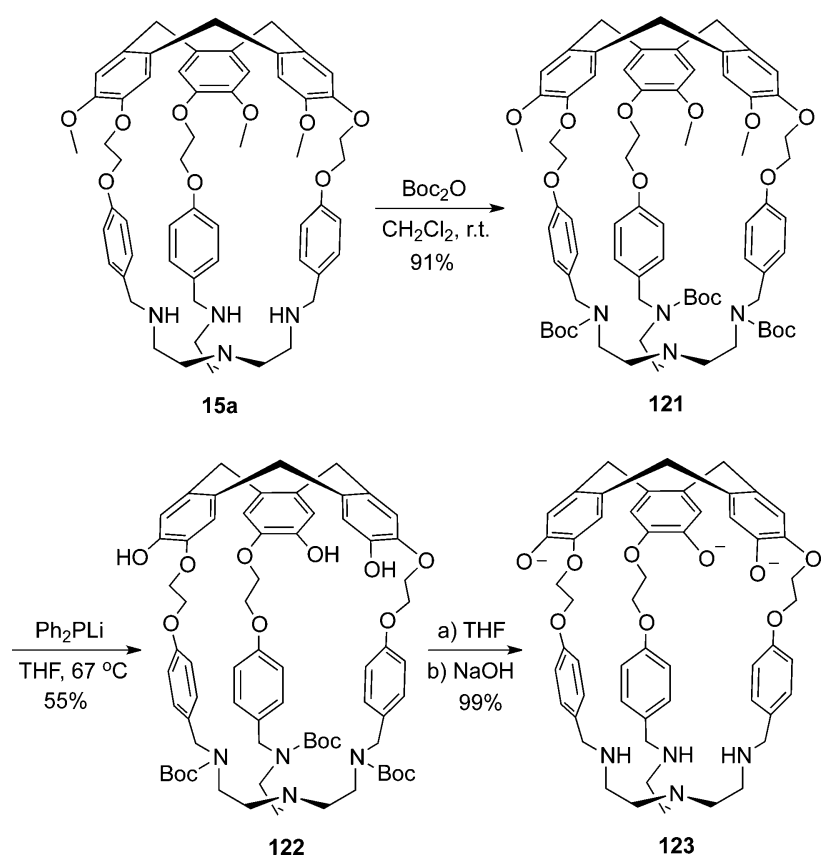
Scheme 28. Synthesis of Water-Soluble Hemicryptophane 125
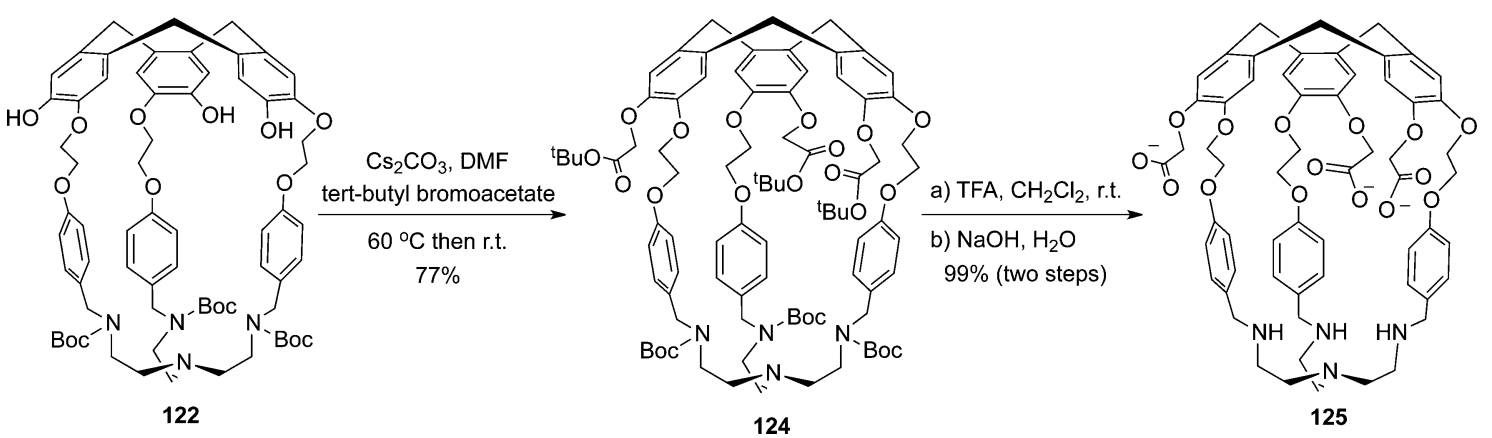

Scheme 29. Synthesis of (Pro)Azaphosphatrane Encaged Hemicryptophane Complexes

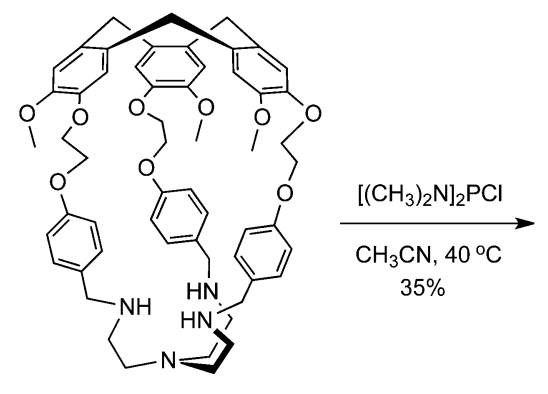

$15 \mathrm{a}$

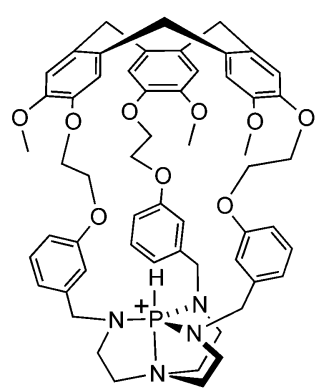

$\mathrm{PH}^{+} @ 15 b$

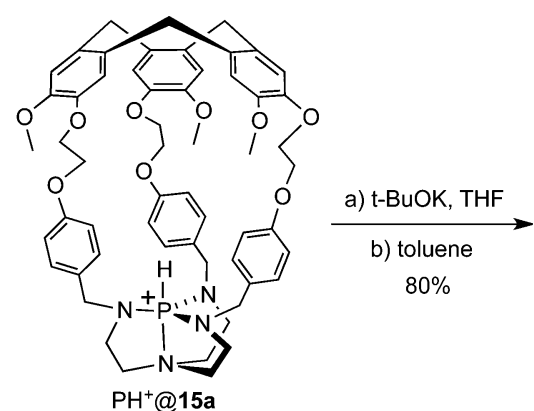

$\mathrm{PH}^{+} @ 15 \mathrm{a}$

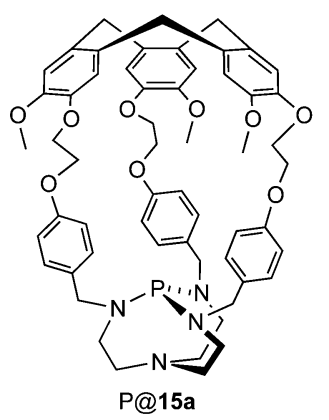

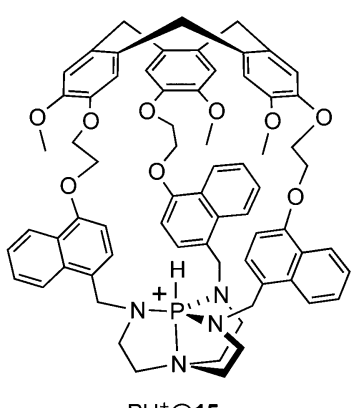

$\mathrm{PH}^{+} @ 15 \mathbf{g}$

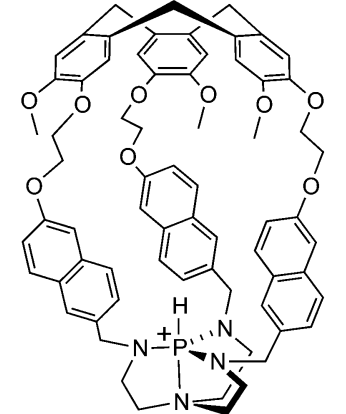

$\mathrm{PH}^{+} @ 15 \mathrm{i}$

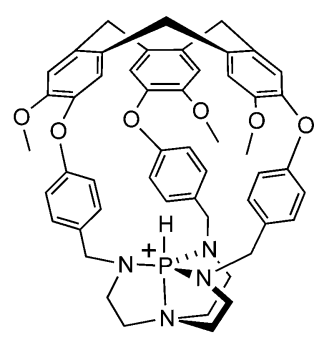

$\mathrm{PH}^{+} @ 22$ of compounds presenting simultaneously amine and phenol functions. Then the methoxy groups of $\mathbf{1 2 1}$ are removed using $\mathrm{Ph}_{2} \mathrm{PLi}$ to afford the trihydroxy- $N$-Boc-protected derivative 122. Finally, deprotection of the amine functions in 122 using trifluoroacetic acid led quantitatively to the hexaphenolate hemicryptophane 123 soluble in water at $\mathrm{pH}=12$.

Hemicryptophane $\mathbf{1 2 3}$ is only soluble in water at strong basic $\mathrm{pH}$, which does not allow its use in biological environment at physiological $\mathrm{pH}$. To overcome this problem the hemicryptophane 125 was synthesized based on the above intermediate 122 (Scheme 28). ${ }^{106}$ The first step involves reaction of 122 with tert-butyl-bromoacetate in DMF in the presence of $\mathrm{Cs}_{2} \mathrm{CO}_{3}$ to yield the protected triester derivative 124. Deprotection of the amine and the ester functions with trifluoroacetic acid affords quantitatively the desired hemicryptophane 125 bearing three carboxylate groups and soluble in water at physiological $\mathrm{pH}(\mathrm{pH} \approx 7)$.

2.3.2. Endohedral Functionalization of Hemicryptophanes. Endohedral functionalization of a molecular cavity is a highly challenging topic, arousing growing interest from the international community. ${ }^{110-115}$ Endohedral nonmetal or metal functional groups inside the molecular cavity can participate as binding sites to enhance the host-guest interactions or act as reactive centers to promote catalytic reactions in the confined space of the inner cavity, mimicking biological entities such as enzymes. ${ }^{113-117}$ The endohedral functionalization of the hemicryptophane cages reported so far is mainly concerned with (pro)azaphosphatrane derivatives and the vanadium $(\mathrm{V}(\mathrm{V}))$, zinc $(\mathrm{Zn}(\mathrm{II}))$, copper ( $\mathrm{Cu}(\mathrm{II}))$, and ruthenium $(\mathrm{Ru}(\mathrm{II}))$ hemicryptophane complexes, the crucial role of which as supramolecular catalysts has been investigated.

2.3.2.1. Encaged (Pro)Azaphosphatranes: Synthesis and Cage Effect. Proazaphosphatranes, also known as Verkade's superbases, and their azaphosphatrane protonated counterparts exhibit catalytic properties in a wide range of reactions. $^{47,118-122}$ In 2011, Dutasta and Martinez et al. synthesized the first hemicryptophane-Verkade's superbase P@15a and its conjugated acid $\mathrm{PH}^{+} @ 15 \mathrm{a}$ from their precursor 15a using the experimental conditions reported for other azaphosphatranes (Scheme 29). Addition of hemicryptophane 15a to a solution of $\left[\left(\mathrm{CH}_{3}\right)_{2} \mathrm{~N}\right]_{2} \mathrm{PCl}$ in $\mathrm{CH}_{3} \mathrm{CN}$ afforded $\mathrm{PH}^{+} @ \mathbf{1 5 a}$ in $35 \%$ yield, which was then deprotonated using potassium tert-butoxide $(t-$ $\mathrm{BuOK})$ in THF to give the encaged superbase P@15a in 80\% yield. ${ }^{123,124}$ The azaphosphatrane-hemicryptophanes $\mathrm{PH}^{+} @ 15 a$ was optically resolved by chiral semipreparative HPLC, leading to the enantiopure compounds $\mathrm{PH}^{+} @ M-15 \mathrm{a}$ and $\mathrm{PH}^{+} @ P$ - 


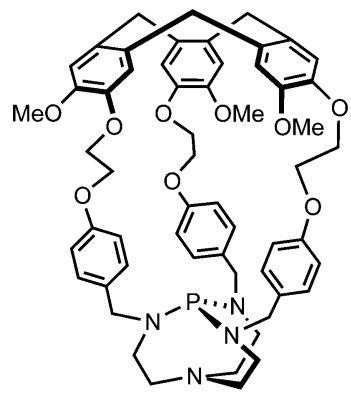

P@15a

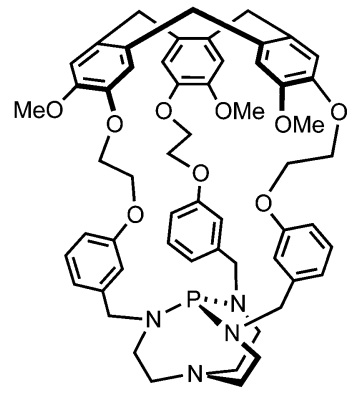

P@15b

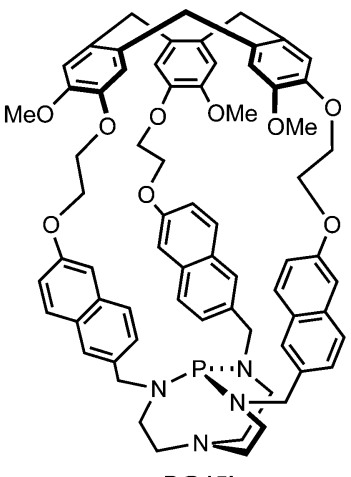

P@15i

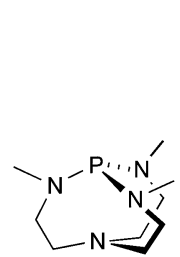

P@126

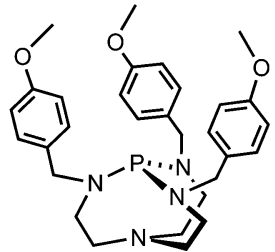

P@126a

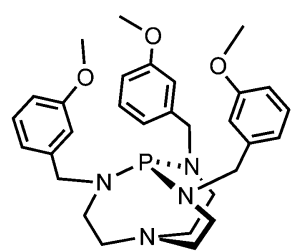

P@126b

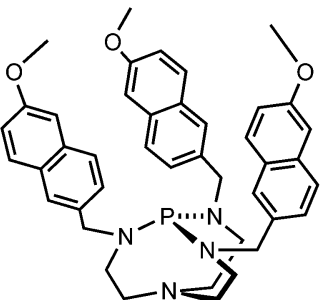

P@126i

Figure 7. Structures of hemicryptophane superbases and the noncaged models.

(a)

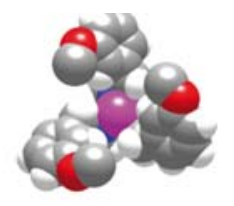

(b)

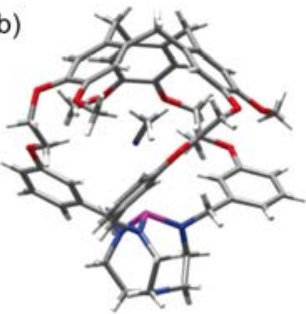

P@15b
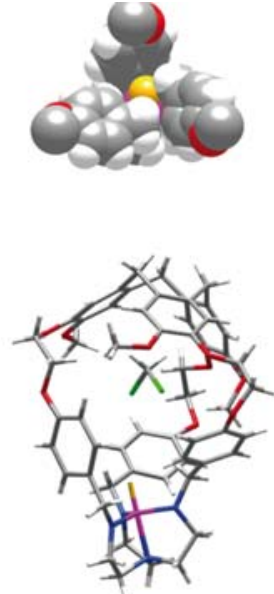

$\mathrm{PH}^{+} @ 15 \mathrm{a}$
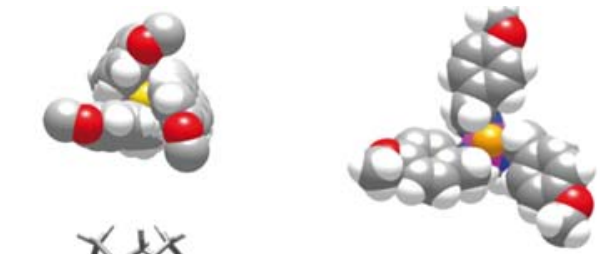

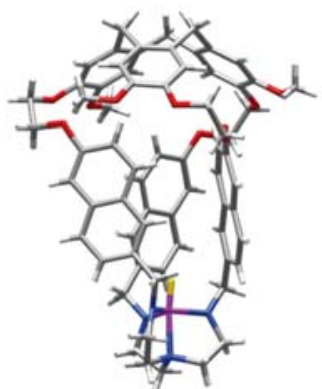

$\mathrm{PH}^{+} @ 15 \mathrm{i}$

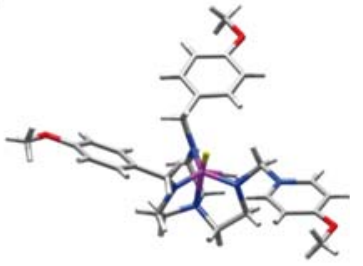

$\mathrm{PH}^{+} @ 126 \mathrm{a}$

Figure 8. X-ray crystal structures of the encaged Verkade's superbase $\mathrm{P} @ 15 \mathbf{b}$ and the azaphosphatrane cations $\mathrm{PH}^{+} @ 15 \mathrm{a}, \mathrm{PH}^{+} @ 15 \mathrm{i}$, and $\mathrm{PH}^{+} @$ 126a: (a) space-filling top views of the phosphorus centers (for $\mathrm{P} @ 15 b, \mathrm{PH}^{+} @ 15 \mathrm{a}$, and $\mathrm{PH}^{+} @ 15 \mathrm{i}$, the CTV units have been removed for clarity); (b) stick views. Reproduced with permission from ref 124. Copyright 2013 American Chemical Society.

15a. ${ }^{125}$ Likewise, hemicryptophane-superbases P@15b, P@ 15g, and P@15i and their corresponding protonated forms were also obtained using the same synthetic pathway. Makita et al. also prepared the encaged azaphosphatrane $\mathrm{PH}^{+} @ 22,{ }^{126}$ but depronation of the $\mathrm{PH}^{+}$failed even with an excess of $t$-BuOK or sodium hexamethyldisilazide (Scheme 29). This was attributed to the smaller size of the molecular cavity that protects the endohedral proton. Most of the encaged azaphosphatranes display a characteristic single ${ }^{31} \mathrm{P}$ NMR signal, which is about $20 \mathrm{ppm}$ downfield shifted compared to nonencaged azaphosphatranes. $^{125}$

Then Martinez et al. investigated the cage effect on the basicity and reactivity of the superbases. ${ }^{123}$ Indeed, the kinetics and thermodynamics of proton transfer in biological systems can be strongly modified by the surrounding medium. ${ }^{127}$ Changes in the reactivity in such confined biological entities have led to the design of bioinspired supramolecular structures. ${ }^{128,129}$ These investigations are likely to provide valuable information for a better understanding of enzymes or other complex biological systems. For that purpose, the model compounds P@126 and P@126a were prepared (Figure 7), and competition experiments were run for determination of $\mathrm{p} K_{\mathrm{a}}$ of $\mathrm{P} @ 15 \mathrm{a}$ and $\mathrm{P} @ 126 \mathrm{a}$ relative to $\mathrm{P} @ 126$ in $\mathrm{CD}_{3} \mathrm{CN}$ using ${ }^{31} \mathrm{P}$ and ${ }^{1} \mathrm{H}$ NMR spectroscopy. This afforded a value of $K_{\mathrm{a}}=1.03 \times 10^{-33}$ for $\mathrm{P} @ 15 \mathrm{a}, 7$ times smaller than that of its model superbase $\mathrm{P} @ 126 \mathrm{126}\left(K_{\mathrm{a}}=7.25 \times 10^{-33}\right)$, making the encaged superbase $\mathrm{P} @ 15 a 7$ times more basic than the model molecule P@126a. In addition, the deprotonation rate constant is more than 500-fold lower with the encaged $\mathrm{PH}^{+} @ 15 \mathrm{a}$ than with the model $\mathrm{PH}^{+} @ 126 \mathrm{a}$. In spite of the higher basicity of the superbase $\mathrm{P} @ 15 \mathrm{a}$, the rate constant for its protonation is nearly 2 orders of magnitude lower than that for the model 

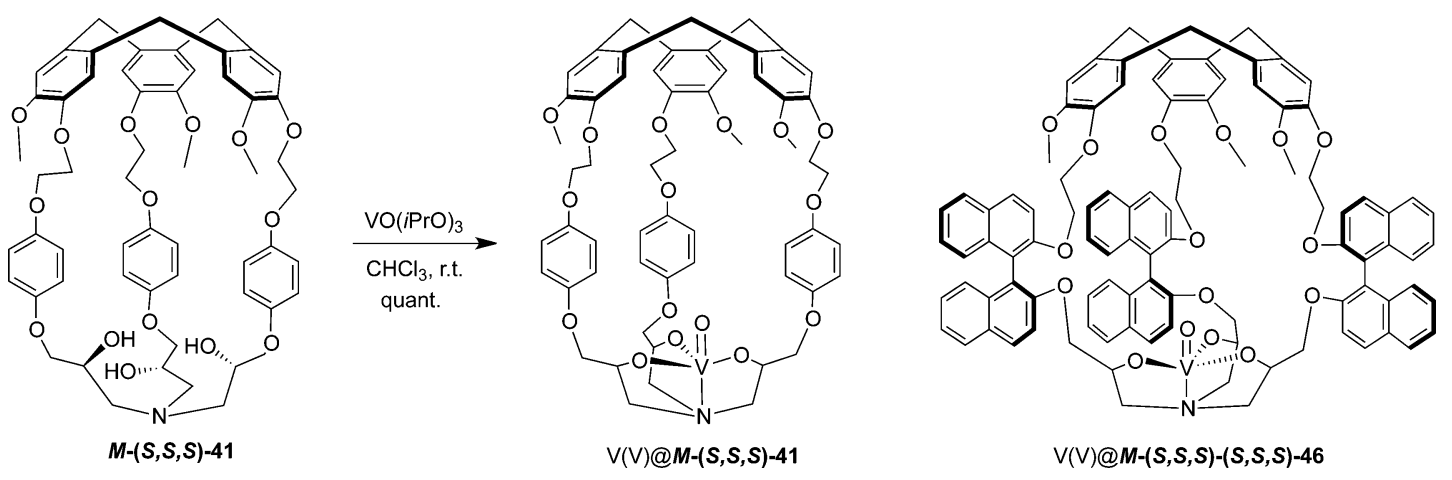

Scheme 31. Synthesis of $\mathrm{Zn}$ (II) Hemicryptophane Complexes
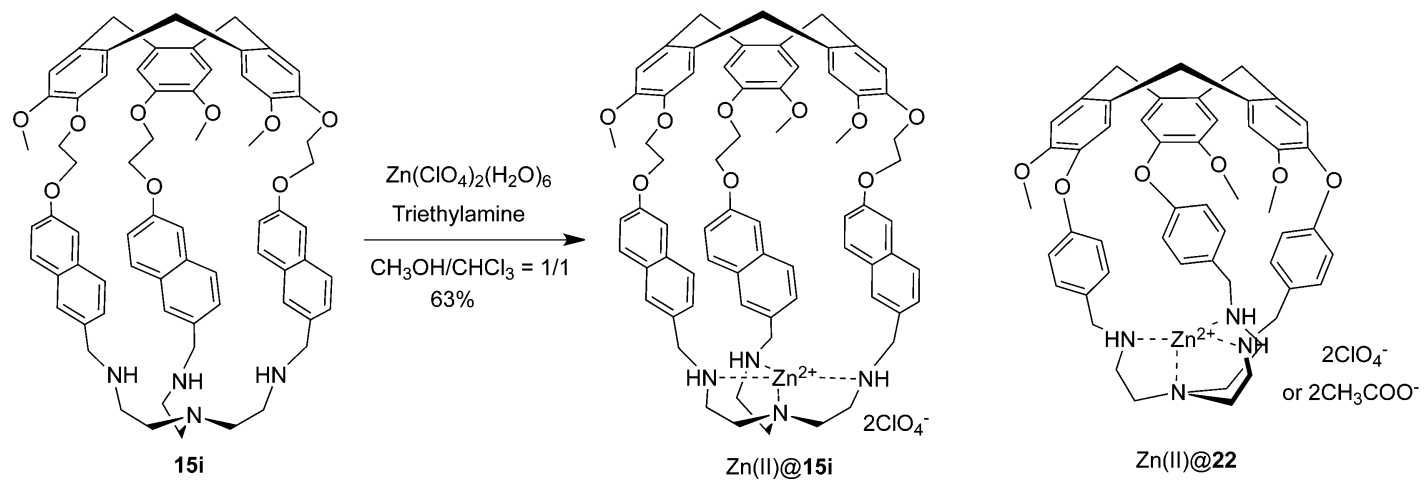

superbase P@126a, meaning that the rate constant is unrelated to the thermodynamics of proton transfer. These observations indicate that encapsulation of the phosphorus moiety inside the cage affects the basicity of the superbase and strongly decreases the rate of proton transfer.

In order to further investigate how the size and shape of the nanospace around this highly reactive center can control the basicity and the rate of the proton transfer, the authors prepared a series of encaged proazaphosphatrane superbases having a molecular cavity with different volumes and shapes and also their corresponding model compounds without a cavity (Figure 7). ${ }^{124} \mathrm{X}$-ray crystal structures reveal that from $\mathrm{P} @ 15 b$ to $\mathrm{PH}^{+} @ 15 a$ and $\mathrm{PH}^{+} @ 15 i$ the molecular cavity grows along the pseudo- $C_{3}$ axis of the molecule but also becomes narrower (Figure 8). It has been shown that the encapsulation greatly affects the basicity of the superbase. For example, according to the $\mathrm{p} K_{\mathrm{a}}$ values, the encaged superbase $\mathrm{P} @ 15 \mathrm{a}$ is 7 times more basic than its model P@126a, whereas $\mathrm{P} @ 15 b$ is more than 30 times less basic than its model P@126b, and P@ 15i was found to be over 100 times more basic than its model $\mathrm{P} @ 126 i$. These results were closely related to the geometry of the environment around the $\mathrm{P}-\mathrm{H}$ site, and the congestion of the inner space around the phosphorus center corresponds to an increase of the basicity of the superbases P@15a and P@15i compared to their respective models P@126a and P@126i. In addition, the kinetic data show that the rates of the proton transfer for these superbases are in the order of $\mathrm{PH}^{+} @ 121 \mathrm{a}>$ $\mathrm{PH}^{+} @ 15 b>\mathrm{PH}^{+} @ 15 a>\mathrm{PH}^{+} @ 15 \mathbf{1}$, which is consistent with the accessibility of the reactive phosphorus center also observed from the crystal structures.

2.3.2.2. Synthesis of Endohedral Metal@Hemicryptophane Complexes. Metal complexes possess a variety of coordination topologies, thermodynamic stabilities, and kinetics and have found wide applications in molecular recognition and catalysis. They can serve both as binding and as catalytic sites in the development of sensors and catalysts, similar to the function of metalloenzymes in bioinorganic chemistry. ${ }^{130-135}$ The hemicryptophane cages including tren and trialkanolamine units, such as $\mathbf{1 5 a}$ and 41 , can easily coordinate a metal ion such as $\mathrm{Zn}(\mathrm{II}), \mathrm{Cu}(\mathrm{II}), \mathrm{Ru}(\mathrm{II}), \mathrm{Al}(\mathrm{III})$, or $\mathrm{V}(\mathrm{V})$ to form atrane structures, which are an interesting class of compounds well represented across the periodic table and widely studied. $^{44,136-138}$

The oxidovanadium hemicryptophane complexes, such as the two diastereomers V(V)@M- $(S, S, S)-41$ and V(V)@P-(S,S,S)41, were synthesized in one step from their precursors bearing trialkanolamine moieties (Scheme 30). ${ }^{60,139}$ Hemicryptophane $M-(S, S, S)-41$ reacted with 1 equiv of vanadium oxytriisopropoxide to give the corresponding complex quantitatively. Similarly, the oxidovanadium hemicryptophane complex V(V) $@ M-(S, S, S)-(S, S, S)-46$ and its stereoisomers were also successfully obtained. ${ }^{140}$ It is noteworthy that these vanadium complexes present potential catalytic sites in chiral environments, which may find applications in asymmetric catalysis. Another point is that besides vanadium(V), titanium(IV) and zirconium(IV) are also known to form stable complexes with trialkanolamine ligands. ${ }^{141,142}$

tren-Hemicryptophane 15i reacted with $\mathrm{Zn}\left(\mathrm{ClO}_{4}\right)_{2}\left(\mathrm{H}_{2} \mathrm{O}\right)_{6}$ to yield the Zn(II)@15i complex in 63\% yield (Scheme 31). ${ }^{143}$ Following this method, Makita et al. synthesized Zn(II)@22 with $\mathrm{ClO}_{4}^{-}$or $\mathrm{CH}_{3} \mathrm{COO}^{-}$as counterion ${ }^{54,144}$ and the $\mathrm{RuCl}_{2} @$ 22 hemicryptophane complexes. ${ }^{145}$

The tren unit easily binds $\mathrm{Cu}$ (II) ions, and a series of $\mathrm{Cu}(\mathrm{II})$ @hemicryptophane complexes has been described. Different tren-hemicryptophane ligands reacted with stoichiometric amounts of $\mathrm{Cu}\left(\mathrm{ClO}_{4}\right)_{2}$ in a $\mathrm{CH}_{2} \mathrm{Cl}_{2} / \mathrm{MeOH}$ mixture to 
produce Cu(II)@15a, Cu(II)@15b, Cu(II)@15i, and Cu(II)@ 125 complexes with high yields (Scheme 32). ${ }^{146}$ It is important to point out that $\mathrm{Cu}(\mathrm{II}) @ 125$ constitutes the first water-soluble $\mathrm{Cu}(\mathrm{II}) @$ hemicryptophane complex. ${ }^{106}$

\section{Scheme 32. Synthesis of $\mathrm{Cu}$ (II) Hemicryptophane} Complexes

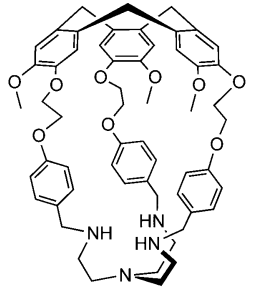

$15 a$

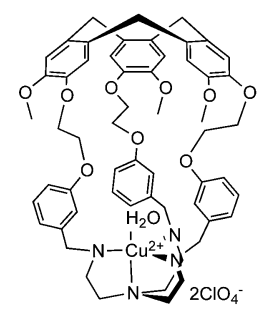

$\mathrm{Cu}(I 1) @ 15 b$

\section{$\mathrm{Cu}\left(\mathrm{ClO}_{4}\right)_{2} 6 \mathrm{H}_{2} \mathrm{O}$ $\overrightarrow{\mathrm{Et}_{3} \mathrm{~N}, \mathrm{CH}_{2} \mathrm{Cl}_{2} / \mathrm{MeOH}}$} $82 \%$

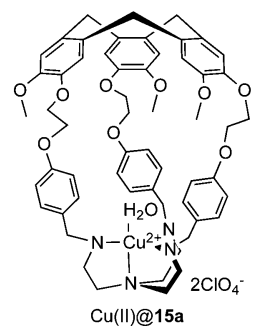

Cu(II)@15a
Recently, Dutasta et al. reported the preparation of Ga(III)@ 101 and Fe(III)@101 hemicryptophane complexes presenting an octahedral coordination site inside the molecular cavity of the host molecule. ${ }^{71}$ The complexes were obtained by addition of $\mathrm{Ga}(\mathrm{acac})_{3}$ or $\mathrm{Fe}(\mathrm{acac})_{3}$ to a solution of 101 in 1,1,2,2tetrachloroethane and characterized by ${ }^{1} \mathrm{H},{ }^{13} \mathrm{C}$, and ${ }^{31} \mathrm{P}$ NMR spectroscopies. The EPR spectrum of the iron complex Fe(III) @101 indicated a high-spin $\mathrm{Fe}(\mathrm{III})$ ion in an octahedral environment. The isostructural X-ray molecular structures of both complexes showed the metal ions nested in the phosphorylated part of the ligand (Figure 9). It is interesting
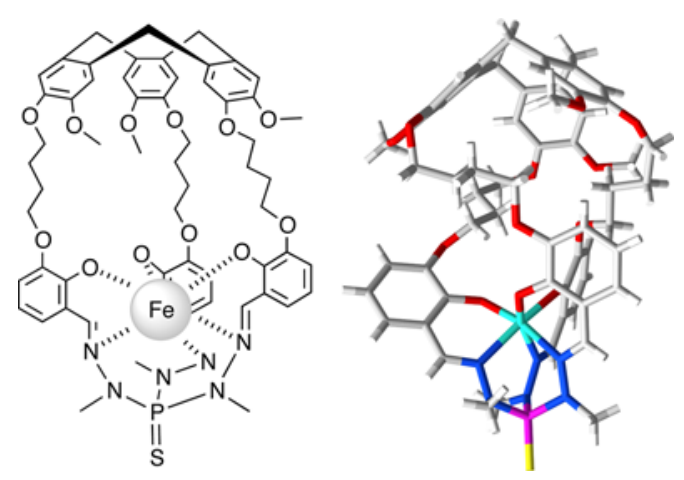

Figure 9. X-ray molecular structure of Fe(III)@101 complex.

to note that the chiral CTV cap induces a helical arrangement of the three linkers of the host molecule, whose configuration is related to that of the CTV unit. Moreover, the complexes present two stereogenic centers, the CTV unit with $P$ or $M$ configuration and the octahedral coordination site with $\Delta$ or $\Lambda$ configuration, that should lead to two diasteromeric racemates $(P \Delta / M \Lambda$ and $M \Delta / P \Lambda)$. In the present case the authors only observed the $(P \Delta / M \Lambda)$ racemate. This seems to be a general feature observed with other hemicryptophane structures where the CTV imposes the right- or left-handed conformation of the linkers and also the stereochemistry of other stereogenic elements present in the host molecule.

\section{HOST-GUEST CHEMISTRY OF HEMICRYPTOPHANES}

The use of molecular containers for complexation and recognition of neutral or charged guests is of increasing interest as they can lead to a better understanding of recognition phenomena in biological systems. ${ }^{12,24,147-130}$ In particular, hemicryptophane molecular receptors present several advantages. (i) The rigid CTV scaffold results in a preorganized cavity in terms of shape and size, enhancing guest binding. Futhermore, the size of the cavity can be controlled and adjusted by changing the linkages between CTV and south units. (ii) The versatile south unit is easily modified to specifically recognize cations, anions, or neutral molecules depending on its interacting sites; thus, various homoditopic and heteroditopic hosts can be designed when combined with the electron-rich CTV moiety. (iii) Signaling groups, for instance, fluorophore, can be incorporated into the cages to provide fast responses with a low detection limit for host-guest complexation. The position of the signaling groups is relatively flexible as they can be tethered to the north or south units or included in the three linkages. (iv) Taking advantage of the chirality of the CTV unit, enantio- and diastereoselective recognition properties are expected.

The first complexation experiment was described in 1982 with hemicryptophane $1,{ }^{27}$ followed 26 years later by a second example reported by Le Gac and Jabin. ${ }^{70}$ Only recently, hemicryptophanes have been investigated as complexing agents for various chiral or achiral guests such as ammoniums, ${ }^{94,105,151,152}$ ion pairs, ${ }^{49,70,153}$ zwitterions, ${ }^{63,65,143,154}$ carbohydrates, ${ }^{56,57,61,155}$ and $\mathrm{C}_{60}$ or $\mathrm{C}_{70}$ fullerenes. ${ }^{69}$ This section aims at reporting the complexation properties in the solid state and in a solution of hemicryptophane hosts, emphasizing the enantioselective recognition with enantiopure receptors.

\subsection{Guest Inclusion in the Solid State: X-ray Molecular Structures}

Dutasta et al. reported in 1999 the first structure of a guest imprisoned in the lipophilic cavity of a hemicryptophane host. ${ }^{30}$ The crystal structure of hemicryptophane 6 , recrystallized from toluene, shows a well-preorganized cavity defined by the CTV and phosphotrihydrazone moieties, with the $\mathrm{S}=\mathrm{P}$ bond oriented outward of the cavity (Figure 10). One toluene guest is totally encapsulated in the cavity of the host to form a host-guest complex stabilized by van der Waals and $\mathrm{C}-\mathrm{H} \cdots \pi$ interactions. In the solid, host 101 encapsulates a toluene molecule and displays the two $P$ and $M$ configurations of the CTV unit. ${ }^{71}$ Interestingly, the linkers adopt an $\alpha$ - or $\beta$-helical conformation, and only the $P$ - $\alpha$-helix and $M-\beta$-helix enantiomers coexist in the crystal (Figure 10). Single crystals of hemicryptophane 14 were also obtained by slow evaporation from a $\mathrm{CH}_{2} \mathrm{Cl}_{2}$ solution (Figure 10). ${ }^{48}$ Hemicryptophane 14 exhibits an asymmetric structure with respect to the $C_{3}$ axis of the CTV cap, introduced by the inward orientation of one $\mathrm{C}=$ $\mathrm{O}$ amide bond stabilized by $\mathrm{H}$ bonds with the adjacent $\mathrm{NH}$ groups. The two other $\mathrm{C}=\mathrm{O}$ groups are oriented outward and participate in the crystalline cohesion through intermolecular hydrogen bonding. One $\mathrm{CH}_{2} \mathrm{Cl}_{2}$ guest molecule is fully 

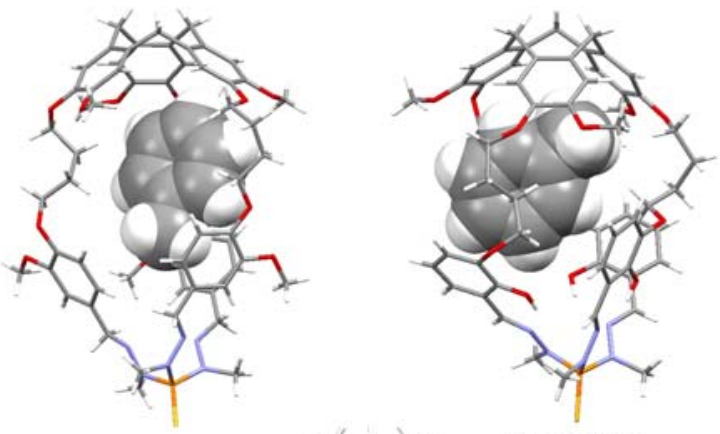

toluene@6

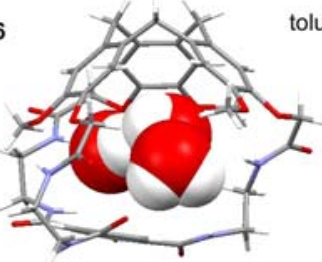

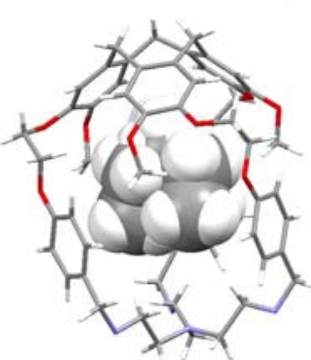

n-pentane@15a

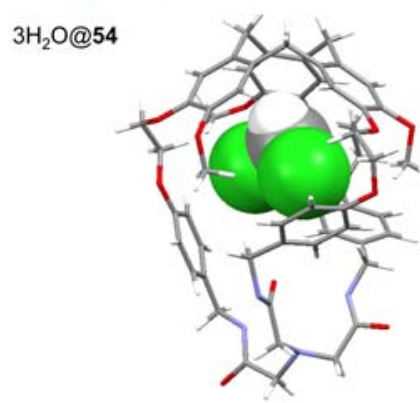

$\mathrm{CH}_{2} \mathrm{Cl}_{2} @ 14$
Figure 10. Crystal structures of toluene@6, toluene@101,3 $\mathrm{H}_{2} \mathrm{O} @ 54$, n-pentane@15a, and $\mathrm{CH}_{2} \mathrm{Cl}_{2} @ 14$ complexes.

encapsulated in the host cavity and localized close to the CTV unit in the more lipophilic environment of the cavity. This important feature indicates the possible ditopic character of the hemicryptophane host toward guest compounds. Slow diffusion of pentane in a solution of $15 \mathrm{a}$ in $\mathrm{CH}_{2} \mathrm{Cl}_{2}$ gave crystals suitable for X-ray analysis (Figure 10). ${ }^{48}$ The structure presents a $\mathrm{C}_{3^{-}}$ symmetrical axis with a well-preorganized cavity encapsulating a molecule of $n$-pentane. In the complex, $\mathrm{C}-\mathrm{H} \cdots \pi$ interactions between $\mathrm{CH}_{3}$ groups of the guest and aromatic groups of the linkers are observed. Interestingly, water molecules can also be included in the cavity of hemicryptophanes. In the $\mathrm{X}$-ray structure of 54, crystallized from $\mathrm{CH}_{3} \mathrm{CN} / \mathrm{H}_{2} \mathrm{O}$, three water molecules are encaged inside the hemicryptophane cavity. ${ }^{63}$ Two of them interact with an amide group of the host through hydrogen bonding, and one is in the proximity of the electrondeficient aromatic ring. This anticipates the recognition properties of this host toward hydrophilic species.

Makita et al. also described a series of crystal structures of inclusion complexes with hemicryptophane hosts. For example, the X-ray crystal structure of hemicryptophane 22 (Figure 11), obtained by slow evaporation from a $\mathrm{CH}_{3} \mathrm{CN}$ solution, exhibited a preorganized cavity constructed by the CTV and the tren moieties. ${ }^{44} \mathrm{~A}$ molecule of $\mathrm{CH}_{3} \mathrm{CN}$ is entrapped inside the molecular cavity stabilized by hydrogen-bonding and $\mathrm{CH} \cdots \pi$ interactions. ${ }^{54}$ Interestingly, the $\mathrm{Zn}(\mathrm{II})$-coordinated complex of $22\left(\mathrm{ClO}_{4}^{-}\right.$as counterion) also bound a $\mathrm{CH}_{3} \mathrm{CN}$ molecule as observed from its crystal structure prepared by slow diffusion of THF into a $\mathrm{CH}_{3} \mathrm{CN}$ solution. ${ }^{144}$ In this case, the cage maintains the $\mathrm{C}_{3}$ symmetry and includes a $\mathrm{CH}_{3} \mathrm{CN}$
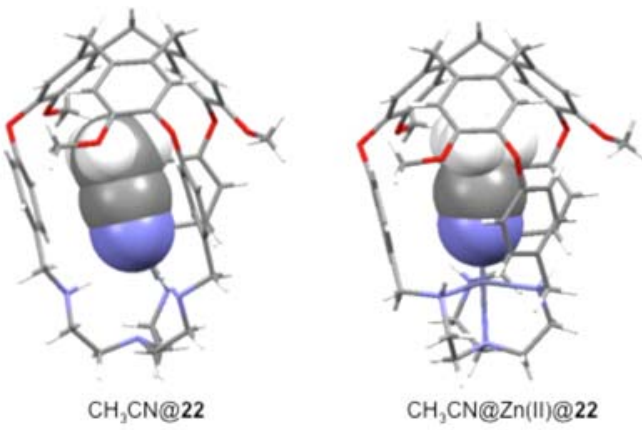

$\mathrm{CH}_{3} \mathrm{CN} @ \mathrm{Zn}$ (II)@22

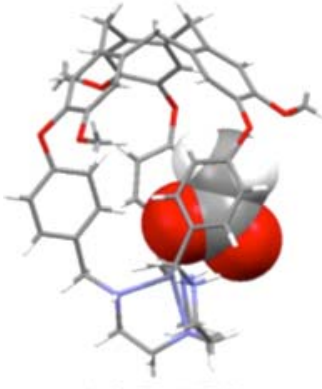

AcO-@Zn(II)@22

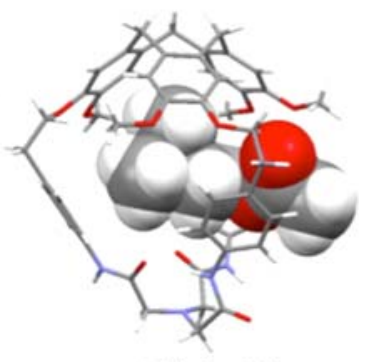

acetylcholine@24
Figure 11. Crystal structures of $\mathrm{CH}_{3} \mathrm{CN} @ 22, \mathrm{CH}_{3} \mathrm{CN} @ \mathrm{Zn}(\mathrm{II}) @ 22$, $\mathrm{AcO}^{-} @ \mathrm{Zn}(\mathrm{II}) @ 22$, and acetylcholine@24.

molecule through $\mathrm{CH} \cdots \pi$ interactions. In addition, the $\mathrm{CH}_{3} \mathrm{CN}$ $\mathrm{N}$ atom also loosely coordinates to the $\mathrm{Zn}$ (II) ion, which indicates the binding ability of this metal center. However, when $\mathrm{AcO}^{-}$was used as the counterion, the $\mathrm{Zn}(\mathrm{II}) @ 22$ complex does not include a $\mathrm{CH}_{3} \mathrm{CN}$ molecule despite the crystals being obtained by slow diffusion of $\mathrm{Et}_{2} \mathrm{O}$ into a $\mathrm{CH}_{3} \mathrm{CN}$ solution. ${ }^{54}$ Instead, an $\mathrm{AcO}^{-}$counterion was embedded inside the molecular cavity according to the coordination bond between the $\mathrm{O}$ atom in $\mathrm{AcO}^{-}$and $\mathrm{Zn}(\mathrm{II})$. This inclusion behavior of $\mathrm{Zn}(\mathrm{II}) @ 22$ toward $\mathrm{AcO}^{-}$was also observed in solution. These results underline the strong binding ability and heteroditopic character of the Zn(II)@22 host.

Most of the X-ray structures of guest inclusion in hemicryptophane hosts reported so far are often restricted to solvent@hemicryptophane complexes. However, in 2016 Makita et al. reported the solid-state structure of an acetylcholine molecule encaged in the cavity of hemicryptophane $24 .{ }^{55}$ A partial encapsulation of the neurotransmitter was observed: indeed, the ammonium head of acetylcholine is trapped inside the cavity, whereas the acetyl group is located outside, leading to an original pseudorotaxane structure (Figure 11). This important result highlights the ability of hemicryptophane to tolerate partial encapsulation and thus to complex only a part of large guest molecules.

$\mathrm{X}$-ray molecular structures of free hosts, without guest molecules in the molecular cavity, have also been reported and result from two main factors. (i) The cavity is too small to accommodate any guest molecules as, for instance, in the crystal structure of hemicryptophane 105 described by Dmochowski et al. ${ }^{52}$ or in hemicryptophane $\mathbf{1 5 b}$ where hydrogen bonds involving the three linkages induce a twisted structure, giving rise to very small available space inside the cavity (Figure 12). ${ }^{51}$ (ii) The hemicryptophane structure collapses and the molecule adopts a compact structure with the molecular cavity occupied by one of the linkages or the south moieties such as the crystal structures of $\mathrm{V}(\mathrm{V}) @ P$ - 


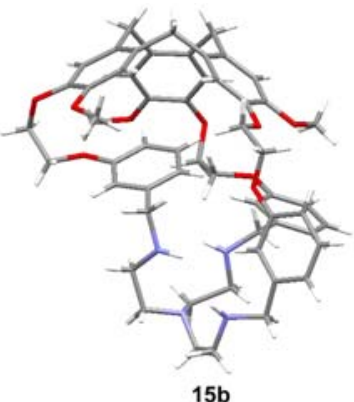

$15 b$

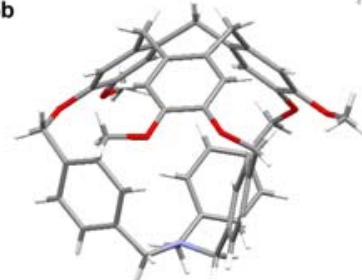

105

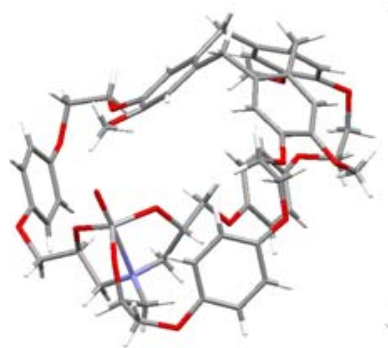

$\mathrm{V}(\mathrm{V}) @ P-(\mathrm{S}, \mathrm{S}, \mathrm{S})-41$

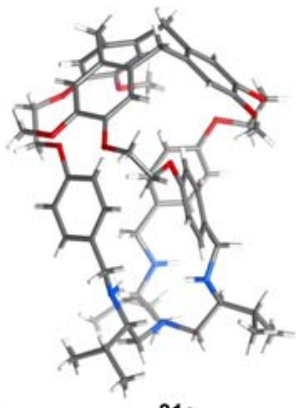

$31 \mathrm{a}$

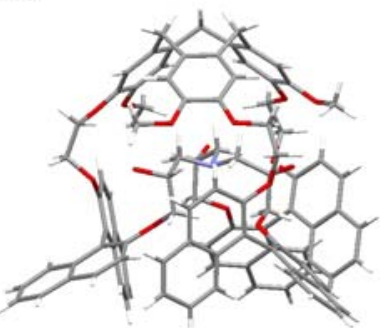

$M-(R, R, R)-(R, R, R)-46$
Figure 12. Crystal structures of 15b, 31a, 105, V(V)@P-(S,S,S)-41, and $M-(R, R, R)-(R, R, R)-46$.

$(S, S, S)-41^{156}$ and $M-(R, R, R)-(R, R, R)-46$ (Figure 12)..$^{61}$ Therefore, when designing a hemicryptophane host with the purpose of complexing molecules, these factors, which may induce no guest encapsulation, should be taken into account.

Interestingly, the X-ray molecular structures can be used to assign the absolute configuration of the chiral CTV unit. For instance, in the solid-state structure of hemicryptophane 31a, recrystallized from a dichloromethane solution, a well-defined molecular cavity was observed (Figure 12). Because the $S$ configuration of the three stereogenic carbons of the tren moiety was controlled during the synthetic pathway, it was possible to assign the $M$ configuration of the CTV unit (Flack parameter $=0.00(1)) .^{58}$

\subsection{Complexation in Solution}

Most of the host-guest systems with hemicryptophane hosts have been investigated in solution. The binding affinities rely on the lipophilic and electron-donor properties of the CTV moiety, which can be associated with various southern units leading to a wide range of suitable guests. Thus, the peculiar properties of the hemicryptophanes are strongly related to their heteroditopic character with modulable cavity size and shape, polarity, hydrophilicity, and hydrophobicity. Among the various noncovalent interactions that can take place with hemicryptophane hosts, hydrogen-bonding and cation $-\pi$ or anion $-\pi$ interactions prevail due to the aromatic environment of the receptors built from the CTV platform. This review will cover the most encountered hemicryptophane-guest complexes reported in the literature including charged species (ammonium, ion pairs, zwitterions) and neutral guests such as fullerenes and carbohydrates.
Because of the chirality of the CTV unit, the recognition of achiral molecules by hemicryptophane hosts usually involves racemic mixtures. Conversely, the complexation of chiral guests uses enantiopure hemicryptophane hosts. The enantioselective recognition of chiral molecules with $C_{3}$-symmetrical hosts is highly challenging. Indeed, the first enantioselective recognition of chiral primary ammonium ions with $C_{3}$-symmetric tripodal receptors was reported by Ahn et al. only in 2002, ${ }^{157}$ followed by a few other examples. ${ }^{158,159}$ Then Moberg et al. were able to rationalize the enantioselectivity observed with $C_{3}$-symmetric hosts, putting an end to an old scientific controversy. ${ }^{160,161}$ This highlights that enantioselective recognition of chiral molecules with $C_{3}$-symmetrical hosts remains a difficult task. Access to enantiomerically pure hemicryptophanes as described in the preceding sections allowed important investigations in the field of chiral recognition in solution that will be underlined in the following sections.

3.2.1. Recognition of Ammonium Guests. The first hemicryptophane, speleand 1, developed by Collet and Lehn, was shown to be an efficient binding receptor for primary ammonium. ${ }^{27} \mathrm{~A}$ schematic representation of the inclusion complex is shown in Figure 13: the $\mathrm{NH}_{3}{ }^{+}$group interacts with

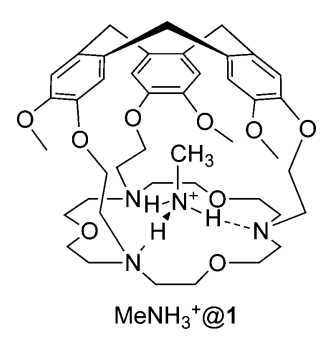

Figure 13. Proposed binding mode between hemicryptophane 1 and $\mathrm{MeNH}_{3}^{+}$.

the azacrown ether by hydrogen bonding, and the $\mathrm{CH}_{3}$ head is located inside the molecular cavity. A host-guest complex with the $\mathrm{CH}_{3}$ group located outside of the cavity below the azacrown ether is also detected, and a 2:1 ratio between the exo and the endo complexes is observed.

The second example of encapsulation of ammoniums was reported in 2009 using the $n-\mathrm{Bu}_{3} \mathrm{~N}$-triggered hemicryptophane capsule 118 in $\mathrm{CD}_{3} \mathrm{OD} / \mathrm{CD}_{3} \mathrm{CN}$. ${ }^{94}$ The $n-\mathrm{Bu}_{3} \mathrm{NH}^{+}$cannot go inside the cavity because of its too large size. However, addition of ammoniums $\mathrm{Et}_{4} \mathrm{~N}^{+}$and $\mathrm{Me}_{4} \mathrm{~N}^{+}$or phosphonium $\mathrm{Me}_{4} \mathrm{P}^{+}$to a solution of the empty capsule $\mathbf{1 1 6}$ gave rise to new signals in the range of $0.3-0.7 \mathrm{ppm}$ on the ${ }^{1} \mathrm{H}$ NMR spectra, indicating the formation of encapsulated species. The authors then used competition experiments to investigate the relative binding affinities of the hemicryptophane capsule toward these three guests. For instance, when a 1:1 mixture of $\mathrm{Et}_{4} \mathrm{~N}^{+} \mathrm{I}^{-}$and $\mathrm{Me}_{4} \mathrm{~N}^{+} \mathrm{I}^{-}$was added to 116 , two kinds of guest-filled capsules $\mathrm{Et}_{4} \mathrm{~N}^{+} @ 116$ and $\mathrm{Me}_{4} \mathrm{~N}^{+} @ 116$ appeared in a 2.3:1 ratio. In this way, the relative binding abilities were determined in the following order: $\mathrm{Et}_{4} \mathrm{~N}^{+}>\mathrm{Me}_{4} \mathrm{~N}^{+}>\mathrm{Me}_{4} \mathrm{P}^{+}$. Interestingly, the authors also characterized the encapsulation of the $\mathrm{Cs}^{+}$cation by host 116. However, for the two above cases no binding constants are reported.

tren-Hemicryptophanes were also used for the recognition of primary ammonium. For example, host 15a was demonstrated to be an efficient primary alkylammonium receptor in $\mathrm{CDCl}_{3}$ / MeOD solution. ${ }^{152}$ Upon addition of the host 15 a to the solution of picrate salts of ammoniums, such as $\mathrm{BnNH}_{3}{ }^{+}$, 
$\mathrm{MeNH}_{3}{ }^{+}, t$ - $\mathrm{BuNH}_{3}{ }^{+}$, and $n-\mathrm{PrNH}_{3}{ }^{+}$, the guest's protons displayed significant high-field shifts due to the shielding effect of the aromatic cavity, in agreement with the formation of inclusion complexes. The binding constants were thus determined based on the 1:1 stoichiometry indicated by Job's plot and showed relatively high values $\left(10^{4}-10^{5} \mathrm{M}^{-1}\right)$ with an order $\mathrm{BnNH}_{3}{ }^{+}>\mathrm{MeNH}_{3}{ }^{+}>t-\mathrm{BuNH}_{3}{ }^{+}>n-\mathrm{PrNH}_{3}{ }^{+}$. Combination of a stabilizing hydrogen-bonding network between the encapsulated ammonium and the tren moiety and a good fit allowing both favorable $\mathrm{CH} \cdots \pi$ interactions within the aromatic cavity and minimization of steric repulsions can account for these results. In addition, the ability of hemicryptophane 15 a to complex ammonium neurotransmitters was also investigated. A binding constant of $2.5 \times 10^{4} \mathrm{M}^{-1}$ was measured with dopamine as guest molecule, highlighting the potential use of hemicryptophane hosts for the recognition of neurotransmitters. A binding mode between 15a and dopamine has been proposed by DFT calculations (Figure 14a).

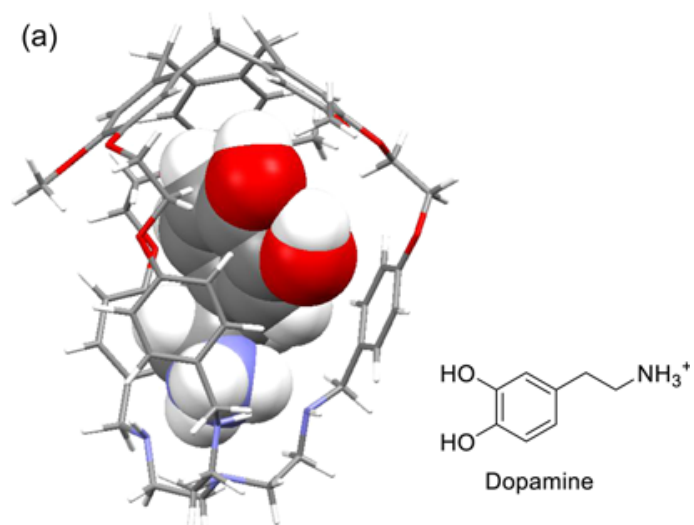

Dopamine@15a
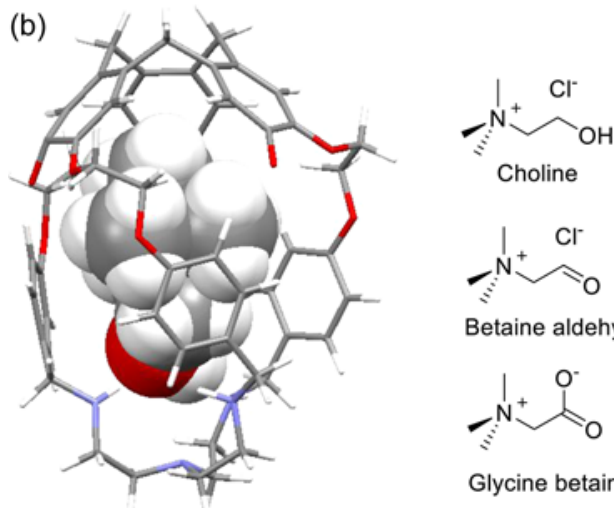

Betaine aldehyde

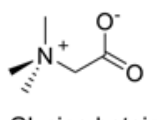

Choline@123

Figure 14. (a) DFT-optimized structure of dopamine@15a, and structure of dopamine. (b) DFT-optimized structure of choline@123, and structures of choline, betaine aldehyde, and glycine betaine.

Efficient complexation of choline neurotransmitter in water using the water-soluble hemicryptophane $\mathbf{1 2 3}$ was reported, constituting a real advance in host-guest recognition, rarely described in aqueous medium. ${ }^{105}{ }^{1} \mathrm{H}$ NMR titration was first used for characterizing the host-guest association, where significant high-field shifts of the guest's protons were observed attributed to the shielding effect of the aromatic environment.
At lower temperature $(270 \mathrm{~K})$, under slow exchange conditions on the NMR time scale, a new signal appeared in the high-field region corresponding to the included choline ammonium. In addition, DFT calculations are consistent with the ${ }^{1} \mathrm{H}$ NMR data and confirm the location of the ammonium part of the guest in the vicinity of the CTV unit (Figure 14b). A binding constant of $2300 \mathrm{M}^{-1}$ was determined by isothermal titration calorimetry (ITC). Surprisingly, no association was observed by ITC for betaine aldehyde and glycine betaine guest molecules, highlighting the high specificity and selectivity of hemicryptophane 123 toward choline.

Complexation of choline emphasized the use of hemicryptophanes for the recognition of compounds of biological interest in water. More importantly, the recognition of neurotransmitters is very meaningful since many of them are involved in important biological processes. ${ }^{162}$ However, most of them are chiral amine derivatives that lead to the formation of diastereomeric host-guest complexes in the recognition experiments run with racemic host compounds. To this end, enantiopure hemicryptophanes have been synthesized and used successfully in the recognition of chiral ammonium guests. Enantiopure tren-hemicryptophanes, $M-(S, S, S)-30, P-(S, S, S)$ 30, $M-(R, R, R)-30$, and $P-(R, R, R)-30$, were tested in the stereoselective recognition of norephedrine and ephedrine in $\mathrm{CDCl}_{3} / \mathrm{CD}_{3} \mathrm{OD}$ solution. ${ }^{151}{ }^{1} \mathrm{H}$ NMR titration experiments were performed showing the formation of $1: 1$ and $1: 2$ hostguest complexes. The authors explained the 1:2 stoichiometry with the fact that both the tren and the CTV moieties are able to bind ammonium guests according to hydrogen-bonding and cation $-\pi$ interactions, as previously observed in the recognition of dopamine and choline with $15 \mathrm{a}$ and 123 , respectively. Examination of the binding constants reported in Table 1 shows that these hosts are able to complex ephedrine and norephedrine with high binding constants, and in addition, most of the host diastereomers discriminate norephedrine from ephedrine, exhibiting larger affinity toward the former. Furthermore, remarkable enantioselectivities in favor of the $P$ $(S, S, S)$ enantiomer over $M-(R, R, R)$ are displayed for both guests.

The large scale and easy synthesis of enantiopure hemicryptophanes $M-15 \mathrm{a}$ and $P-15 \mathrm{a}$ allowed the authors to investigate their stereoselective recognition properties toward norephedrine in $\mathrm{CDCl}_{3} / \mathrm{CD}_{3} \mathrm{OD}$ solution. ${ }^{53}{ }^{1} \mathrm{H}$ NMR titration experiments and binding stoichiometry similar to those for enantiopure 30 were observed for hosts $M-15 a$ and $P$-15a. Interestingly, compared with $\mathbf{3 0}$, the two simplest hosts exhibited higher enantioselectivity toward norephedrine (91:9), indicating the important role of the inherently chiral CTV and highlighting the high potentiality of such simple and easy accessible enantiopure hemicryptophane hosts.

Makita et al. reported the formation of the 1:1 complex between acetylcholine and hemicryptophane 24 in a 20/1 $\mathrm{CDCl}_{3} / \mathrm{CD}_{3} \mathrm{OD}$ solution. ${ }^{55} \mathrm{~A}$ binding constant of $1.3 \times 10^{4}$ $\mathrm{M}^{-1}$ was obtained by fitting the curve obtained from the NMR titration experiment. Interestingly, the ${ }^{1} \mathrm{H}$ NMR signals of the $\mathrm{NCH}_{2} \mathrm{CH}_{2}$ and $\mathrm{N}\left(\mathrm{CH}_{3}\right)_{3}$ protons of acetylcholine are broadened in the presence of host 24, whereas those of the acetyl $\mathrm{CH}_{3}$ remain sharp, suggesting that the former are encapsulated inside the cavity of the hemicryptophane and the latter are outside the cavity, as observed in the solid state (Figure 11). Recognition of ammonium-chloride salts was also achieved using hemicryptophane 24 . In the ${ }^{1} \mathrm{H}$ NMR spectra, the protons of the guests display downfield shifts upon 


\begin{tabular}{|c|c|c|c|c|}
\hline & \multicolumn{2}{|c|}{ norephedrine } & \multicolumn{2}{|c|}{ ephedrine } \\
\hline & $\beta_{1}\left(\mathrm{M}^{-1}\right)^{b} 1: 1$ host-guest & $\beta_{2}\left(\mathrm{M}^{-1}\right)^{b} 1: 2$ host-guest & $\beta_{1}\left(\mathrm{M}^{-1}\right)^{b} 1: 1$ host-guest & $\beta_{2}\left(\mathrm{M}^{-1}\right)^{b} 1: 2$ host-guest \\
\hline$(M-(R, R, R))-\mathbf{3 0}$ & $c$ & $1.39 \times 10^{7}$ & $c$ & $4.60 \times 10^{6}$ \\
\hline$(P-(S, S, S))-\mathbf{3 0}$ & $3.99 \times 10^{3}$ & $2.18 \times 10^{7}$ & $8.06 \times 10^{3}$ & $2.52 \times 10^{7}$ \\
\hline$(P-(R, R, R))-30$ & $2.50 \times 10^{5}$ & $1.95 \times 10^{9}$ & $1.65 \times 10^{4}$ & $7.92 \times 10^{7}$ \\
\hline
\end{tabular}

${ }^{a} \beta_{1}$ and $\beta_{2}$ values were determined by fitting the ${ }^{1} \mathrm{H}$ NMR titration curves of the methyl protons of the guests using hypNMR2008 software ${ }^{163}$ $\left(\mathrm{CDCl}_{3} / \mathrm{CD}_{3} \mathrm{OD} 95 / 5,500 \mathrm{MHz}, 298 \mathrm{~K}\right) .{ }^{b}$ Estimated error: $10 \% .{ }^{c}$ No $1: 1$ complex observed after fitting the titration curves.

progressive addition of the ammonium salts to the host solutions. The binding constants were measured for $\mathrm{Me}_{4} \mathrm{NCl}$ $\left(6.5 \times 10^{4} \mathrm{M}^{-1}\right), \mathrm{Et}_{2} \mathrm{Me}_{2} \mathrm{NCl}\left(9.8 \times 10^{3} \mathrm{M}^{-1}\right)$, and $\mathrm{Et}_{3} \mathrm{MeNCl}$ $\left(5.5 \times 10^{2} \mathrm{M}^{-1}\right)$ and showed that the decrease of the affinity of $\mathbf{2 4}$ for the guests is related to the size of the cation, the highest the size having the lowest the affinity. ${ }^{55}$

3.2.2. Recognition of Ion Pairs. In 2008, Jabin et al. reported a heteroditopic hemicryptophane cage that displays versatile host-guest properties toward organic associated ionpair salts (Figure 15). ${ }^{70}$ Upon addition of an excess of

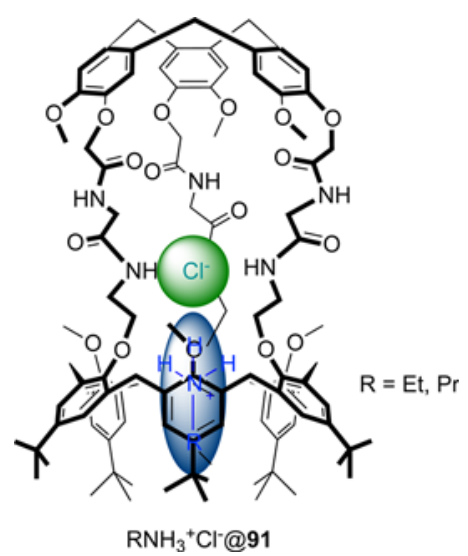

Figure 15. Proposed binding mode between hemicryptophane 91 and $\mathrm{RNH}_{3}{ }^{+} \mathrm{Cl}^{-}$.

$\mathrm{RNH}_{3}^{+} \mathrm{Cl}^{-}\left(\mathrm{R}=\mathrm{Et}\right.$ or Pr) to a solution of 91 in $\mathrm{CDCl}_{3}$, highfield-shifted signals of the alkyl chain of the ammonium ions were observed, indicating that the ammonium ions are located inside the cavity of the calixarene. In addition, the amide protons close to the calixarene subunit also show a significant downfield shift, suggesting a strong hydrogen-bonding interaction with the $\mathrm{Cl}^{-}$anion. Hence, hemicryptophane 91 behaves as a heteroditopic receptor because of the simultaneous endo complexation of cation and anion. Concerning the ammonium cation, in addition to the electrostatic interaction with its counterion, it is also probably stabilized through a combination of $\mathrm{CH} \cdots \pi$ interactions and hydrogen bonding to the ethereal oxygen atoms of the amide arms. Furthermore, by using $n \mathrm{Bu}_{4} \mathrm{~N}^{+} \mathrm{Cl}^{-}$and $\mathrm{RNH}_{3}{ }^{+} \mathrm{Pic}^{-}$salts, the authors demonstrated that the complexation of the $\mathrm{Cl}^{-}$anion might only occur when an ammonium cation is present in the calixarene cavity, and corollary efficient binding of ammonium needs the presence of the $\mathrm{Cl}^{-}$anion. This remarkable positive cooperativity benefits from a combination of polarization and induced-fit effects.

Hemicryptophane 14, which bears a tripodal anion binding site (triamide moiety) and a cation recognition site (CTV unit), is an efficient ion-pair receptor in $\mathrm{CDCl}_{3} .{ }^{153}$ First, the anion binding properties of 14 were evaluated by ${ }^{1} \mathrm{H}$ NMR titration and showed binding constants in the order of $K_{\mathrm{a}}\left(\mathrm{F}^{-}\right)>K_{\mathrm{a}}\left(\mathrm{Cl}^{-}\right)$ $>K_{\mathrm{a}}\left(\mathrm{Br}^{-}\right)>K_{\mathrm{a}}\left(\mathrm{AcO}^{-}\right)$, which is related with the hydrogenbond-accepting ability and symmetry factors. Then the complexation of ammonium cations was investigated and showed that the affinity of hemicryptophane $\mathbf{1 4}$ decreases from $\mathrm{Me}_{4} \mathrm{~N}^{+}\left(K=380 \mathrm{M}^{-1}\right)$ to $\mathrm{Et}_{4} \mathrm{~N}^{+}\left(K=97 \mathrm{M}^{-1}\right)$ in accord with an increase of the steric hindrance. Finally, the ability of $\mathbf{1 4}$ to accommodate associated organic ion pairs was achieved by measuring the apparent anion binding constants $K_{\mathrm{a}}{ }^{\prime}$ of 14 in the presence of 1 equiv of $\mathrm{Me}_{4} \mathrm{~N}^{+}$. As shown in Figure 16a, host 14 binds anions more strongly in the presence of 1 equiv of $\mathrm{Me}_{4} \mathrm{~N}^{+}$, emphasizing the heteroditopic character of receptor 14 . In particular, a cooperativity factor, defined by the ratio $K_{\mathrm{a}}^{\prime} / K_{\mathrm{a}}$ $=15$, was observed for the complexation of $\mathrm{Cl}^{-}$, which also exhibits the largest binding constant. DFT calculations demonstrated that efficient hydrogen bonding between $\mathrm{Cl}^{-}$ and triamide and $\mathrm{CH}-\pi$ interactions between $\mathrm{Me}_{4} \mathrm{~N}^{+}$and CTV together with maximized electrostatic interactions between the bound $\mathrm{Me}_{4} \mathrm{~N}^{+}$and $\mathrm{Cl}^{-}$account for this high positive cooperativity (Figure 16b).

Hemicryptophanes 16 and 17, bearing fluorinated aromatic rings close to the anion binding site, were also investigated for the ion-pair complexation. ${ }^{49}$ In this work the authors expected that the introduction of fluorine atoms increases the anion $-\pi$ attractive interactions, with valuable consequences on the binding cooperativity between anion $-\pi$ and cation $-\pi$ interactions. The recognition properties were found to largely depend on the position of the fluorine atoms in the aromatic linkages, and anion binding constants were significantly increased and decreased with 16 and 17 (Scheme 1), respectively, compared with host $\mathbf{1 4}$. For ion-pair recognition, the cooperativity switched from positive to negative: host 14 displayed high positive cooperativity, whereas it was moderate for host 16, and a strong negative cooperative effect was observed with host 17 (Figure 17). Thus, depending on the nature of the guest and the location of the fluorine atoms, the cooperativity can be modulated. These unexpected binding behaviors were rationalized by DFT calculations and complete active space self-consistent field (CASSCF) calculations. ${ }^{164}$ These wave function calculations highlight how short- and long-range interactions interfere in this recognition process and suggest that a disruption of the anion $-\pi$ interactions occurs in 
(a)

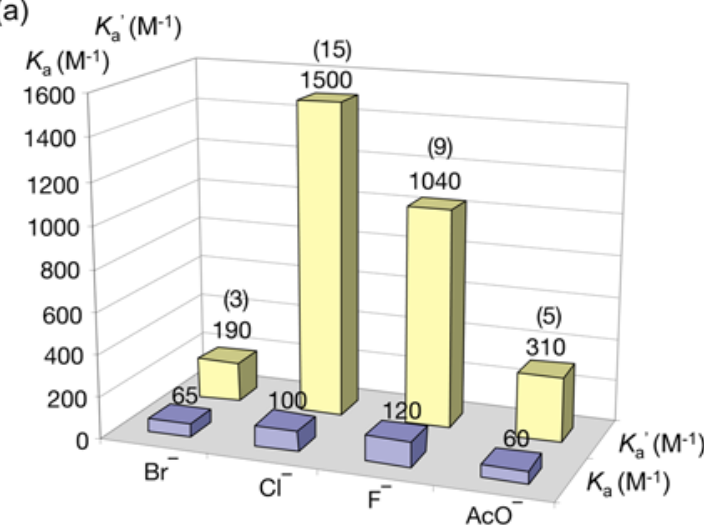

(b)

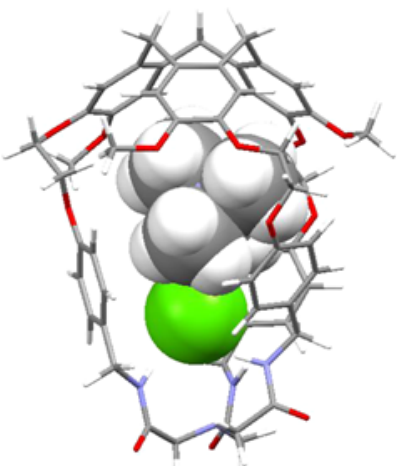

$\mathrm{Me}_{4} \mathrm{~N}^{+} \mathrm{Cl} @ 14$

Figure 16. (a) Anion binding constants of hemicryptophane 14 in the absence or presence of 1 equiv of $\mathrm{Me}_{4} \mathrm{~N}^{+}$. Cooperativity factors are given in parentheses. (b) DFT-optimized structure of $\mathrm{Me}_{4} \mathrm{~N}^{+} \mathrm{Cl}^{-} @ 14$. Reproduced with permission from ref 153. Copyright 2011 Wiley$\mathrm{VCH}$.

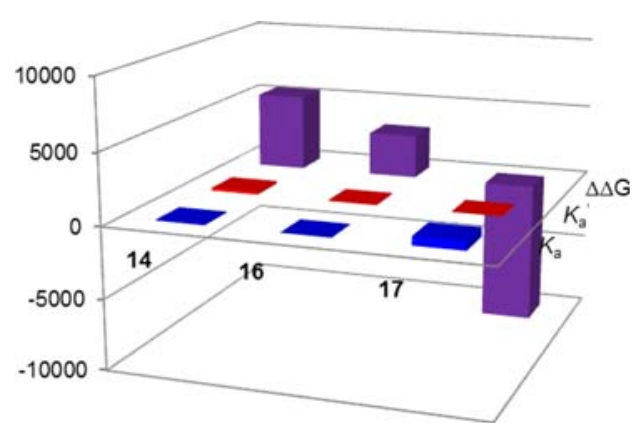

Figure 17. Binding constants for (a) $\mathrm{Cl}^{-}$and (b) $\mathrm{Br}^{-}$with hosts 14, 16, and 17 without $\mathrm{Me}_{4} \mathrm{~N}^{+}$inside the cavity $\left(K_{a}\right.$ in blue) and with 1 equiv of $\mathrm{Me}_{4} \mathrm{~N}^{+}\left(K_{\mathrm{a}}^{\prime}\right.$, in red). Cooperativity $\Delta \Delta G^{\circ}$ is also given (purple). Adapted with permission from ref 49. Copyright $2015 \mathrm{John}$ Wiley \& Sons.

the presence of a cobound cation. Such molecules can be viewed as prototypes for examining complex processes controlled by competitive weak interactions.

3.2.3. Recognition of Zwitterions. Zwitterions, such as those shown in Figure 18, play an important role in the transfer of neuronal information, which is the subject of numerous studies involving chemical, biochemical, and clinical approaches. ${ }^{165,166}$ As these guests are strongly solvated species in aqueous media, their biomimetic encapsulation through endohedral weak interactions in a hydrophobic neutral molecular pocket is still a challenge. The principle of

$$
\begin{aligned}
& \mathrm{H}_{3} \mathrm{~N}^{+} \mathrm{SO}_{3}^{-} \mathrm{H}_{\text {taurine }}^{\mathrm{HO}_{3}^{+}} \underbrace{\mathrm{H}_{3} \mathrm{~N}^{+}}_{\text {glycine }} \mathrm{COO}^{-} \mathrm{Me}_{3} \mathrm{~N}_{\text {betaine }}^{+} \mathrm{COO}
\end{aligned}
$$

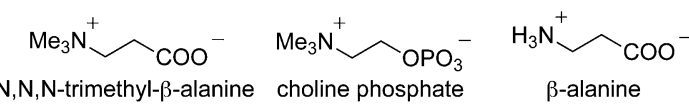

$$
\begin{aligned}
& \mathrm{H}_{\text {homotaurine }}^{\mathrm{N}^{+}} \mathrm{SO}_{3}^{-} \mathrm{H}_{3} \mathrm{~N}_{\text {GABA }}^{+} \mathrm{COO}^{-} \mathrm{Me}_{3} \mathrm{~N}_{\text {carnitine }}^{\mathrm{OH}_{1}^{\mathrm{H}}} \mathrm{COO}
\end{aligned}
$$

Figure 18. Structures of zwitterionic guests.

complexation of zwitterions using heteroditopic hemicryptophane hosts is almost similar to that of ion pairs, i.e., stabilizing the cation part of zwitterions with the CTV unit via $\mathrm{CH} \cdots \pi$ / cation $-\pi$ interactions and binding the anion part with the south moiety using other supramolecular interactions.

Hemicryptophane 14, used for the recognition of ion pairs, is also an efficient heteroditopic host for the recognition of zwitterions since, as mentioned above, the CTV unit can stabilize the ammonium part and the triamide subunit can form hydrogen bonds with the anionic part. ${ }^{154}$ The binding constants determined by NMR experiments in $\mathrm{CD}_{3} \mathrm{CN} / \mathrm{D}_{2} \mathrm{O}$ are shown in Table 2 . These results indicate that the

Table 2. Association Constants $K_{\mathrm{a}}$ of Hemicryptophane 14 with Neurotransmitters and Related Guests $\left(\mathrm{CD}_{3} \mathrm{CN} / \mathrm{D}_{2} \mathrm{O}\right.$ 9:1, $T=298 \mathrm{~K}$ )

\begin{tabular}{llcc}
\multicolumn{1}{c}{ guest $^{a}$} & $K_{\mathrm{a}}\left(\mathrm{M}^{-1}\right)^{b}$ & $V_{\text {vdw }}\left(\AA^{3}\right)$ & $p c(\%)^{c}$ \\
$\mathrm{H}_{3} \mathrm{~N}^{+} \mathrm{CH}_{2} \mathrm{SO}_{3}{ }^{-}$ & & 82 & 48 \\
taurine & 14000 & 99 & 59 \\
homotaurine & 530 & 116 & 69 \\
glycine & & 69 & 41 \\
$\beta$-alanine & 8500 & 86 & 51 \\
GABA & 510 & 104 & 61 \\
betaine & 80 & 121 & 78 \\
$\left(\mathrm{CH}_{3}\right)_{3} \mathrm{~N}^{+} \mathrm{CH}_{2} \mathrm{CH}_{2} \mathrm{COO}^{-}$ & & 138 & 82 \\
choline phosphate & & 160 & 94
\end{tabular}

${ }^{a}$ Picrate salts. ${ }^{b} K_{\mathrm{a}}$ values were determined by DOSY NMR experiments except for $\left(\mathrm{CH}_{3}\right)_{3} \mathrm{~N}^{+} \mathrm{CH}_{2} \mathrm{CH}_{2} \mathrm{COO}^{-}$for which $K_{\mathrm{a}}$ was determined by ${ }^{1} \mathrm{H}$ NMR titration using WinEQNMR2 sofware ${ }^{169}$ (estimated error $10 \%)$. ${ }^{c}$ Packing coefficient based on a cavity volume of $169 \AA^{3}$.

encapsulation of guests by hemicryptophane 14 relies on three main criteria: (i) the zwitterionic character of the guest, (ii) its van der Waals volume since the packing coefficient has to be close to $55 \%$, in agreement with Rebek's criteria, ${ }^{167,168}$ and (iii) its shape. Indeed, two $\mathrm{CH}_{2}$ groups, between the anionic and the cationic parts, are necessary to have an optimal recognition process. Only the simultaneous existence of these three factors allows optimum complexation with this receptor. As a consequence, host $\mathbf{1 4}$ is highly selective toward taurine. DFT calculations emphasize that only weak intermolecular interactions stabilize the host-guest association (Figure 19a).

The authors noted that the structure of $\mathbf{1 4}$ revealed one major drawback as the three linkages are formed of electronrich aromatic rings, which can induce electrostatic repulsions with the guest anion located inside the cavity. To tackle this problem, aromatic rings were replaced by an electron-deficient system in hemicryptophane 54, which improved the stability of the host-guest complex by favorable anion $-\pi$ interactions. ${ }^{63}$ Adding three amide functions also increased the number of hydrogen-bond donors, and the binding abilities of host 54 


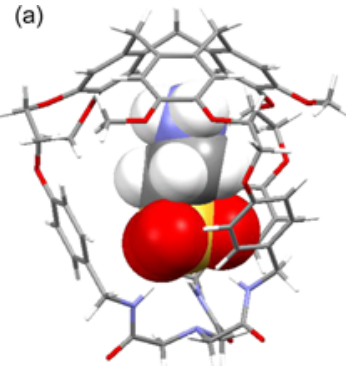

taurine@14

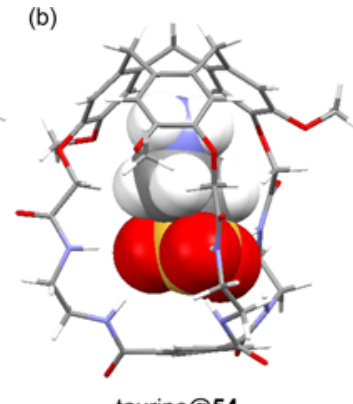

taurine@54
Figure 19. DFT-optimized structures of (a) taurine@14 and (b) taurine@54.

toward zwitterions have been significantly improved compared to host 14 (Table 3). For some guests, binding constants are up

Table 3. Association Constants $K_{\mathrm{a}}$ and ComplexationInduced Shifts (CIS) $\Delta \delta_{\max }$ Measured by ${ }^{1} \mathrm{H}$ NMR Titration of Guests with Host $54\left(\mathrm{CD}_{3} \mathrm{CN} / \mathrm{D}_{2} \mathrm{O} 8: 2 ; 500 \mathrm{MHz} ; 298\right.$ K)

\begin{tabular}{lcccc}
\multicolumn{1}{c}{ guest } & $K_{\mathrm{a}}\left(\mathrm{M}^{-1}\right)^{a}$ & $\begin{array}{c}V_{\mathrm{vdw}} \\
\left(\AA^{3}\right)^{b}\end{array}$ & $\begin{array}{c}\Delta \delta_{\max } \mathrm{NCH}_{2}^{+} \\
(\mathrm{ppm})\end{array}$ & $\begin{array}{c}\Delta \delta_{\max } \mathrm{CH}_{2} \mathrm{X}^{-} \\
(\mathrm{ppm})\end{array}$ \\
$\beta$-alanine & $1.5 \pm 0.1 \times 10^{4}$ & 86 & -0.41 & -0.25 \\
taurine & $5.0 \pm 0.4 \times 10^{5}$ & 99 & -0.39 & -0.20 \\
GABA & $2.3 \pm 0.1 \times 10^{5}$ & 103 & -0.41 & -0.20 \\
homotaurine & $1.1 \pm 0.2 \times 10^{5}$ & 116 & -0.31 & -0.07
\end{tabular}

${ }^{a} K_{\mathrm{a}}$ values were determined by fitting ${ }^{1} \mathrm{H}$ NMR titration curves using WinEQNMR2 software. ${ }^{169} b_{\text {van }}$ der Waals volumes were calculated according to the method of Abraham et al. ${ }^{170}$

to 3 orders of magnitude larger than those previously reported for host 14, whereas the solvent is even more competitive (20\% of water in $\mathrm{CD}_{3} \mathrm{CN}$ vs $10 \%$ initially). In particular, the binding constant for taurine reaches $5 \times 10^{5} \mathrm{M}^{-1}$, which was attributed to the good complementarity in size and shape between the host and the guest, as demonstrated by DFT calculations (Figure 19b). In order to investigate whether this recognition process was driven by both hydrogen-bonding and ion $-\pi$ interactions (cation $-\pi$ in the north part and anion $-\pi$ in the south part) or the contribution of the latter could be neglected in the formation of the complex, multireference wave functionbased calculations ${ }^{164}$ were carried out to have deeper insight on ion $-\pi$ interactions. The results showed that the two ion $-\pi$ interactions (cation $-\pi$ and anion $-\pi$ interaction) play a crucial role in the recognition process and could be combined in a synergistic manner to build up a recognition framework.

The $\mathrm{Zn}$ (II)-based fluorescent hemicryptophane host ( $\mathrm{Zn}$ (II) (a15i; Scheme 31) was synthesized for the sensing of choline phosphate. ${ }^{143}$ This heteroditopic $\mathrm{Zn}$-hemicryptophane complex binds the ammonium head of choline phosphate into the CTV core and locates the phosphate part close to the $\mathrm{Zn}$ (II) center. Futhermore, the naphthalene units in the linkers provide fluorescent properties. As shown in Figure 20a, significant fluorescence quenching at $350 \mathrm{~nm}$ of $\mathrm{Zn}$ (II)@15i was observed upon addition of choline phosphate in DMSO/ $\mathrm{H}_{2} \mathrm{O}$ solution $(98: 2 \mathrm{v} / \mathrm{v})$ with a binding constant of $4.2 \times 10^{5}$ $\mathrm{M}^{-1}$. The authors then investigated the heteroditopicity of the host by performing the titrations of butylphosphate and butyltrimethylammonium, which bears only one of the two recognized moieties. Results show that the guest bearing both the phosphate and the ammonium moieties give rise to the most significant fluorescence quenching and the largest binding constant, highlighting the heteroditopic character of the $\mathrm{Zn}$ (II) @15i host. Furthermore, choline and taurine, which are the most efficient guests in the above cases, only gave rise to smaller or even no fluorescent response, emphasizing the remarkable selectivity of the $\mathrm{Zn}$-hemicryptophane complex. ${ }^{1} \mathrm{H}$ NMR and ${ }^{31} \mathrm{P}$ NMR titrations, COSY experiments, and DFT calculations were also performed and demonstrated the encapsulation of choline phosphate inside the cavity (Figure 20b). In particular, ${ }^{1} \mathrm{H}$ NMR titration evidenced the four expected signals in the upfield region $(-0.5-1.79 \mathrm{ppm})$, which correspond to the four diastereotopic protons of the methylene group of the encaged choline phosphate, meaning that a chiralization-like behavior occurred for the achiral molecules. The present work also provided a new approach toward guest recognition using fluorescent hemicryptophane hosts. ${ }^{162}$

Benefiting from the heteroditopicity of the hemicryptophane hosts, stereoselective recognition of chiral zwitterions was also achieved. For instance, Hutton et al. synthesized the enantiopure hemicryptophanes $M L-67$ and PL-67 (section 2.1.4.2), which associate a CTV and a cyclic peptide (Scheme $15)$, for the enantioselective binding of $(R / S)$-carnitine in $\mathrm{CD}_{3} \mathrm{CN} .{ }^{65}$ During ${ }^{1} \mathrm{H}$ NMR titration experiments, significant downfield shifts were observed for the glycyl and tyrosyl $\mathrm{NH}$ protons of the cyclic peptide, indicating the encapsulation of the guest within the cavity to form 1:1 host-guest complex in accord with Job's plot and ESI-MS. Binding of carnitine with

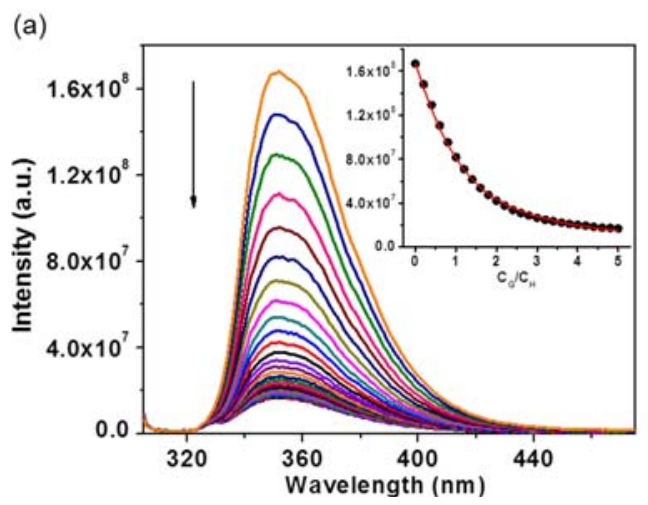

(b)

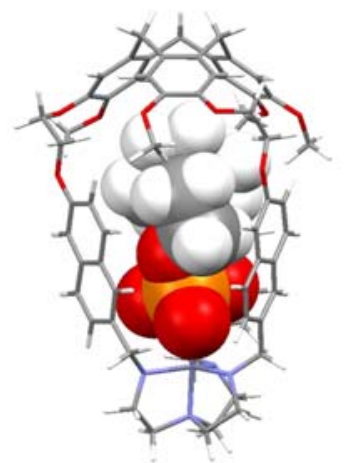

Choline phosphate@Zn(II)@15i

Figure 20. (a) Fluorescence titration curves of $5 \mu \mathrm{M} \mathrm{Zn}$ (II)@15i excited at $300 \mathrm{~nm}$ with choline phosphate in DMSO containing 2\% water. (Inset) Fluorescence intensity at $350 \mathrm{~nm}$ as a function of the equivalents of added choline phosphate. Reprinted in part with permission from ref 143. Copyright 2015 The Royal Society of Chemistry. (b) DFT-optimized structure of choline phosphate@Zn(II)@15i. 
$P L-67$ was found to be enantioselective with (R)-carnitine with a 1.5-fold greater $K_{\mathrm{a}}$ than with $(S)$-carnitine (Table 4 ). With

Table 4. Association Constants $K_{\mathrm{a}}$ of Host 67 with (R)- and (S)-Carnitine

$\begin{array}{clcc} & & \\ \text { host } & \text { guest } & K_{\mathrm{a}}\left(\mathrm{M}^{-1}\right)^{a} & \Delta \delta_{\max }(\mathrm{ppm})^{b} \\ P L-67 & (R) \text {-carnitine } & 4.1 \pm 0.3 \times 10^{3} & -0.8945 \\ P L-67 & (S) \text {-carnitine } & 2.7 \pm 0.2 \times 10^{3} & -0.5937 \\ M L-67 & (R) \text {-carnitine } & 9.1 \pm 0.1 \times 10^{2} & -0.7194 \\ M L-67 & (S) \text {-carnitine } & 6.9 \pm 0.5 \times 10^{2} & -0.4791\end{array}$

${ }^{a} K_{\mathrm{a}}$ values were determined by fitting ${ }^{1} \mathrm{H}$ NMR titration curves using WinEQNMR2 software. ${ }^{169} b \delta$ from the Gly-NH proton of host 67.

$M L-67$, a 1.3-fold larger $K_{\mathrm{a}}$ was observed for $(R)$-carnitine compared to the $(S)$-enantiomer. In addition, considering that the association constant for the D-tyrosine-glycine hemicryptophane complex of $(R)$-carnitine (PDR complex) is identical to the known enantiomeric L-tyrosine-glycine hemicryptophane complex of (S)-carnitine (MLS-complex), the authors determined a 5.9-fold difference in association constants of $(R)$-carnitine with the PL-67 and PD-67 hosts. In contrast, switching from $P L-67$ to $M L-67$ results in a 4.5 -fold drop in binding affinity for $(R)$-carnitine. These results suggest that the PL-67 stereoisomer is the best matched to bind $(R)$ carnitine with a modest chiral discrimination. DFT calculations indicate that carnitine was bound to the host in a ditopic mode exploiting hydrogen-bond interactions between the cyclic peptide and the carnitine carboxylate group together with the cation $-\pi / \mathrm{CH} \cdots \pi$ interactions between the CTV and the carnitine ammonium moieties (Figure 21).

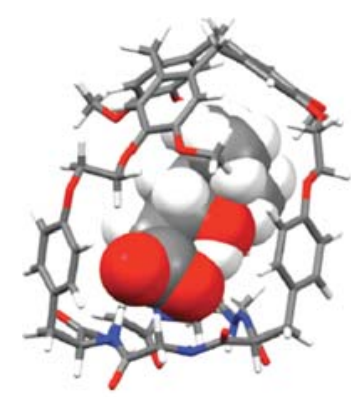

(R)-carnitine@PL-67

Figure 21. DFT-optimized structure of (R)-carnitine@PL-67.

3.2.4. Recognition of Carbohydrates. The recognition of carbohydrates, such as those in Figure 22, is involved in numerous biological processes such as protein folding, cell-cell recognition, infection by pathogens, or tumor metastasis. ${ }^{171}$ Thus, there is great interest in mimicking biological receptors of carbohydrates. ${ }^{172-177}$ However, these guests are challenging for supramolecular chemists as they possess complex threedimensional structures, which often present subtle changes, so that a large selectivity is difficult to achieve. In this regard, hemicryptophane hosts appear as potential carbohydrate recognition receptors, since they can provide appropriate matches for both polar functionalities (through hydrogen bonding in the south part with the $\mathrm{OH}$ group of carbohydrates)
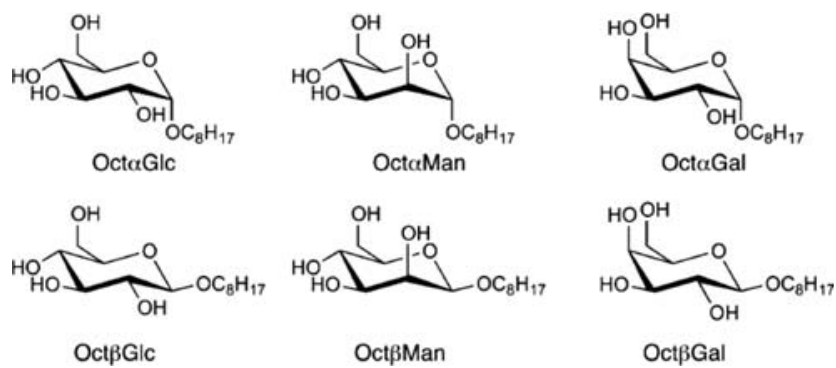

OctßGal

Figure 22. Structures of carbohydrate guests.

and apolar surfaces (through $\mathrm{C}-\mathrm{H} \cdots \pi$ interactions with the aromatic rings of the host molecule)

In 2011, the first octyl- $\beta$-D-glucopyranoside (Oct $\beta$ Glc) and octyl- $\alpha$-D-glucopyranoside (Oct $\alpha$ Glc) recognition using enantiopure hemicryptophanes $M-14$ and P-14 (Scheme 1) was reported. ${ }^{155}$ The binding constants, measured in $\mathrm{CDCl}_{3}$ solution, reveal two main features (Table 5). First, a good diastereodiscrimination is observed for host $M-\mathbf{1 4}$, with a factor of ca. 3 between the binding constants with Oct $\alpha$ Glc and Oct $\beta$ Glc, and exclusive diastereoselective recognition of Oct $\alpha$ Glc is achieved with $P$-14. Second, a 7:1 enantioselectivity for Oct $\alpha$ Glc and exclusive enantioselective recognition for Oct $\beta$ Glc are, respectively, observed, indicating the perfect enantiodiscrimination induced by the inherent chirality of the $M$ enantiomer. Next, the authors also tested the recognition of the same sugar derivatives with the four stereoisomers of hemicryptophane 41 (Scheme 7) to investigate more accurately the control of the inherent chirality of the CTV on the enantioselective recognition. In this case, modest to high diastereoselectivity in favor of Oct $\beta$ Glc over Oct $\alpha$ Glc for the four isomers of $\mathbf{4 1}$ is reported. In addition, in most cases the exclusive binding of the $M$ enantiomers is observed, in accord with the above results, demonstrating the crucial role of the inherent chirality of the CTV by comparison with the central chirality of the trialkanol amine moiety.

Recently, the enantiopure hemicryptophane hosts 46 (Scheme 8) have been designed for the recognition of carbohydrates in $\mathrm{CDCl}_{3}$ (Table 5). ${ }^{61}$ Three mains features can be drawn: (i) concerning the recognition of glucose derivatives, excellent diastereoselectivity is obtained, since only the stereoisomers $M-(S, S, S)-(R, R, R)-46$ and $P-(R, R, R)-(S, S, S)-$ 46 exhibit binding properties. Good enantioselectivity was also achieved in the recognition of the anomer Oct $\beta$ Glc $\left(K_{\mathrm{a}(P-(R, R, R)-(S, S, S)-46)} / K_{\mathrm{a}(M-(S, S, S)-(R, R, R)-46)}=6.0\right)$, associated with an improvement of the binding constant compared to those of the previous hosts 41 (531 vs $184 \mathrm{M}^{-1}$ ). (ii) In contrast with hosts $\mathbf{4 1}$, the new hosts 46 are also able to complex mannose derivatives, displaying improved binding affinities. Both exclusive enantio- and diastereodiscrimination have been observed.

The four stereoisomers of hemicryptophane 29, which bear four stereogenic centers (three asymmetric carbons and the CTV unit, Scheme 4), were also tested for the stereoselective recognition of glucopyranoside in $\mathrm{CDCl}_{3} .{ }^{56}$ As shown in Table 5, the binding abilities of $\mathbf{2 9}$ have been improved compared to the previous hosts, with $K_{\mathrm{a}}$ values up to 1 order of magnitude larger. For example, host $M-(S, S, S)-29$ shows the largest binding constants for Oct $\alpha$ Glc $\left(595 \mathrm{M}^{-1}\right)$ and Oct $\beta$ Glc $(1660$ $\left.\mathrm{M}^{-1}\right)$. The trend in diastereoselectivity is opposite to that of host 14, since for all isomers of 29 Oct $\beta$ Glc shows larger binding constants than its $\alpha$-anomer with a diastereoselective 
Table 5. Binding Constants $K_{\mathrm{a}}\left(\mathrm{M}^{-1}\right)$ for the 1:1 Complexes Formed between Different Enantiopure Hemicryptophane Hosts and Carbohydrate Guests ${ }^{a, b}$

\begin{tabular}{|c|c|c|c|c|c|c|c|}
\hline host & Oct $\alpha$ Glc & Oct $\beta$ Glc & Oct $\alpha$ Man & Oct $\beta$ Man & Oct $\alpha \mathrm{Gal}$ & Oct $\beta \mathrm{Gal}$ & ref \\
\hline$M-14$ & 216 & 64 & & & & & 155 \\
\hline$P-14$ & 31 & $c$ & & & & & 155 \\
\hline$M-(R, R, R)-41$ & 123 & 226 & $c$ & $c$ & & & 155 \\
\hline$P-(R, R, R)-41$ & $c$ & 115 & $c$ & $c$ & & & 155 \\
\hline$M-(S, S, S)-41$ & 155 & 184 & $c$ & $c$ & & & 155 \\
\hline$P-(S, S, S)-41$ & $c$ & $c$ & $c$ & $c$ & & & 155 \\
\hline$M-(S, S, S)-(R, R, R)-46$ & 105 & 83 & 58 & $c$ & & & 61 \\
\hline$P-(R, R, R)-(S, S, S)-46$ & 89 & 537 & 135 & 48 & & & 61 \\
\hline$M-(R, R, R)-(S, S, S)-46$ & $c$ & $c$ & 50 & $c$ & & & 61 \\
\hline$P-(S, S, S)-(R, R, R)-46$ & $c$ & $c$ & 100 & $c$ & & & 61 \\
\hline$M-(R, R, R)-46$ & $c$ & $c$ & $c$ & $c$ & & & 61 \\
\hline$P-(S, S, S)-(S, S, S)-46$ & $c$ & $c$ & $c$ & $c$ & & & 61 \\
\hline$M-(S, S, S)-(S, S, S)-46$ & $c$ & $c$ & $c$ & $c$ & & & 61 \\
\hline$P-(R, R, R)-(R, R, R)-46$ & $c$ & $c$ & $c$ & $c$ & & & 61 \\
\hline$P-(S, S, S)-29$ & $c$ & 183 & & & & & 56 \\
\hline$P-(R, R, R)-29$ & 34 & 384 & & & & & 56 \\
\hline$M-(R, R, R)-29$ & 56 & 192 & & & & & 56 \\
\hline$M-(S, S, S)-\mathbf{3 0}$ & 213 & 378 & 1410 & 804 & 29 & 13 & 57 \\
\hline$P-(S, S, S)-\mathbf{3 0}$ & 141 & 400 & 1648 & 387 & 112 & 68 & 57 \\
\hline$P-(R, R, R)-30$ & 95 & 722 & 1544 & 967 & 142 & 59 & 57 \\
\hline$M-(R, R, R)-30$ & 83 & 270 & 2511 & 641 & 22 & $c$ & 57 \\
\hline$M-(S, S, S)-56$ & 41 & $c$ & $c$ & 61 & & & 64 \\
\hline$P-(S, S, S)-56$ & 174 & $c$ & $c$ & 118 & & & 64 \\
\hline$P-(R, R, R)-56$ & 29 & 72 & 182 & 458 & & & 64 \\
\hline$M-(R, R, R)-56$ & 223 & 287 & 55 & 40 & & & 64 \\
\hline$P-(R, R, R)-57$ & 177 & 359 & 616 & 204 & & & 64 \\
\hline$M-(R, R, R)-57$ & 122 & 457 & 1174 & 375 & & & 64 \\
\hline$M-(S, S, S)-57$ & 161 & 403 & 393 & 288 & & & 64 \\
\hline
\end{tabular}

${ }^{a} K_{\mathrm{a}}$ was determined by fitting ${ }^{1} \mathrm{H}$ NMR titration curves $\left(\mathrm{CDCl}_{3}, 500 \mathrm{MHz}, 298 \mathrm{~K}\right)$ with HypNMR2008; estimated error $10 \% .{ }^{b}$ Blank cells indicate no measurement for this host and guest. ${ }^{c}$ No complexation detected.

ratio of 2.8 for $M-(S, S, S)-29$ and exclusive binding for $P$ - $(S, S, S)$ 29. According to the authors, the binding sites are similar in hosts 14 and 29; conformational changes induced by the addition of the methyl groups account for both the improvement of the binding affinity and the change in selectivity. A marked, or even exclusive, enantioselectivity in favor of the $M$ configurated hosts is also observed, such as the binding of Oct $\alpha$ Glc with $P-(S, S, S)-29$ and $M-(R, R, R)-29$, which is consistent with the results obtained with 14 .

Remarkable diastereoselective recognition of $\alpha$-mannoside in $\mathrm{CDCl}_{3}$ was achieved using the four stereoisomers of hemicryptophane 30 (Scheme 4). ${ }^{57}$ An overall trend of the selectivity, defined from the binding constants toward the different guests with the four hosts, was observed with the following order (Table 5): Oct $\alpha$ Man $>$ Oct $\beta$ Man $>$ Oct $\beta$ Glc $>$ Oct $\alpha$ Glc $>\operatorname{Oct} \alpha \mathrm{Gal}>\operatorname{Oct} \beta \mathrm{Gal}$, which is in good agreement with the different abilities of the guest to be involved in intermolecular hydrogen bonds. ${ }^{178,179}$ The more the saccharide can make hydrogen bonds with other molecules, the higher the binding constant. This also highlights that hydrogen-bonding interactions are crucial for the recognition process. For instance, receptor $M-(R, R, R)-30$ can complex almost exclusively Oct $\alpha$ Man facing to Oct $\beta$ Gal with the higher binding constant $K_{\mathrm{a}}=2511 \mathrm{M}^{-1}$. However, the authors report excellent diastereoselectivity for the four stereoisomers of $\mathbf{3 0}$ with the carbohydrate guests but a moderate enantioselectivity.
The binding properties of the stereoisomers of hemicryptophane 56 were compared to those of the model openshell compounds 57 (Scheme 13). ${ }^{64}$ The cage derivatives 56 exhibit lower binding constants than 57 , probably because of the lack of $\mathrm{OH}$ groups able to induce hydrogen bonding with the alcohol functions of the carbohydrate guests. The affinity toward carbohydrates follows the same order with hemicryptophane 56 and model host 57: Oct $\alpha$ Man $>$ Oct $\beta$ Glc > Oct $\beta$ Man $\approx$ Oct $\alpha$ Glc. Nevertheless, a better stereoselectivity was achieved with the cage compounds, probably due to a better preorganization. For instance, excellent enantioselectivities were observed with $P-(R, R, R)-56$ and $M-(R, R, R)-56$ with binding constants of 182 and $287 \mathrm{M}^{-1}$ toward Oct $\alpha$ Man and Oct $\beta$ Glc, respectively, whereas no complexation occurred with the enantiomer hosts (Table 5). Furthermore, the role played by the inherent chirality of the CTV unit of the hemicryptophanes in the recognition process is highlighted by the fact that the affinity for Oct $\beta$ Man guest is 10 times higher with the host $P-(R, R, R)-2$ than with its diastereomer $M-(R, R, R)-2$. A good 1:16 diastereoselectivity ratio was also reached in the recognition of Oct $\beta$ Glc over Oct $\alpha$ Man using hemicryptophane $P-(R, R, R)-1$ as receptor.

3.2.5. Recognition of Fullerenes. Hemicryptophanes 85a and $\mathbf{8 5 b}$ (Scheme 18) are good receptors for $\mathrm{C}_{60}$ and $\mathrm{C}_{70}$ fullerenes. ${ }^{69}$ The ${ }^{1} \mathrm{H}$ NMR NOESY experiments of $\mathbf{8 5 b}$ in $\mathrm{CDCl}_{3} / \mathrm{CS}_{2}$ revealed the existence of NOE cross-peaks 


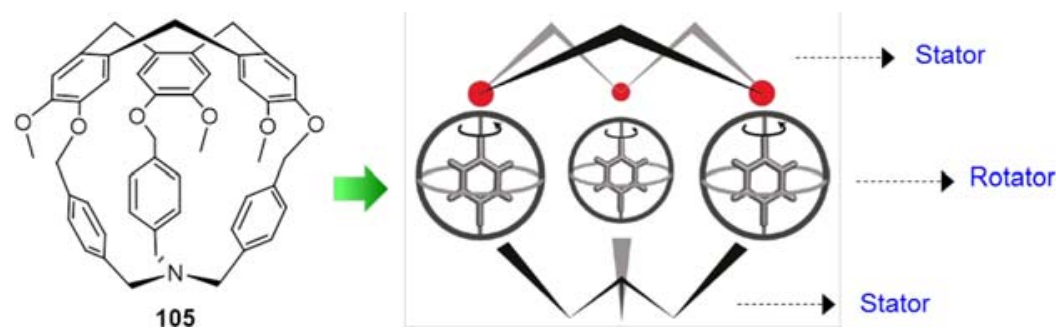

Figure 23. Gyroscope-inspired hemicryptophane 105 possessing two rigid stator and three rotator groups. Adapted from ref 52 . Copyright 2011 American Chemical Society.

between some protons in CTV and cyclic triimine, indicating the close contact between the two cyclic units. Addition of 1 equiv of $\mathrm{C}_{60}$ or $\mathrm{C}_{70}$ caused the disappearance of these NOE signals, suggesting the encapsulation of the fullerenes in the molecular cavity of $\mathbf{8 5 b}$. DOSY experiments performed with $\mathbf{8 5 b}$ showed a significant decrease of the diffusion coefficients of the host molecule in the presence of $\mathrm{C}_{60}$ or $\mathrm{C}_{70}$ in accord with the increase of the apparent size of $\mathbf{8 5 b}$, resulting in an extended conformation of the linkers after fullerene binding. Vapor pressure osmometry (VPO) experiments in toluene were also performed, and the number-average molecular weights of 85b, $C_{60} @ 85 b$, and $C_{70} @ 85 b$ were determined to be 2500, 3200 , and $3500 \mathrm{u}$, respectively, in agreement with the corresponding calculated values. Finally, UV-vis titrations were used for determining the binding constants of 85a and $85 \mathbf{b}$ toward $\mathrm{C}_{60}$ and $\mathrm{C}_{70}$, giving values up to $10^{5} \mathrm{M}^{-1}$.

\section{HEMICRYPTOPHANES IN MOTION: TOWARD MOLECULAR MACHINES}

There is increased interest in the synthesis and development of complex systems capable of performing a well-defined function at the molecular level like brakes, gears, propellers, ratchets, turnstiles, rotors, scissors, gyroscopes, and molecular springs. ${ }^{180-189}$ Most supramolecular assemblies are particularly concerned with those novel approaches of functional intelligent molecules and materials. We may assume that changes in the molecular cage conformational space can affect not only the thermodynamic properties, such as binding affinity, but also the dynamic properties, such as molecular motions, on different time scales and rates due to conformational changes. In this section we report recent works involving hemicryptophane structures, which have been investigated for their reversible and controllable conformational changes, foreseeing molecular machines and switches.

\subsection{Molecular Gyroscope}

Molecular gyroscopes are chemical compounds or supramolecular complexes containing a rotor that moves freely relative to a stator. ${ }^{190}$ Generally, the following three criteria are required for the design of molecular gyroscopic systems: (i) rotary elements (rotators) should be attached to a static framework (stator); (ii) steric contacts, internal rotation barriers, and interaction with solvent should be minimized to allow low-barrier rotary motion; and (iii) rotating groups should be isolated and/or well separated from each other.

Dmochowski et al. reported the gyroscope-inspired scaffold shown in Figure 23 in which the CTV and trisbenzylamine units of hemicryptophane 105 serve as the two-component stator bridged by three $p$-phenylenes, which are rotators. ${ }^{52}$ The $\mathrm{X}$-ray molecular structure of $\mathbf{1 0 5}$ showed an empty tribenzylamine hemicryptophane cavity because of the compact size of the cage. This absence of encapsulated solvent molecules that could hinder $p$-phenylene rotation suggests a high freedom degree of rotation for the three rotators. The ${ }^{1} \mathrm{H}$ NMR experiments performed in the $180-300 \mathrm{~K}$ temperature range allowed determining the energy barrier of $9.2 \mathrm{kcal} \mathrm{mol}^{-1}$ for the rotation of the $p$-phenylene groups at the coalescence temperature $(203 \mathrm{~K})$. To investigate the conformational fluctuations of the rotators and stator, molecular dynamic simulations were carried out, which reveal the existence of weak steric hindrance between neighboring $p$-phenylenes, accounting for the measured energy barrier for rotation. Hence, this work presents a rigid hemicryptophane framework bearing close multiple rotators, which constitutes a molecular gyroscopic system. It should be noted that in spite of the fact that the correlared rotation of the aromatic rings was not observed and the control of the direction of the motion was not achieved, this gyroscope-inspired hemicryptophane is an important step toward control of the direction and coupling of rotators within molecular systems.

\subsection{Molecular Propeller}

Atrane structures are an interesting class of compounds, which adopt a right- or left-handed propeller-like geometry defining a helical chirality with $\Delta$ or $\Lambda$ configuration, respectively. ${ }^{138,191,192}$ For instance, the vanatrane derivatives obtained from the triethanolamine core and oxidovanadium compounds provide $\Delta / \Lambda$ enantiomers (Figure 24). If an additional chiral

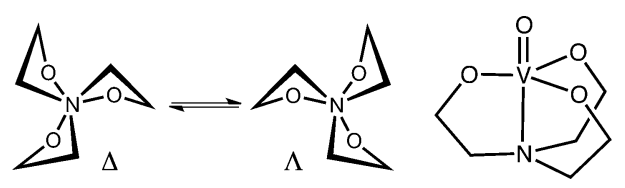

Figure 24. Vanatrane structure and its $\Delta$ and $\Lambda$ forms viewed down the $\mathrm{N}-\mathrm{V}$ bond.

element, for example with $S$ configuration, is introduced to the framework, the two $S-\Delta$ and $S$ - $\Lambda$ diastereomers combining the new stereocenter with the helical chirality of the atrane structure are formed. If the two diastereomers are rigid so that the stereoconversion of the clockwise and anticlockwise orientations of the properller-like arrangement is slow on the NMR time scale, the $\Delta$ or $\Lambda$ forms corresponding to the two species could be observed on the ${ }^{1} \mathrm{H}$ NMR spectra. More importantly, if the $\Delta$ and $\Lambda$ configuration of the atrane structure can be controlled by external stimuli, such as chemical, electrochemical, photochemical, or thermal input, a real molecular propeller system with molecular switch function could be developed.

Martinez et al. investigated the oxidovanadium hemicryptophane complex V(V)@41 including the vanatrane 
structure (Scheme 30). Because of the atrane structure of the vanadyl moiety, they identified in the ${ }^{1} \mathrm{H}$ NMR spectra the two diastereomers V(V)@M-(S,S,S- $\Lambda)-41$ and V(V)@M- $(S, S, S-\Delta)-$ 41 in a 1:0.35 ratio in $\mathrm{CDCl}_{3}$, respectively. ${ }^{139,156}$ Similarly, the $\mathrm{V}(\mathrm{V}) @ P-(S, S, S-\Lambda)-41$ and $\mathrm{V}(\mathrm{V}) @ P-(S, S, S-\Delta)-41$ diastereomers were obtained in a 1:0.17 ratio. The molecular structures obtained from DFT calculations and from X-ray diffraction demonstrate that the major species in each complex adopts the $\Lambda$ configuration, more stable than the $\Delta$ one. Interestingly, it was found that the nature of the solvent strongly affects the $\Delta / \Lambda$ ratio (solvent-driven process). For instance, when the solid of $\mathrm{V}(\mathrm{V}) @ M-(S, S, S)-41$, obtained by evaporation from a $\mathrm{CHCl}_{3}$ solution, is dissolved in $\mathrm{C}_{6} \mathrm{D}_{6}$, the $\Delta / \Lambda$ ratio gradually decreased from $1 / 0.35$ to $1 / 1$ as a result of interconversion between the two diastereomers. Afterward, evaporation and redissolution of the solid in $\mathrm{CDCl}_{3}$ resulted in the slow increase of the $\Delta / \Lambda$ ratio from $1 / 1$ to $1 / 0.35$. Therefore, an alternating change of the solvent could give rise to a diastereoselective interconversion between the two stable states having $\Lambda-41 / \Delta-41$ ratios of $74 / 26$ and 50/50, respectively (Figure 25a). At least six switching cycles in the

(a) $\Lambda / \Delta$ ratio

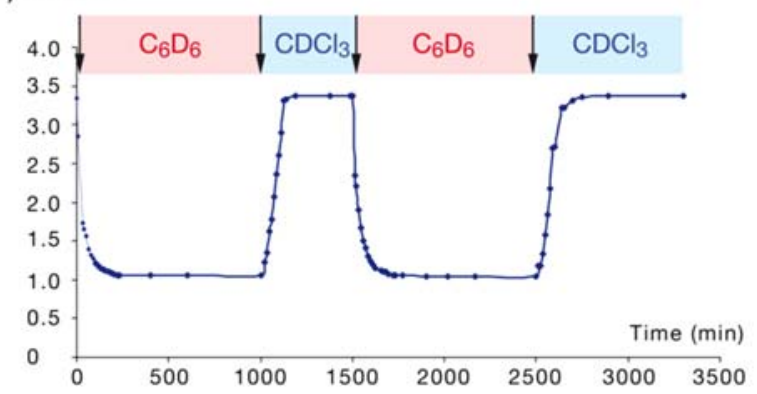

(b) $\Lambda / \Delta$ ratio

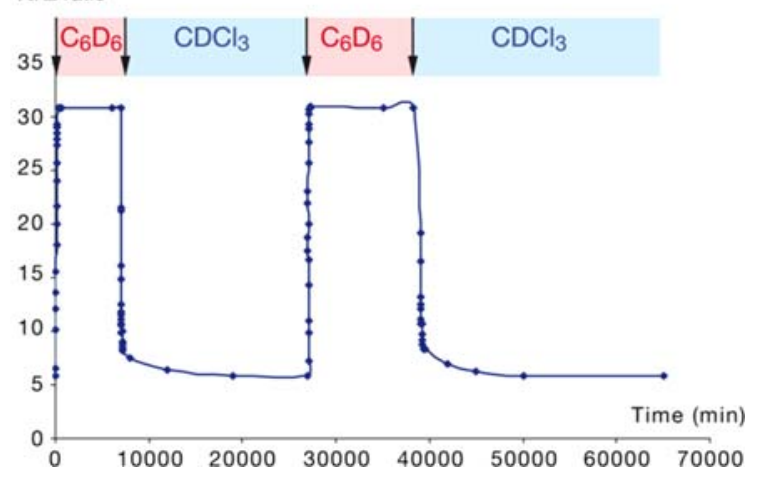

Figure 25. Plot of the $\Lambda / \Delta$ ratio (from ${ }^{1} \mathrm{H}$ NMR data) vs time for the $\Delta \leftrightarrows \Lambda$ stereoconversion of (a) V(V)@M-(S,S,S)-41 and (b) V(V)@ $P$ - $(S, S, S)-41$ after alternating dissolution in $\mathrm{C}_{6} \mathrm{D}_{6}$ and $\mathrm{CDCl}_{3}$. Reproduced with permission from ref 139. Copyright 2010 American Chemical Society.

reversible bistable system were performed. Alternating change of the solvent for $\mathrm{V}(\mathrm{V}) @ P-(S, S, S)-41$ also led to a diastereoselective interconversion (Figure 25b). These results show that the motion of the hemicryptophane molecular propellers not only can be controlled but also could be developed as molecular chiral switches by means of the solvent as an external stimulus. The energy barriers for the $\Delta \leftrightarrows \Lambda$ equilibrium were determined by NMR experiments and gave high values (around $100 \mathrm{~kJ} \mathrm{~mol}^{-1}$ for both complexes). This class of atrane propellers can be considered as a novel mode of chiral switching that is worthy of being explored for potential applications.

\subsection{Molecular Breathing}

Systems capable of performing a defined function at the molecular level have caused growing interest. Quasi-mechanical movements can be obtained from molecular machines upon the action of external stimuli. For instance, coordination/ decoordination of metal ions has provided a remarkable tool to achieve molecular motions of molecular strands from folding to unfolding states. ${ }^{193}$ Molecular cages have been also used to achieve nanomechanical processes, and recently, control of the shape and size of the molecular cavity by an external imput has been reported in both covalent and self-assembled cages. ${ }^{194,195}$

In this context it was demonstrated that dynamic motion can be induced with hemicryptophane 46 from fully folded to extended states by coordination/decoordination of the metal ion (Figure 26). ${ }^{62}$ Indeed, stereoisomers of hemicryptohane 46
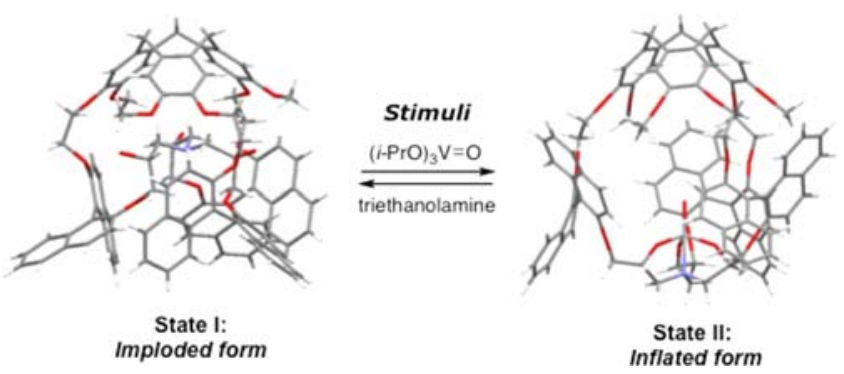

Figure 26. Graphical representation of the hemicryptophane cage switching between its bistable states, i.e., imploded and inflated conformations, with external inputs (State I, X-ray crystal structure of $M-(R, R, R)-(R, R, R)-46 ;^{62}$ State II, structure from MM3 calculation).

present "imploded" conformations in solution as evidenced by NMR spectroscopy and in the X-ray crystal structure of $M$ $(R, R, R)-(R, R, R)-46$. The imploded form adopts a "cup-withincup" structure where the triethanolamine moiety occupies the molecular cavity. ${ }^{196}$ The collapsed molecular cavity can reinflate upon binding of an oxidovanadium unit, restoring a welldefined globular form. When the vanadium core is removed by an ancillary complexing ligand (triethanolamine), the expanded form collapses to give back the initial folded state. Thus, it appears that using metal binding-unbinding as an external stimulus, a reversible conformational change between the collapsed and the expanded form can be achieved, allowing one to mimic breathing motion at the molecular scale.

\section{HEMICRYPTOPHANES: SUPRAMOLECULAR CATALYSTS}

Because of their high activity and selectivity, enzymes have been a source of inspiration for supramolecular catalysis. ${ }^{111,116,117}$ The peculiar confined environment induced by the cavity around the substrate should provide a structural preorganization that can stabilize a transition state and ensure desolvation of the guest molecules. Thus, catalysts involving host-guest complexes have been synthesized to mimic such properties of enzymes. To avoid any misunderstanding, by supramolecular catalysis we mean here catalysis for "reactions that involve supramolecular interactions that do not form part of the basic catalytic reaction". ${ }^{110}$ Therefore, hemicryptophanes, presenting a well-defined cavity just above a reactive center, constitute a 
class of supramolecular catalysts. From the above sections it has been shown that hemicryptophane cages can encapsulate various guests, including both charged and neutral species. It is thus expected that endohedral location of highly reactive species in such artificially protected and confined space of hemicryptophanes will lead to new catalytic activities and selectivities because of the specific size, shape, and chemical environment that may impose specific orientation and conformation of the guest substrates. Moreover, the rigid framework of the host molecule may also protect the catalytic site inside the cavity from degradation during the reaction, improving the stability of the catalyst. In this section we report on the use of hemicryptophane complexes that possess endohedral functions acting as supramolecular catalysts. Peculiar attention is paid to the comparison with the corresponding model catalyst, which lacks cavity, in order to highlight the key role of the confinement on the catalytic activity. Two main topics have been investigated: organocatalysis with (pro)azaphosphatrane derivatives (section 5.1) and catalysis using metal-hemicryptophane complexes (section 5.2).

\subsection{Hemicryptophanes as Organocatalysts}

Pro-azaphosphatranes, often named Verkade's superbases ( $\mathrm{p} K_{\mathrm{a}}$ $\approx 32$ ), display remarkable properties as basic or nucleophilic catalysts in numerous reactions, such as transesterification, allylation, silylation, and elimination. ${ }^{118,122,197}$ In contrast, their conjugated acid azaphosphatranes, resulting from protonation of the phosphorus atom of the proazaphosphatrane, have received less attention. In this section, the use of encaged azaphosphatrane and Verkade's superbase hemicryptophane complexes as organocatalysts is described.

5.1.1. Encaged Verkade's Superbases: Catalysts for Diels-Alder Reactions. A first example concerns the use of pro-azaphosphatranes in Diels-Alder reactions. Despite Verkade's superbases displaying remarkable properties as basic or nucleophilic catalysts in numerous reactions, their use in Diels-Alder reaction was only reported in 2014. The encaged Verkade's superbase P@15a and the model one P@ 126a, which lacks a cavity (Figure 7), were used as organocatalyst for the base-catalyzed Diels-Alder reactions (Table 6). ${ }^{198}$ The model catalyst P@126a is able to perform this reaction efficiently for both substrates with high yields, while the supramolecular catalyst P@15a displays a catalytic activity that is substrate dependent. For instance, a quantitative yield is achieved with $N$-methylmaleimide as dienophile, whereas no reaction occurs with dimethylfumarate (Table 6). According to the authors, the confinement of the organocatalyst in a deep and narrow cavity combined with the steric hindrance of the trans-dimethylfumarate can account for this result. In addition, it could be noticed that both catalysts exhibit quantitative yields for the reaction between 3-hydroxy-2-pyrone and $N$-methylmaleimide, but the caged catalyst $\mathrm{P} @ 15 a$ displays much higher diastereomeric excess than the model P@126a (77\% and $43 \%$, respectively, both in favor of the 127-endo product). It is suggested that large active sites allow various transition-state geometries, whereas a catalyst encaged in a tight space can limit them, thus favoring the most compact ones and leading to an overall improvement of the selectivity. These results indicate that not only are the yields and catalytic activities altered by the confinement of the active site but the encapsulation of the organocatalyst also improves the stereoselectivity of the Diels-Alder reaction. This case constitutes an
Table 6. Diels-Alder Reaction between 3-Hydroxy-2-pyrone and $\mathrm{N}$-Methylmaleimide or Dimethylfumarate with Catalysts P@15a and P@126a

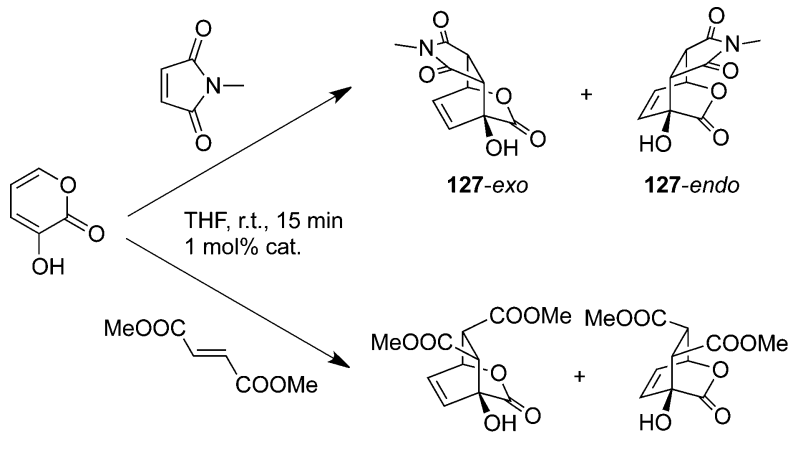

$\begin{array}{clcc}\text { dienophile } & \text { catalyst } & \text { compound }(\%)^{a} & \text { de }(\%)^{b} \\ N \text {-methylmaleimide } & \mathrm{P} @ \mathbf{1 2 6 a} & \mathbf{1 2 7}(99) & 43^{c} \\ N \text {-methylmaleimide } & \mathrm{P} @ \mathbf{1 5 a} & \mathbf{1 2 7}(100) & 77^{c} \\ \text { dimethylfumarate } & \mathrm{P} @ \mathbf{1 2 6 a} & \mathbf{1 2 8}(95) & 20 \\ \text { dimethylfumarate } & \mathrm{P} @ \mathbf{1 5 a} & \mathbf{1 2 8}(<1) & \end{array}$

${ }^{a}$ Yields were determined from NMR spectra using 2,4-dibromomesitylene as internal reference. ${ }^{b}$ Diastereomeric excesses were determined by NMR. ${ }^{c}$ The major product is 127 -endo.

important step in the development of stereoselective catalysis based on active sites confined in a hemicryptophane cavity.

5.1.2. Encaged Azaphosphatrane Catalysts for $\mathrm{CO}_{2}$ Conversion. The use of azaphosphatranes as organocatalysts for $\mathrm{CO}_{2}$ conversion was developed recently. The conversion of carbon dioxide $\left(\mathrm{CO}_{2}\right)$ into cyclic carbonate has emerged as a powerful tool to produce renewable chemical feedstocks for organic synthesis from this greenhouse effect gas, since this carbon source is abundant, cheap, and nontoxic. ${ }^{199-201}$ In 2013, Dufaud and Martinez et al. found that azaphosphatranes, such as those in Scheme 33, can be used as efficient catalysts for the synthesis of cyclic carbonates from $\mathrm{CO}_{2}$ and epoxides. ${ }^{202}$ They demonstrated that the catalytic reaction was first-order rate dependent on epoxide, catalyst, and $\mathrm{CO}_{2}$ and proposed a mechanism where both the epoxide and the $\mathrm{CO}_{2}$ were simultaneously activated at a single molecule of catalyst. They

Scheme 33. Synthesis of Cyclic Carbonates from Epoxide and Carbon Dioxide Catalyzed by Azaphosphatranes $\mathrm{PH}^{+} @$ 126, $\mathrm{PH}^{+} @ 126 a$, and $\mathrm{PH}^{+} @ 129$

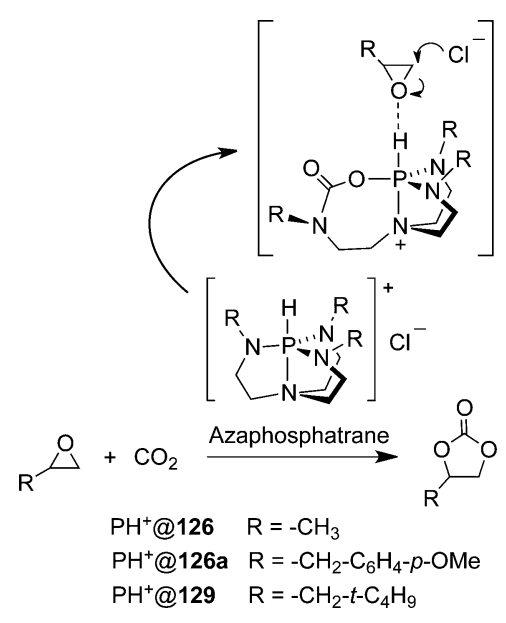


also found that the substitution pattern on the catalyst greatly affects activity and stability; for instance, catalysts $\mathrm{PH}^{+} @ 126 a$ and $\mathrm{PH}^{+} @ 129$ are much more efficient and stable than $\mathrm{PH}^{+} @$ 126 because of the steric protection of the $\mathrm{P}-\mathrm{H}$ site in the former catalysts.

In order to further improve the efficiency and stability of the catalyst, azaphosphatrane@hemicryptophane catalysts, such as $\mathrm{PH}^{+} @ 15 \mathrm{a}, \mathrm{PH}^{+} @ 15 \mathbf{b}$, and $\mathrm{PH}^{+} @ 15 \mathrm{i}$ (Scheme 29), were engaged in $\mathrm{CO}_{2}$ conversion into cyclic carbonates. ${ }^{203}$ The caged catalyst $\mathrm{PH}^{+} @ 15 a$ was found to be much more efficient than the corresponding model catalyst $\mathrm{PH}^{+} @ 126 a$, as shown in Figure 27. First, regarding the turnover number (TON) after

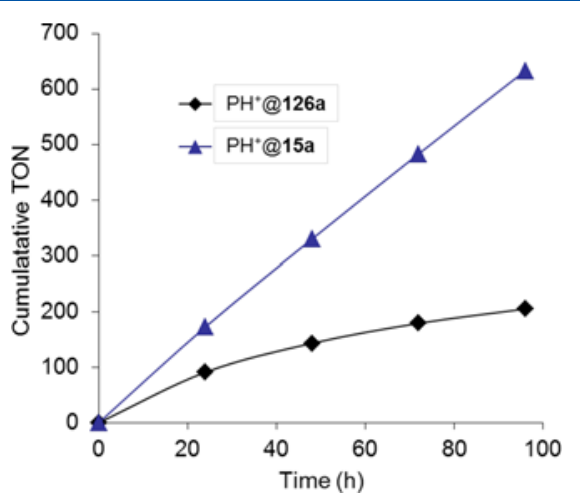

Figure 27. Changes of the cumulative TON for catalysts $\mathrm{PH}^{+} @ 15 a$ and $\mathrm{PH}^{+} @ 126 \mathrm{a}$ as a function of time. Reaction conditions: styrene oxide $(50.0 \mathrm{mmol})$, catalyst $(0.05 \mathrm{mmol}), \mathrm{CO}_{2}(1 \mathrm{bar})$, and $100{ }^{\circ} \mathrm{C}$. Reprodued with permission from ref 203. Copyright 2014 Wiley VCH.

$24 \mathrm{~h}$, the caged $\mathrm{PH}^{+} @ 15 \mathrm{a}$ was twice as active as its model $\mathrm{PH}^{+} @ 126 a$ when a ratio of 1000:1 was inputted between the epoxide (styrene oxide) and the catalyst ( 1 bar, $373 \mathrm{~K})$. In addition, no noticeable alteration of activity for $\mathrm{PH}^{+} @ 15 a$ was observed, whereas a steady decline in activity occurred for model catalyst $\mathrm{PH}^{+} @ 126 a$. Hence, these results indicate that the $\mathrm{P}-\mathrm{H}$ active site of $\mathrm{PH}^{+} @ \mathbf{1 5 a}$ is protected from degradation. The preorganization of the molecular cage likely reinforces the ability of the catalytic core to maintain its atrane structure during the catalytic cycle, thus improving the stability. Interestingly, it was also found that the reactivity of the caged catalyst $\mathrm{PH}^{+} @ 15 \mathbf{i}$, which has a narrower cavity, was much lower than $\mathrm{PH}^{+} @ 15$ a. These observations suggest that the size and shape of the nanospace for the caged catalysts significantly affect their reactivity in the conversion of $\mathrm{CO}_{2}$ to cyclic carbonates.

\subsection{Metal-Hemicryptophane Complexes as Catalysts}

It is widely recognized that metal ion embedded in the proteic cavity has key roles not only in the recognition events but also in catalysis for generating transient species and directing their reactivity. ${ }^{11,112,116}$ Thus, the design of biomimetic cage complexes for the modeling of these metalloenzyme active sites is very meaningful. Although most of the supramolecular systems designed for catalysis are not so active either because they are too rigid or because they should be used in stoichiometric amounts since the reaction product remains in the cavity preventing the next catalytic cycle, the metalhemicryptophane complexes have proved to be very efficient in catalysis achieving usually very high turnover number (TON). In this section, the organometallic hemicryptophane complexes bearing metal active sites, such as vanadium(V), zinc(II),
copper(II), and ruthenium(II), for supramolecular catalysis will be presented.

5.2.1. Encaged Vanadium(V) Catalysts for Sulfoxidation Reactions. In 2009, the first metal-hemicryptophane complex used for catalysis was reported. ${ }^{204}$ The diastereomeric hemicryptophane-oxidovanadium(V) complexes, V(V)@M$(S, S, S)-41$ and $V(V) @ P-(S, S, S)-41$, succeeded in efficient oxidation of sulfide to sulfoxide. With $10 \mathrm{~mol} \mathrm{\%} \mathrm{catalyst} \mathrm{and}$ cumene hydroperoxide (CHP) as oxygen source, oxidation of thioanisole is much faster with the encaged catalyst $\mathrm{V}(\mathrm{V}) @ M$ $(S, S, S)-41$ than with the model catalyst V(V)@(S,S,S)-126a, which lacks a cavity (Figure 28). Within $90 \mathrm{~min}$, the yield

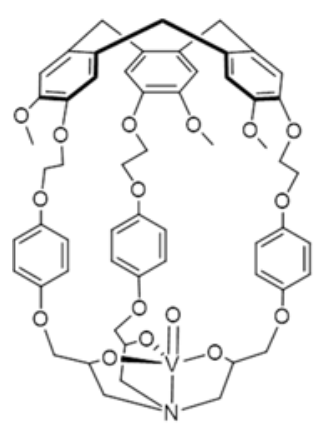

$\mathrm{V}(\mathrm{V}) @ M-(S, S, S)-41$

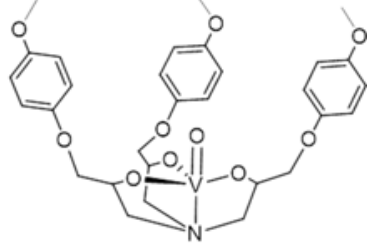

$V(V) @(S, S, S)-126 a$
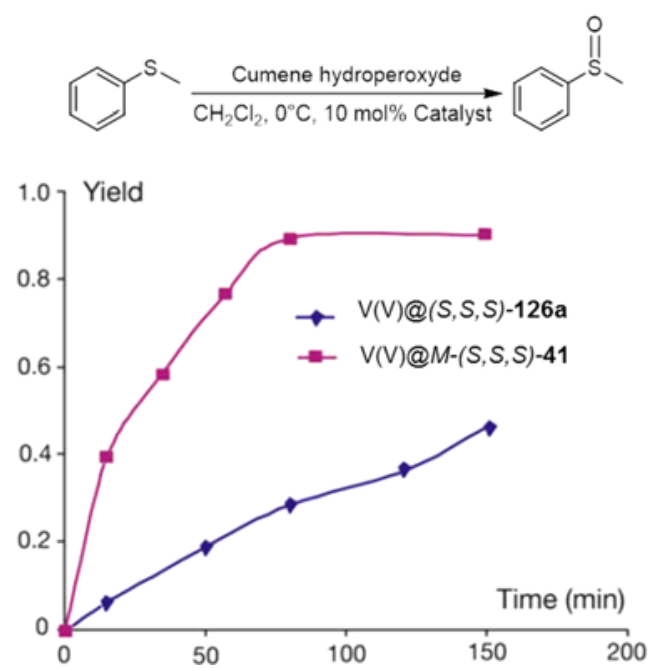

Figure 28. Time course of oxidation of thioanisole catalyzed by catalysts V(V)@M- $(S, S, S)-41$ and V(V)@(S,S,S)-126a. Conditions: 10 mol \% catalyst, 1.0 equiv of $\mathrm{CHP}, \mathrm{CH}_{2} \mathrm{Cl}_{2}, 0{ }^{\circ} \mathrm{C}$. Reproduced in part with permission from ref 204. Copyright 2009 Elsevier.

reaches $95 \%$ with high selectivity (98\%). In addition, when decreasing the amount of catalyst to $0.5 \mathrm{~mol} \%$ and performing catalysis at room temperature, a TON up to 180 was obtained, indicating the high efficiency of these supramolecular catalysts.

Catalysis is also very efficient when tert-butyl hydroperoxide (TBHP) is used as oxidant. Almost the same catalytic performance is achieved using catalyst V(V)@P-(S,S,S)-41. The kinetic constants for the reaction are estimated to be up to 6-fold higher with the hemicryptophane complex 41 than with the model complex V(V)@126. The improvement in the reaction rate by the cage was attributed to guest activation via molecular encapsulation and also by the relative flexibility of this cage that can allow fast responsiveness. 


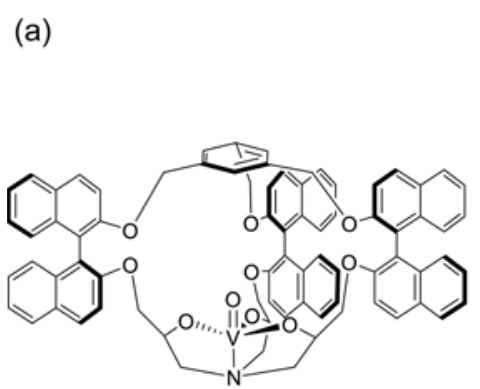

$V(V) @(S, S, S)-(S, S, S)-130$ $V(V) @(S, S, S)-(R, R, R)-130$

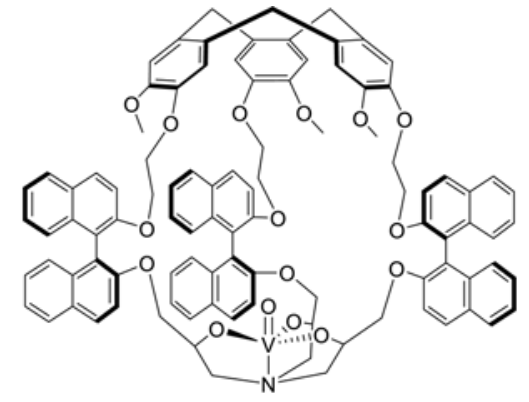

$V(V) @ P-(S, S, S)-(S, S, S)-46 V(V) @ M-(S, S, S)-(S, S, S)-46$ $V(V) @ P-(S, S, S)-(R, R, R)-46 V(V) @ M-(S, S, S)-(R, R, R)-46$

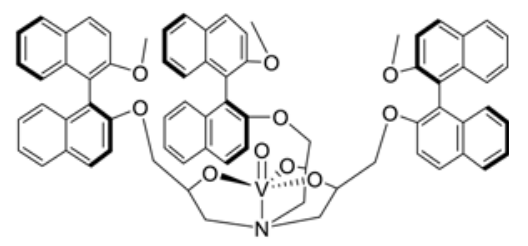

$V(V) @(S, S, S)-(S, S, S)-131$ $V(V) @(S, S, S)-(R, R, R)-131$ (b)

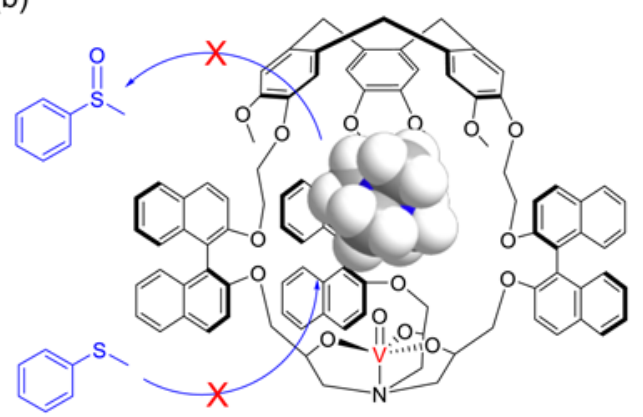

(c)

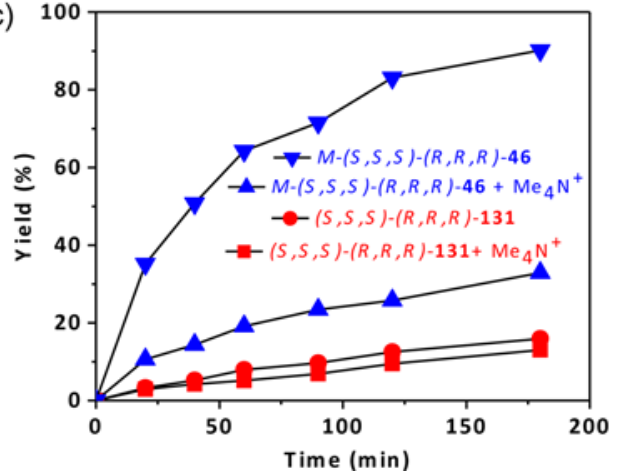

Figure 29. (a) Structures of the oxido-vanadium complexes; (b) principle for stopping the catalytic reaction with catalyst $\mathrm{V}(\mathrm{V}) @ M-(S, S, S)-(R, R, R)-$ 46 inhibited by $\mathrm{Me}_{4} \mathrm{~N}^{+}$; (c) time course of oxidation of thioanisole in the absence and presence of $\mathrm{Me}_{4} \mathrm{~N}^{+}$catalyzed by $\mathrm{V}(\mathrm{V}) @ M-(S, S, S)-(R, R, R)-46$ or $\mathrm{V}(\mathrm{V}) @(S, S, S)-(R, R, R)-131$ (1.5 mol \% catalyst, 1.0 equiv of $\left.\mathrm{CHP}, 0{ }^{\circ} \mathrm{C}, \mathrm{CH}_{2} \mathrm{Cl}_{2}\right)$. Adapted with permission from ref 140 . Copyright $2017 \mathrm{The}$ Royal Society of Chemistry.

More recently, the same group used the different stereoisomers of the hemicryptophane complexes V(V)@46, V(V)@ 130, and model catalyst V(V)@131 (Figure 29a) to further improve the catalytic sulfoxidation performance. The binaphthol moieties were introduced into the hemicryptophane cages aiming at constructing more hydrophobic cavities compared to the previous oxidovanadium hemicryptophanes V(V)@41. ${ }^{140}$ In addition, the location of the bulky binaphthol units in the linkages of the molecular cages can isolate more efficiently the heart of the cavity from the bulk solution; thus, the effect of the confinement could be more pronounced. Results show that the new binaphthol-based hemicryptophane complexes are the most efficient catalysts, which are suitable to accommodate and convert the thioanisole substrate. A reaction rate of 3-fold, 5fold, and 33-fold faster was observed for oxidation of thioanisole with the hemicryptophane catalysts V(V)@46 than with catalysts V(V)@130, V(V)@41, and V(V)@131, respectively. The specific shape of the confined hydrophobic space above the metal center induced by the bulky binaphthol linkages leads to a strong improvement of the yield, selectivity, and catalytic activity. Moreover, when decreasing the catalyst amount to $0.01 \mathrm{~mol} \%$, the catalysts V(V)@M- $(S, S, S)-(R, R, R)-$ 46 exhibit extremely high levels of efficiency with almost 10000 TON. Competitive inhibition experiments using $\mathrm{Me}_{4} \mathrm{~N}^{+} \mathrm{Pic}^{-}$ and the test with more sterically hindered substrates indicate that the catalytic reaction occurs inside the cavity of the hemicryptophane cages. For instance, after adding $\mathrm{Me}_{4} \mathrm{~N}^{+} \mathrm{Pic}^{-}$ to the reaction mixture, a significant decrease in the reaction rate and yield was observed when using $\mathrm{V}(\mathrm{V}) @ M-(S, S, S)$ $(R, R, R)-46$, whereas no noticeable change was displayed with model catalyst V(V)@(SSS)-(R,R,R)-131 (Figure 29b and $29 c)$. This enzyme-like behavior is also supported by the fact that when catalyzed by the cage complex the oxidation reaction followed Michaelis-Menten kinetics.

5.2.2. Encaged Zinc(II) Catalysts for Carbonate Hydrolysis. The $\mathrm{Zn}(\mathrm{II})$-coordinated hemicryptophane complex Zn(II)@22 and the Zn(II)@132 model catalyst were used for hydrolysis of alkyl carbonates. ${ }^{54,205}$ The $\mathrm{Zn}$ catalysts were generated in situ by adding $\mathrm{Zn}(\mathrm{OAc})_{2}$ to a solution of the corresponding ligand. The reaction conditions and kinetic data for hydrolysis of alkyl carbonate $\mathbf{1 3 3 a}-\mathbf{f}$ are shown in Table 7 . DMSO- $d_{6}$ was used as the solvent because it was found that the reaction rates are much faster in $\mathrm{DMSO}-d_{6}$ than in other solvent, such as $\mathrm{CDCl}_{3}$ or $\mathrm{CD}_{3} \mathrm{CN}$. From Table 7 it can be seen that for all substrates, except 133f, the reaction rates with hemicryptophane catalyst Zn(II)@22 are much higher than with the model catalyst Zn(II)@132 with a ratio ranging from 1.8 to 3.5. In addition, different reactivities are also observed for different substrates with the hemicryptophane catalyst.

For example, hydrolysis of substrate 133a bearing a methyl group gives the highest rate constant and a 2.2 ratio for $k_{\mathrm{Zn}(\mathrm{II}) @ 22} / k_{\mathrm{Zn}(\mathrm{II}) @ 132}$. Despite the large size of benzyl and $p$ nitrophenoxy groups in 133c, the rate constant is still acceptable, suggesting that part of the substrate goes inside the cavity. The hydrolysis of $133 \mathrm{~d}$ and $133 \mathrm{e}$ gives rise to the largest value of $k_{\mathrm{Zn}(\mathrm{II}) @ 22} / k_{\mathrm{Zn}(\mathrm{II}) @ 132}$ between hemicryptophane and model catalysts. Surprisingly, hydrolysis of $133 \mathrm{f}$ with the hemicryptophane catalyst is slower than the model compound, indicating that the $t$-Bu group has fully hindered access to the inner zinc site. Hence, all these results demonstrate that the 
Table 7. Zinc-Catalyzed Hydrolysis of Alkyl Carbonates 133a-f with Zn(II)@22 Hemicryptophane Complex and Zn(II)@132 Model Complex ${ }^{a}$

\begin{tabular}{|c|c|c|c|c|}
\hline 133a-f & & & $\begin{array}{l}\operatorname{EtN}(i-P r)_{2}(5 \text { eq }) \\
\mathrm{D}_{2} \mathrm{O}(10 \text { eq }) \\
\mathrm{Zn}(\mathrm{OAc})_{2}(0.1 \text { eq }) \\
\stackrel{\text { Ligand }(0.1 \text { eq })}{\underset{\text { DMSO- } d_{6}}{\longrightarrow}}\end{array}$ & $\begin{array}{c}\mathrm{O}_{2} \mathrm{~N} \\
\stackrel{+}{\mathrm{CO}_{2}} \\
\stackrel{+}{+} \\
\stackrel{\mathrm{ROH}}{\mathrm{H}}\end{array}$ \\
\hline substrate & ligand & $k_{\mathrm{obs}}$ & $\left(10^{-3} h^{-1}\right)$ & $k(22) / k(120)$ \\
\hline $133 a$ & 22 & & 35 & 2.2 \\
\hline $133 a$ & 132 & & 16 & \\
\hline $133 b$ & 22 & & 18 & 1.8 \\
\hline $133 b$ & 132 & & 10 & \\
\hline $133 c$ & 22 & & 27 & 1.8 \\
\hline $133 c$ & 132 & & 15 & \\
\hline $133 d$ & 22 & & 6.2 & 2.6 \\
\hline $133 d$ & 132 & & 2.4 & \\
\hline $133 \mathrm{e}$ & 22 & & 9.2 & 3.5 \\
\hline $133 \mathrm{e}$ & 132 & & 2.6 & \\
\hline $133 \mathrm{f}$ & 22 & & 4.4 & 0.8 \\
\hline $133 \mathrm{f}$ & 132 & & 5.4 & \\
\hline
\end{tabular}

${ }^{a}$ Conditions: $85 \mu \mathrm{M}$ substrate, 5.0 equiv of $\operatorname{EtN}(i-\operatorname{Pr})_{2}, 10$ equiv of $\mathrm{D}_{2} \mathrm{O}$, and 0.1 equiv of catalyst in DMSO- $d_{6}$ at $295 \mathrm{~K}$.
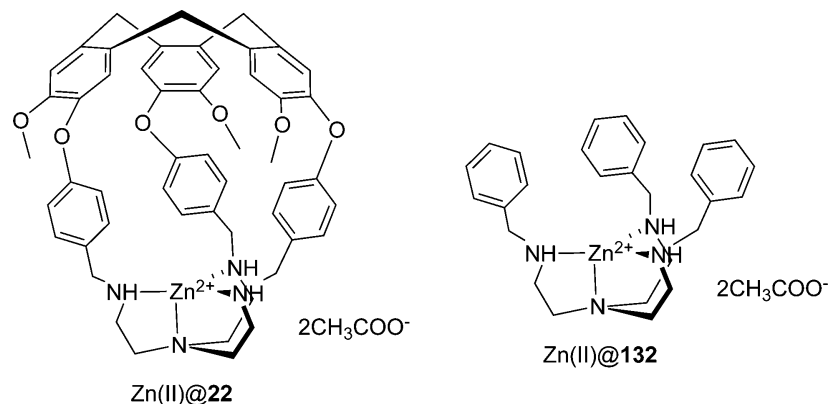

higher catalytic reactivity of the hemicryptophane catalyst is due not only to the proximity, thanks to the substrate encapsulation within the cavity, but also to control of the solvent access, inhibiting DMSO coordination with the zinc site into the cavity.

5.2.3. Encaged Ruthenium(II) Catalysts for the Oxidation of Alcohols. $\mathrm{RuCl}_{2} @ 22$ was tested as catalyst in the oxidation of alcohols into aldehyde and carboxylic acid using cerium(IV) ammonium nitrate $\left(\mathrm{Ce}\left(\mathrm{NH}_{4}\right)_{2}\left(\mathrm{NO}_{3}\right)_{6}\right)$ as stoichiometric oxidant (Table 8). ${ }^{145}$ The cage catalyst was found to be much more selective than the model compound based on the tris(2-benzylaminoethyl)amine ligand 132 $\left(\mathrm{RuCl}_{2} @ 132\right)$. Indeed, a complex mixture of aldehyde and carboxylic acid was obtained when catalyst $\mathrm{RuCl}_{2} @ 132$ was used for oxidation of primary alcohols, whereas the hemicryptophane complex $\mathrm{RuCl}_{2} @ \mathbf{2 2}$ strongly favored formation of the aldehyde and suppressed overoxidation to the carboxylic acid. Moreover, using the electro-deficient 4-nitrobenzyl alcohol substrate, the cage complex was found to be both more efficient and more selective than the model one. However, with the 2-dodecanol secondary alcohol, the model catalyst $\mathrm{RuCl}_{2} @ 132$ displayed a better activity: the higher steric hindrance of the secondary alcohol could prevent its access to the encaged catalytic site, accounting for this experimental result.

5.2.4. Encaged Copper(II) Catalysts for Cycloalkane Oxidation. Direct conversion of largely available alkanes into
Table 8. Ruthenium-Catalyzed Oxidation Reaction ${ }^{a}$

\begin{tabular}{|c|c|c|c|}
\hline catalyst & substrate & $\begin{array}{l}\text { aldehyde yield } \\
(\%)\end{array}$ & $\begin{array}{l}\text { carboxylic acid } \\
\text { yield (\%) }\end{array}$ \\
\hline $\mathrm{RuCl}_{2} @ 132$ & 1-octanol & 18 & 82 \\
\hline $\mathrm{RuCl}_{2} @ 22$ & 1-octanol & 90 & 0 \\
\hline $\mathrm{RuCl}_{2} @ 132$ & benzyl alcohol & 52 & 48 \\
\hline $\mathrm{RuCl}_{2} @ 22$ & benzyl alcohol & 91 & 9 \\
\hline $\mathrm{RuCl}_{2} @ 132$ & $\begin{array}{l}\text { 4-methoxybenzyl } \\
\text { alcohol }\end{array}$ & 55 & 41 \\
\hline $\mathrm{RuCl}_{2} @ 22$ & $\begin{array}{l}\text { 4-methoxybenzyl } \\
\text { alcohol }\end{array}$ & 94 & 6 \\
\hline $\mathrm{RuCl}_{2} @ 132$ & $\begin{array}{l}\text { 4-nitrobenzyl } \\
\text { alcohol }\end{array}$ & 27 & 10 \\
\hline $\mathrm{RuCl}_{2} @ \mathbf{2 2}$ & $\begin{array}{l}\text { 4-nitrobenzyl } \\
\text { alcohol }\end{array}$ & 88 & 12 \\
\hline $\mathrm{RuCl}_{2} @ 132$ & 2-dodecanol & \multicolumn{2}{|l|}{$68^{b}$} \\
\hline $\mathrm{RuCl}_{2} @ 22$ & 2-dodecanol & \multicolumn{2}{|l|}{$26^{b}$} \\
\hline \multicolumn{4}{|c|}{$\begin{array}{l}{ }^{a} \text { Conditions: alcohol }(0.1 \mathrm{mmol}) \text {, catalyst }(5 \mathrm{~mol} \%) \text {, and } \\
\mathrm{Ce}\left(\mathrm{NH}_{4}\right)_{2}\left(\mathrm{NO}_{3}\right)_{6}(4 \text { equiv }) \text { in } \mathrm{CH}_{3} \mathrm{CN} / \mathrm{H}_{2} \mathrm{O}(1 / 0.3) \text {. }{ }^{b} \text { Product is } \\
\text { 2-dodecanone. }\end{array}$} \\
\hline
\end{tabular}

more valuable products is a subject of great interest. ${ }^{206-209}$ An example with industrial significance concerns the oxidation products of cyclohexane, cyclohexanol, and cyclohexanone since they are used for production of adipic acid and caprolactame involved in the manufacture of nylon- $6,6^{\prime}$ and nylon-6, respectively. ${ }^{210-213}$ The industrial process uses homogeneous cobalt(III) - naphtalenate as catalyst and dioxygen as oxidant at high temperature $\left(150{ }^{\circ} \mathrm{C}\right)$, forming cyclohexanone in low yield (4\%) to achieve good selectivity (85\%). Hence, alternative approaches to transform alkane efficiently and selectively under relatively mild conditions are necessary.

Efficient alkane $\mathrm{C}-\mathrm{H}$ bond oxidation with $\mathrm{H}_{2} \mathrm{O}_{2}$ as a clean oxidant under mild conditions was achieved using the $\mathrm{Cu}$ (II)hemicryptophane complex Cu(II)@15a. ${ }^{214}$ As shown in Figure 30, when using $1 \mathrm{~mol} \%$ catalyst for oxidation of cyclohexane $(\mathrm{CyH})$ by $\mathrm{H}_{2} \mathrm{O}_{2}$ in $\mathrm{MeCN}$ at room temperature, a much higher yield is obtained after $2 \mathrm{~h}$ with the hemicryptophane catalyst Cu(II)@15a than with the model catalyst Cu(II)@126 or $\mathrm{Cu}\left(\mathrm{ClO}_{4}\left(\mathrm{H}_{2} \mathrm{O}\right)_{6}\right.$, indicating the important role of the cage structure. The time course also shows similar initial reaction rates for $\mathrm{Cu}(\mathrm{II}) @ 15 a$ and $\mathrm{Cu}(\mathrm{II}) @ 126$; however, the reaction stopped after1 h with Cu(II)@126 (14\% yield), whereas it still proceeded using $\mathrm{Cu}(\mathrm{II}) @ 15$ a until 2-fold higher yield was displayed. These observations suggest that the improved catalytic performance of the hemicryptophane catalyst is attributed to prevention of active site degradation protected by the cage rather than the direct increase of reactivity of the catalytic center. Self-oxidation reactions between two molecules of the hemicryptophane catalysts should be avoided because of the location of the active site in the inner cavity. When decreasing the catalyst amount to $0.1 \mathrm{~mol} \%$, a TON of about 110-130 was achieved, indicating the high efficiency of $\mathrm{Cu}$ (II) @15a for $\mathrm{CyH}$ oxidation. Furthermore, competition experiments between the closely related $\mathrm{CyH}$ and cyclooctane or adamantane were performed and show that $\mathrm{Cu}(\mathrm{II}) @ 15 \mathrm{a}$ is able to discriminate more efficiently $\mathrm{CyH}$ from cyclooctane or adamantane than its model compound, emphasizing that the oxidation occurs inside the catalyst cavity similar to enzyme catalysis. 

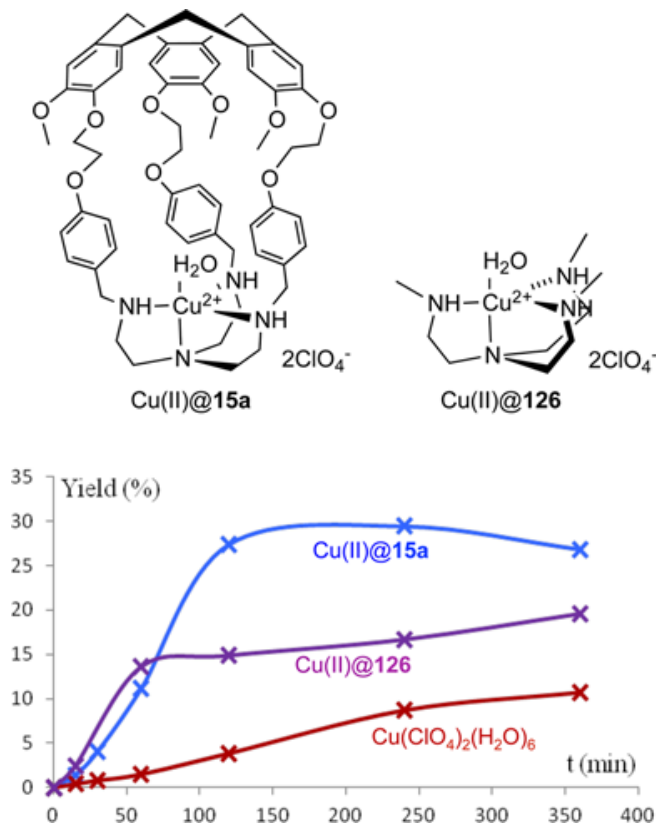

Figure 30. Time course of oxygenation of $\mathrm{CyH}$ catalyzed by $\mathrm{Cu}(\mathrm{II}) @$ 15a, $\mathrm{Cu}(\mathrm{II}) @ 126$, and $\mathrm{Cu}\left(\mathrm{ClO}_{4}\left(\mathrm{H}_{2} \mathrm{O}\right)_{6}\right.$. Conditions: $\mathrm{MeCN}(250$ $\mu \mathrm{L}), \mathrm{CyH}(3.2 \mu \mathrm{L}, 30 \mu \mathrm{mol}), \mathrm{H}_{2} \mathrm{O}_{2}(300 \mu \mathrm{mol})$, catalyst $(0.3 \mu \mathrm{mol})$, $35{ }^{\circ} \mathrm{C}$. Adapted with permission from ref 214. Copyright 2013 The Royal Society of Chemistry.

\section{CONCLUSIONS}

In this review advances in hemicryptophane chemistry have been thoroughly reviewed. A brief history about its development is first given in the Introduction. Then synthetic methods and applications in recognition, molecular machines, and supramolecular catalysis were described. When compared to other molecular containers such as cryptophanes, hemicryptophanes appear as a young family of molecular cages, which were only gradually recognized within the past decade. It cannot be neglected that they bear plenty of inborn advantages that have greatly promoted their development.

(1) With respect to synthesis, their synthetic strategies are quite flexible. The cage closure could end up with the reaction at the north or south part or $[1+1]$ coupling between the north and the south moieties. Sometimes a high overall yield could be obtained starting from commercially available materials. In addition, hemicryptophanes are chiral cages because of the inherent chirality of the CTV, and many enantiopure hemicryptophanes have been successfully obtained, including molecular cages that bear three stereogenic elements giving rise to eight stereoisomers. Furthermore, watersoluble compounds, capsules constructed by dynamic reversible bonds/interactions, and metal/nonmetal functionalized cages represent important developments in the synthesis of hemicryptophanes.

(2) In terms of their application in recognition, the hemicryptophanes are a versatile class of host molecules that can encapsulate various substrates, including neutral or charged guests and chiral or achiral molecules. The rigid CTV scaffold provides a well-preorganized cavity, of which size and shape can be adjusted by changing the linkages between the CTV and the south units. The south moiety is also modulable and can lead to cage molecules with ditopic recognition properties. Thus, elegant heteroditopic recognition of ion pairs and zwitterions has been successfully achieved. Other exciting progress includes the use of water-soluble cages for recognition of choline in pure water, fluorescent sensing of choline phosphate, and exclusive enantioselective complexation of carbohydrates.

(3) Despite hemicryptophane entering the field of molecular machinery only recently, some appealing results have been achieved. For instance, hemicryptophane oxidovanadium complexes exhibit a reversible change in its propeller motion of the vanatrane structure uniquely controlled by the solvent, establishing an atrane-based molecular chiral switch displaying stimuli-responsive properties. The relatively rigid scaffold of the CTV and the multiple functionalizations of the linkages and south moieties imply that hemicryptophanes frequently display unexpected molecular mechanical properties.

(4) With regard to catalysis, the endohedral location of highly reactive sites in this special class of hemicryptophane cages has offered a lifelike biomimetic modeling of enzymes. Benefiting from the easy functionalization of the south part with active species and their guest encapsulation properties, various efficient organo- and organometallic hemicryptophane catalysts have been prepared. A stimulating step is Verkade's encaged hemicryptophane catalysts, whose basicity and reactivity can be controlled by designing the size and shape of the cavity. Another one is that hemicryptophane complexes have proven to be superior catalysts usually exhibiting high TONs, because of their relatively flexible structure compared with other macrocycles. The high stability of the catalysts protected by the cage structure, for instance, observed from the case of $\mathrm{CO}_{2}$ conversion, is also a key feature that can greatly improve their catalytic performance.

Albeit hemicryptophane chemistry has made great progress during the past decade, its potential in synthesis and applications is still waiting to be further explored. (i) More synthetic strategies can be involved for more efficient and greener cage constructions, such as combinatorial dynamic chemistry. $^{215-217}$ (ii) Characterization of the guest recognition mainly relies on NMR spectroscopy, which has a high detection limit and slow analysis speed. More effective signaling groups can be incorporated into the cage, allowing their use in living systems, ${ }^{218-220}$ such as fluorescent bioimaging or magnetic resonance imaging (MRI). (iii) Exploration of their molecular mechanical properties is relatively poor. Indeed, these cages may be able to build various stimuli-responsive host-guest systems based on self-assembly, similar to what has been studied with rotaxanes, pseudorotaxanes, catenanes, or even supramolecular polymers. ${ }^{96,98,185-189,221}$ (iv) Although a few elegant enantiopure hemicryptophanes have been obtained, their application in enantioselective asymmetric catalysis has never been reported, underlining the interest of this challenging task. (v) The major challenge for chemists in supramolecular chemistry is always to run experiments in aqueous medium. ${ }^{103,104}$ In particular, the results can be very exciting if the water-soluble hemicryptophanes achieved the abovementioned outlook of applications in biological media. (vi) The hemicryptophane cages may also be immobilized on various solid materials, such as zeolite, $\mathrm{SiO}_{2}$, or polymer, via covalent bonds or noncovalent interactions, which will open 
new research domains. ${ }^{222}$ Therefore, we can confidently anticipate that the chemistry of hemicryptophanes will go far beyond from what has been reported herein and will be an increasingly active research field further contributing to the progress of supramolecular chemistry.

\section{ACKNOWLEDGMENTS}

D.Z. acknowledges grants from the China Scholarship Council, the Région Auvergne-Rhône-Alpes, France, for an Accueil Doc Bursary, and ENS-Lyon for an Attractiveness Fellowship for Ph.D. studies. Many students and collaborators, whose names appear in the cited references of this review, carried out the work issued from our laboratory. We thank them for their invaluable contribution in the field of hemicryptophanes chemistry.

\section{REFERENCES}

(1) Zarra, S.; Wood, D. M.; Roberts, D. A.; Nitschke, J. R. Molecular containers in complex chemical systems. Chem. Soc. Rev. 2015, 44, 419-432.

(2) Ajami, D.; Liu, L.; Rebek, J., Jr. Soft templates in encapsulation complexes. Chem. Soc. Rev. 2015, 44, 490-499.

(3) Qi, Z.; Schalley, C. A. Exploring macrocycles in functional supramolecular gels: from stimuli responsiveness to systems chemistry. Acc. Chem. Res. 2014, 47, 2222-2233.

(4) Liu, F.; Helgeson, R. C.; Houk, K. N. Building on Cram's legacy: stimulated gating in hemicarcerands. Acc. Chem. Res. 2014, 47, $2168-$ 2176.

(5) Jin, Y.; Wang, Q.; Taynton, P.; Zhang, W. Dynamic covalent chemistry approaches toward macrocycles, molecular cages, and polymers. Acc. Chem. Res. 2014, 47, 1575-1586.

(6) Durot, S.; Taesch, J.; Heitz, V. Multiporphyrinic cages: architectures and functions. Chem. Rev. 2014, 114, 8542-8578.

(7) McKee, V.; Nelson, J.; Town, R. M. Caged oxoanions. Chem. Soc. Rev. 2003, 32, 309-325.

(8) Yu, G.; Jie, K.; Huang, F. Supramolecular amphiphiles based on host-guest molecular recognition motifs. Chem. Rev. 2015, 115, 72407303.

(9) Zheng, B.; Wang, F.; Dong, S.; Huang, F. Supramolecular polymers constructed by crown ether-based molecular recognition. Chem. Soc. Rev. 2012, 41, 1621-1636.

(10) Gokel, G. W. Crown ethers and cryptands. In Monographs in Supramolecular Chemistry; Stoddart, J. F., Ed.; The Royal Society of Chemistry, 1991.

(11) Rebilly, J. N.; Colasson, B.; Bistri, O.; Over, D.; Reinaud, O. Biomimetic cavity-based metal complexes. Chem. Soc. Rev. 2015, 44, 467-489.

(12) Guo, D. S.; Liu, Y. Supramolecular chemistry of p-sulfonatocalix(n)arenes and its biological applications. Acc. Chem. Res. 2014, 47, 1925-1934.

(13) Mokhtari, B.; Pourabdollah, K.; Dalali, N. Molecule and ion recognition of nano-baskets of calixarenes since 2005. J. Coord. Chem. 2011, 64, 743-794.

(14) Kobayashi, K.; Yamanaka, M. Self-assembled capsules based on tetrafunctionalized calix(4)resorcinarene cavitands. Chem. Soc. Rev. 2015, 44, 449-466.

(15) Pochorovski, I.; Diederich, F. Development of redox-switchable resorcin(4)arene cavitands. Acc. Chem. Res. 2014, 47, 2096-2105.

(16) Assaf, K. I.; Nau, W. M. Cucurbiturils: from synthesis to highaffinity binding and catalysis. Chem. Soc. Rev. 2015, 44, 394-418.

(17) Kaifer, A. E. Toward reversible control of cucurbit(n)uril complexes. Acc. Chem. Res. 2014, 47, 2160-2167.

(18) Isaacs, L. Stimuli responsive systems constructed using cucurbit(n)uril-type molecular containers. Acc. Chem. Res. 2014, 47, 2052-2062.

(19) Crini, G. Review: A history of cyclodextrins. Chem. Rev. 2014, 114, 10940-10975.

(20) Engeldinger, E.; Armspach, D.; Matt, D. Capped Cyclodextrins. Chem. Rev. 2003, 103, 4147-4173.

(21) Xue, M.; Yang, Y.; Chi, X.; Zhang, Z.; Huang, F. Pillararenes, a New Class of Macrocycles for Supramolecular Chemistry. Acc. Chem. Res. 2012, 45, 1294-1308. 
(22) Ogoshi, T. Synthesis of novel pillar-shaped cavitands "pillar[5] arenes" and their application for supramolecular materials. J. Inclusion Phenom. Mol. Recognit. Chem. 2012, 72, 247-262.

(23) Ogoshi, T. Pillararenes. In Monographs in Supramolecular Chemistry; Gale, P., Steed, J., Eds.; The Royal Society of Chemistry, 2016; Vol. 18.

(24) Brotin, T.; Dutasta, J.-P. Cryptophanes and their complexess present and future. Chem. Rev. 2009, 109, 88-130.

(25) Collet, A. Cyclotriveratrylenes and cryptophanes. Tetrahedron 1987, 43, 5725-5759.

(26) Collet, A. In Comprehensive Supramolecular Chemistry; Atwood, J. L., Davies, J. E. D., MacNicol, D. D., Vogtle, F., Eds.; Elsevier: Oxford, 1996; Vol. 2, p 325.

(27) Canceill, J.; Collet, A.; Gabard, J.; Kotzyba-Hibert, F.; Lehn, J. M. Speleands. Macropolycyclic receptor cages based on binding and shaping sub-units. Synthesis and properties of macrocycle-cyclotriveratrylene combinations. Helv. Chim. Acta 1982, 65, 1894-1897.

(28) Smeets, J. W. H.; Coolen, H. K. A. C.; Zwikker, J. W.; Norte, R. J. M. A cage compound derived from cyclotriveratrylene and diphenylglycoluril sub-units. Recl. Trav. Chim. Pays-Bas 1989, 108, 215-218.

(29) Rapenne, G.; Crassous, J.; Collet, A.; Echegoyen, L.; Diederich, F. Regioselective one-step synthesis of trans-3,trans-3,trans-3 and e,e,e (60)fullerene tris-adducts directed by a $C_{3}$-symmetrical cyclotriveratrylene tether. Chem. Commun. 1999, 1121-1122.

(30) Gosse, I.; Dutasta, J.-P.; Perrin, M.; Thozet, A. A thiophosphorylated hemicryptophane: structure of the toluene inclusion complex. New J. Chem. 1999, 23, 545-548.

(31) Vériot, G.; Dutasta, J.-P.; Matouzenko, G.; Collet, A. Synthesis of $\mathrm{C}_{3}$-cyclotriveratrylene ligands for iron(II) and iron(III) coordination. Tetrahedron 1995, 51, 389-400.

(32) Wei, J.; Li, Z.-M.; Jin, X.-J.; Yao, X.-J.; Cao, X.-P.; Chow, H.-F.; Kuck, D. Versatile syntheses of hemi-cryptophanes and a metallocryptophane from a hexa-functionalized $C_{3 \mathrm{v}}$-symmetrical tribenzotriquinacene (TBTQ) derivative. Chem. - Asian J. 2015, 10, 1150-1158.

(33) Szumna, A. Inherently chiral concave molecules - from synthesis to applications. Chem. Soc. Rev. 2010, 39, 4274-4285.

(34) Zhang, W.-Z.; Yang, K.; Li, S.-Z.; Ma, H.; Luo, J.; Wang, K.-P.; Chung, W.-S. Inherently chiral calix(5)arenes incorporating an axially chiral binaphthyl moiety: synthesis, structures and chiral recognition. Eur. J. Org. Chem. 2015, 2015, 765-774.

(35) Canceill, J.; Collet, A.; Gabard, J.; Gottarelli, G.; Spada, G. Exciton approach to the optical activity of $C_{3}$-cyclotriveratrylene derivatives. J. Am. Chem. Soc. 1985, 107, 1299-1308.

(36) Freedman, T. B.; Cao, X.; Dukor, R. K.; Nafie, L. A. Absolute configuration determination of chiral molecules in the solution state using vibrational circular Dichroism. Chirality 2003, 15, 743-758.

(37) Stephens, P. J.; Devlin, F. J. Determination of the structure of chiral molecules using $\mathrm{Ab}$ initio vibrational circular dichroism spectroscopy. Chirality 2000, 12, 172-179.

(38) Collet, A.; Gottarelli, G. Circular dichroism of $\left(\mathrm{C}_{3}\right)$-Cyclotriveratrylene- $\mathrm{d}_{9}$ : an example of exciton optical activity due to isotopic substitution. J. Am. Chem. Soc. 1981, 103, 5912-5913.

(39) Hembury, G. A.; Borovkov, V. V.; Inoue, Y. Chirality-sensing supramolecular systems. Chem. Rev. 2008, 108, 1-73.

(40) Hamilton, T. D.; MacGillivray, L. R. Enclosed chiral environments from self-assembled metal-organic polyhedra. Cryst. Growth Des. 2004, 4, 419-430.

(41) Brotin, T.; Guy, L.; Martinez, A.; Dutasta, J.-P. Enantiopure supramolecular cages: synthesis and chiral recognition properties. Top. Curr. Chem. 2013, 341, 177-230.

(42) Valiyaveettil, S.; Engbersen, J. F. J.; Verboom, W.; Reinhoudt, D. N. Synthesis and complexation studies of neutral anion receptors. Angew. Chem., Int. Ed. Engl. 1993, 32, 900-901.

(43) Voloshin, Y. Z.; Belov, A. S. Encapsulation of organic and inorganic anions: synthesis of macropolycyclic ligands and their anionreceptor properties. Russ. Chem. Rev. 2008, 77, 161-175.

(44) Verkade, J. G. Main group atranes: chemical and structural features. Coord. Chem. Rev. 1994, 137, 233-295.
(45) Hammes, B. S.; Ramos-Maldonado, D.; Yap, G. P. A.; LiableSands, L.; Rheingold, A. L.; Young, V. G., Jr.; Borovik, A. S. $C_{3^{-}}$ symmetric chiral amidate complexes: effects of ligand binding on cavity structure. Inorg. Chem. 1997, 36, 3210-3211.

(46) Tobey, S. L.; Jones, B. D.; Anslyn, E. V. $C_{3 \mathrm{v}}$ symmetric receptors show high selectivity and high affinity for phosphate. J. Am. Chem. Soc. 2003, 125, 4026-4027.

(47) Verkade, J. G.; Kisanga, P. B. Proazaphosphatranes: a synthesis methodology trip from their discovery to vitamin A. Tetrahedron 2003, 59, 7819-7858.

(48) Raytchev, P. D.; Perraud, O.; Aronica, C.; Martinez, A.; Dutasta, J.-P. A new class of $C_{3}$-symmetrical hemicryptophane hosts: triamideand tren-hemicryptophanes. J. Org. Chem. 2010, 75, 2099-2102.

(49) Zhang, D.; Chatelet, B.; Serrano, E.; Perraud, O.; Dutasta, J.-P.; Robert, V.; Martinez, A. Insights into the complexity of weak intermolecular interactions interfering in host-guest systems. ChemPhysChem 2015, 16, 2931-2935.

(50) Perraud, O.; Raytchev, P. D.; Martinez, A.; Dutasta, J.-P. Resolution and absolute configuration assignment of a chiral hemicryptophane molecular cage. Chirality 2010, 22, 885-888.

(51) Chatelet, B.; Payet, E.; Perraud, O.; Dimitrov-Raytchev, P.; Chapellet, L.-L.; Dufaud, V.; Martinez, A.; Dutasta, J.-P. Shorter and modular synthesis of hemicryptophane-tren derivatives. Org. Lett. 2011, 13, 3706-3709.

(52) Khan, N. S.; Perez-Aguilar, J. M.; Kaufmann, T.; Hill, P. A.; Taratula, O.; Lee, O. S.; Carroll, P. J.; Saven, J. G.; Dmochowski, I. J. Multiple hindered rotators in a gyroscope-inspired tribenzylamine hemicryptophane. J. Org. Chem. 2011, 76, 1418-1424.

(53) Lefevre, S.; Zhang, D.; Godart, E.; Jean, M.; Vanthuyne, N.; Mulatier, J.-C.; Dutasta, J.-P.; Guy, L.; Martinez, A. Large scale synthesis of enantiopure molecular cages: chiroptical and recognition properties. Chem. - Eur. J. 2016, 22, 2068-2074.

(54) Makita, Y.; Sugimoto, K.; Furuyoshi, K.; Ikeda, K.; Fujiwara, S.i.; Shin-ike, T.; Ogawa, A. A Zinc(II)-included hemicryptophane: facile synthesis, characterization, and catalytic activity. Inorg. Chem. 2010, 49, $7220-7222$.

(55) Makita, Y.; Katayama, N.; Lee, H.-H.; Abe, T.; Sogawa, K.; Nomoto, A.; Fujiwara, S.-I.; Ogawa, A. A tri-aromatic amide hemicryptophane host: synthesis and acetylcholine binding. Tetrahedron Lett. 2016, 57, 5112-5115.

(56) Schmitt, A.; Perraud, O.; Payet, E.; Chatelet, B.; Bousquet, B.; Valls, M.; Padula, D.; Di Bari, L.; Dutasta, J.-P.; Martinez, A. Improved hemicryptophane hosts for the stereoselective recognition of glucopyranosides. Org. Biomol. Chem. 2014, 12, 4211-4217.

(57) Schmitt, A.; Chatelet, B.; Padula, D.; Di Bari, L.; Dutasta, J.-P.; Martinez, A. Diastereoselective recognition of $\alpha$-mannoside by hemicryptophane receptors. New J. Chem. 2015, 39, 1749-1753.

(58) Chatelet, B.; Joucla, L.; Padula, D.; Bari, L. D.; Pilet, G.; Robert, V.; Dufaud, V.; Dutasta, J.-P.; Martinez, A. Remote control of helical chirality: thermodynamic resolution of a racemic mixture of CTV units by remote stereogenic centers. Org. Lett. 2015, 17, 500-503.

(59) Rivera, D. G.; Wessjohann, L. A. Supramolecular compounds from multiple Ugi multicomponent macrocyclizations: peptoid-based cryptands, cages, and cryptophanes. J. Am. Chem. Soc. 2006, 128, $7122-7123$.

(60) Gautier, A.; Mulatier, J.-C.; Crassous, J.; Dutasta, J.-P. Chiral trialkanolamine-based hemicryptophanes: synthesis and oxovanadium complex. Org. Lett. 2005, 7, 1207-1210.

(61) Zhang, D.; Mulatier, J.-C.; Cochrane, J. R.; Guy, L.; Gao, G.; Dutasta, J.-P.; Martinez, A. Helical, axial, and central chirality combined in a single cage: synthesis, absolute configuration, and recognition properties. Chem. - Eur. J. 2016, 22, 8038-8042.

(62) Zhang, D.; Cochrane, J. R.; Di Pietro, S.; Guy, L.; Gornitzka, H.; Dutasta, J.-P.; Martinez, A. Breathing motion of a modulable molecular cavity. Chem. - Eur. J. 201710.1002/chem.201700395.

(63) Perraud, O.; Robert, V.; Gornitzka, H.; Martinez, A.; Dutasta, J.P. Combined cation- $\pi$ and anion- $\pi$ interactions for zwitterion recognition. Angew. Chem., Int. Ed. 2012, 51, 504-508. 
(64) Lefevre, S.; Simonet, R.; Pitrat, D.; Mulatier, J.-C.; Vanthuyne, N.; Jean, M.; Dutasta, J.-P.; Guy, L.; Martinez, A. Closed vs open-shell based host compounds: a direct comparison. ChemistrySelect 2016, 1 , $6316-6320$

(65) Cochrane, J. R.; Schmitt, A.; Wille, U.; Hutton, C. A. Synthesis of cyclic peptide hemicryptophanes: enantioselective recognition of a chiral zwitterionic guest. Chem. Commun. 2013, 49, 8504-8506.

(66) Brégier, F.; Karuppannan, S.; Chambron, J.-C. A hybrid cavitand made by capping permethylated $\alpha$-cyclodextrin with cyclotriveratrylene. Eur. J. Org. Chem. 2012, 2012, 1920-1925.

(67) Brégier, F.; Aubert, E.; Espinosa, E.; Chambron, J.-C. An optically-pure hemicryptophane as NMR and ECD responsive probe for chloroalkanes. ChemistrySelect 2016, 1, 2389-2395.

(68) Brégier, F.; Lavalle, J.; Chambron, J.-C. Capping $\alpha$-cyclodextrin with cyclotriveratrylene by triple disulfide-bridge formation. Eur. J. Org. Chem. 2013, 2013, 2666-2671.

(69) Wang, L.; Wang, G.-T.; Zhao, X.; Jiang, X.-K.; Li, Z.-T. Hydrogen bonding-directed quantitative self-assembly of cyclotriveratrylene capsules and their encapsulation of $\mathrm{C}_{60}$ and $\mathrm{C}_{70} . \mathrm{J}$. Org. Chem. 2011, 76, 3531-3535.

(70) Le Gac, S.; Jabin, I. Synthesis and study of calix(6)cryptamides: a new class of heteroditopic receptors that display versatile host-guest properties toward neutral species and organic associated ion-pair salts. Chem. - Eur. J. 2008, 14, 548-557.

(71) Gosse, I.; Robeyns, K.; Bougault, C.; Martinez, A.; Tinant, B.; Dutasta, J.-P. Synthesis and structural studies of gallium(III) and iron(III) hemicryptophane complexes. Inorg. Chem. 2016, 55, 10111013.

(72) Steed, J. W.; Junk, P. C.; Atwood, J. L. Ball and socket nanostructure: new supramolecular chemistry based on cyclotriveratrylene. J. Am. Chem. Soc. 1994, 116, 10346-10347.

(73) Matsubara, H.; Oguri, S.; Asano, K.; Yamamoto, K. Syntheses of novel cyclotriveratrylenophane capsules and their supramolecular complexes of fullerenes. Chem. Lett. 1999, 28, 431-432.

(74) Huerta, E.; Isla, E.; Perez, E. M.; Bo, C.; Martin, N.; Mandoza, J. d. Tripodal exTTF-CTV hosts for fullerenes. J. Am. Chem. Soc. 2010, 132, 5351-5353.

(75) Rapenne, G.; Crassous, J.; Echegoyen, L. E.; Echegoyen, L.; Flapan, E.; Diederich, F. Regioselective one-step synthesis and topological chirality of trans-3,trans-3,trans-3 and e,e,e $\left(\mathrm{C}_{60}\right)$ fullerenecyclotriveratrylene tris-adducts: discussion on a topological meso-form. Helv. Chim. Acta 2000, 83, 1209-1223.

(76) Hirsch, A.; Lamparth, I.; Karfunkel, H. R. Fullerene chemistry in three dimensions: isolation of seven regioisomeric bisadducts and trisadducts of $\mathrm{C}_{60}$ and di(ethoxycarbonyl)methylene. Angew. Chem., Int. Ed. Engl. 1994, 33, 437-438.

(77) Kraszewska, A.; Rivera-Fuentes, P.; Rapenne, G.; Crassous, J.; Petrovic, A. G.; Alonso-Gómez, J. L.; Huerta, E.; Diederich, F.; Thilgen, C. Regioselectivity in tether-directed remote functionalization - The addition of a cyclotriveratrylene-based trimalonate to $\mathrm{C}_{60}$ revisited. Eur. J. Org. Chem. 2010, 4402-4411.

(78) Bougault, C.; Bardet, M.; Laugier, J.; Jordanov, J.; Dutasta, J.-P.; Collet, A. $C_{3}$-cyclotriveratrylene bearing pendant thiol substituents: new biofunctional ligands for the complexation of iron-sulfur clusters. Supramol. Chem. 1994, 4, 139-146.

(79) Van Strijdonck, G. P. F.; van Haare, J. A. E. H.; van der Linden, J. G. M.; Steggerda, J. J.; Nolte, R. J. M. Novel subsite-differentiated (4Fe-4S) clusters based on cyclotriveratrylene. Inorg. Chem. 1994, 33, 999-1000.

(80) Matouzenko, G.; Vériot, G.; Dutasta, J.-P.; Collet, A.; Jordanov, J.; Varret, F.; Perrin, M.; Lecocq, S. New iron (II) complexes of $\mathrm{C}_{3}$ cyclotriveratrylene ligands exhibiting spin state transformations. New J. Chem. 1995, 19, 881-885.

(81) Coolen, H. K. A. C.; Reek, J. N. H.; Ernsting, J. M.; van Leeuwen, P. W. N. M.; Nolte, R. J. M. Rhodium(I)-centered cyclotriveratrylene. Recl. Trav. Chim. Pays-Bas 1995, 114, 381-386.

(82) Sumby, C. J.; Hardie, M. J. Capsules and star-bust polyhedra: an $\left(\mathrm{AgL}_{2}\right)$ capsule and a tetrahedral $\left(\mathrm{AgL}_{4}\right)$ metallosupramolecular prism with cyclotriveratrylene-type ligands. Angew. Chem., Int. Ed. 2005, 44, 2945-2959.

(83) Sumby, C. J.; Fisher, J.; Prior, T. J.; Hardie, M. J. Tris(pyridylmethylamino)cyclotriguaiacylene cavitands: an investigation of the solution and solid-state behaviour of metallo-supramolecular cages and cavitand-based coordination polymers. Chem. Eur. J. 2006, 12, 2945-2959.

(84) Rue, N. M.; Sun, J.; Warmuth, R. Polyimine container molecules and nanocapsules. Isr. J. Chem. 2011, 51, 743-768.

(85) Makita, Y.; Danno, T.; Fujita, T.; Ikeda, K.; Fujiwara, S.; Ogawa, A. Face-to-face structures formed by $3 \mathrm{D}$ hydrogen-bonded networks of tris(4-carboxyphenyl)cyclotriguaiacylene. J. Chem. Crystallogr. 2012, $42,1075-1079$

(86) Cook, T. R.; Zheng, Y.; Stang, P. J. Metal-organic frameworks and self-assembled supramolecular coordination complexes: comparing and contrasting the design, synthesis and functionality of metalorganic materials. Chem. Rev. 2013, 113, 734-777.

(87) Carruthers, C.; Ronson, T. K.; Sumby, C. J.; Westcott, A.; Harding, L. P.; Prior, T. J.; Rizkallah, P.; Hardie, M. J. The dimeric "hand-shake" motif in complexes and metallo-supramolecular assemblies of cyclotriveratrylene-based ligands. Chem. - Eur. J. 2008, 14, 10286-10296.

(88) Hardie, M. J. Self-assembled cages with cyclotriveratrylene-type host molecules. Isr. J. Chem. 2011, 51, 807-816.

(89) Abrahams, B. F.; Boughton, B. A.; FitzGerald, N. J.; Holmes, J. L.; Robson, R. A Highly symmetric diamond-like assembly of cyclotricatechylene-based tetrahedral cages. Chem. Commun. 2011, 47, 7404-7406.

(90) Abrahams, B. F.; FitzGerald, N. J.; Robson, R. Cages with tetrahedron-like topology formed from the combination of cyclotricatechylene ligands with metal cations. Angew. Chem., Int. Ed. 2010, 49, 2896-2899.

(91) Henkelis, J. J.; Carruthers, C. J.; Chambers, S. E.; Clowes, R.; Cooper, A. I.; Fisher, J.; Hardie, M. J. Metallo-cryptophanes decorated with bis-N-heterocyclic carbene ligands: self-assembly and guest uptake into a nonporous crystalline lattice. J. Am. Chem. Soc. 2014, 136, 14393-14396.

(92) Schaly, A.; Rousselin, Y.; Chambron, J.-C.; Aubert, E.; Espinosa, E. The stereoselective self-assembly of chiral metallo-organic cryptophanes. Eur. J. Inorg. Chem. 2016, 2016, 832-843.

(93) Kataoka, K.; James, T. D.; Kubo, Y. Ion pair-driven heterodimeric capsule based on boronate esterification: construction and the dynamic behavior. J. Am. Chem. Soc. 2007, 129, 15126-15127.

(94) Kataoka, K.; Okuyama, S.; Minami, T.; James, T. D.; Kubo, Y. Amine-triggered molecular capsules using dynamic boronate esterification. Chem. Commun. 2009, 13, 1682-1684.

(95) Le Gac, S.; Luhmer, M.; Reinaud, O.; Jabin, I. Self-assembly via ionic interactions of calix (6)arene-based receptors displaying remarkable host-guest properties toward neutral guests. Tetrahedron 2007, 63, 10721-10730.

(96) Dong, S.; Zheng, B.; Wang, F.; Huang, F. Supramolecular polymers constructed from macrocycle-based host-guest molecular recognition motifs. Acc. Chem. Res. 2014, 47, 1982-1994.

(97) Hu, X. Y.; Xiao, T.; Lin, C.; Huang, F.; Wang, L. Dynamic supramolecular complexes constructed by orthogonal self-assembly. Acc. Chem. Res. 2014, 47, 2041-2051.

(98) Ma, X.; Tian, H. Stimuli-responsive supramolecular polymers in aqueous solution. Acc. Chem. Res. 2014, 47, 1971-1981.

(99) Schmidt, A.; Casini, A.; Kühn, F. E. Self-assembled $\mathrm{M}_{2} \mathrm{~L}_{4}$ coordination cages: Synthesis and potential applications. Coord. Chem. Rev. 2014, 275, 19-36.

(100) Castilla, A. M.; Ramsay, W. J.; Nitschke, J. R. Stereochemistry in subcomponent self-assembly. Acc. Chem. Res. 2014, 47, 2063-2073.

(101) Nishiyabu, R.; Kubo, Y.; James, T. D.; Fossey, J. S. Boronic acid building blocks: tools for self assembly. Chem. Commun. 2011, 47, $1124-1150$

(102) Wu, X.; Li, Z.; Chen, X. X.; Fossey, J. S.; James, T. D.; Jiang, Y. B. Selective sensing of saccharides using simple boronic acids and their aggregates. Chem. Soc. Rev. 2013, 42, 8032-8048. 
(103) Kubik, S. Anion recognition in water. Chem. Soc. Rev. 2010, 39, $3648-3663$.

(104) Bistri, O.; Reinaud, O. Supramolecular control of transition metal complexes in water by a hydrophobic cavity: a bio-inspired strategy. Org. Biomol. Chem. 2015, 13, 2849-2865.

(105) Schmitt, A.; Robert, V.; Dutasta, J.-P.; Martinez, A. Synthesis of the first water-soluble hemicryptophane host: selective recognition of choline in aqueous medium. Org. Lett. 2014, 16, 2374-2377.

(106) Schmitt, A.; Collin, S.; Bucher, C.; Maurel, V.; Dutasta, J.-P.; Martinez, A. Synthesis and physico-chemical properties of the first water soluble Cu(ii)@hemicryptophane complex. Org. Biomol. Chem. 2015, 13, 2157-2161.

(107) Brotin, T.; Cavagnat, D.; Berthault, P.; Montserret, R.; Buffeteau, T. Water-soluble molecular capsule for the complexation of cesium and thallium cations. J. Phys. Chem. B 2012, 116, 1090510914.

(108) Dubost, E.; Kotera, N.; Garcia-Argote, S.; Boulard, Y.; Leonce, E.; Boutin, C.; Berthault, P.; Dugave, C.; Rousseau, B. Synthesis of a functionalizable water-soluble cryptophane-111. Org. Lett. 2013, 15, 2866-2868.

(109) Bai, Y.; Hill, P. A.; Dmochowski, I. J. Utilizing a water-soluble cryptophane with fast xenon exchange rates for picomolar sensitivity NMR measurements. Anal. Chem. 2012, 84, 9935-9941.

(110) Raynal, M.; Ballester, P.; Vidal-Ferran, A.; van Leeuwen, P. W. Supramolecular catalysis. Part 1: non-covalent interactions as a tool for building and modifying homogeneous catalysts. Chem. Soc. Rev. 2014, 43, 1660-1733.

(111) Raynal, M.; Ballester, P.; Vidal-Ferran, A.; van Leeuwen, P. W Supramolecular catalysis. Part 2: artificial enzyme mimics. Chem. Soc. Rev. 2014, 43, 1734-1787.

(112) Brown, C. J.; Toste, F. D.; Bergman, R. G.; Raymond, K. N. Supramolecular catalysis in metal-ligand cluster hosts. Chem. Rev. 2015, 115, 3012-3035.

(113) Pluth, M. D.; Bergman, R. G.; Raymond, K. N. Acid catalysis in basic solution: a supramolecular host promotes orthoformate hydrolysis. Science 2007, 316, 85-88.

(114) Yoshizawa, M.; Tamura, M.; Fujita, M. Diels-Alder in aqueous molecular hosts: unusual regioselectivity and efficient catalysis. Science 2006, 312, 251-254.

(115) Kang, J.; Rebek, J. J. Acceleration of a Diels-Alder reaction by a self-assembled molecular capsule. Nature 1997, 385, 50-52.

(116) Homden, D. M.; Redshaw, C. The use of calixarenes in metalbased catalysis. Chem. Rev. 2008, 108, 5086-5130.

(117) Pemberton, B. C.; Raghunathan, R.; Volla, S.; Sivaguru, J. From containers to catalysts: supramolecular catalysis within cucurbiturils. Chem. - Eur. J. 2012, 18, 12178-12190.

(118) Wadhwa, K.; Verkade, J. G. $\mathrm{P}\left(i-\mathrm{PrNCH}_{2} \mathrm{CH}_{2}\right)_{3} \mathrm{~N}$ : an efficient catalyst for TMS-1,3-dithiane addition to aldehydes. Tetrahedron Lett. 2009, 50, 4307-4309.

(119) Wadhwa, K.; Verkade, J. G. $\mathrm{P}\left(\mathrm{i}-\mathrm{PrNCH}_{2} \mathrm{CH}_{2}\right)_{3} \mathrm{~N}$ as a Lewis base catalyst for the synthesis of beta-hydroxynitriles using TMSAN. $J$. Org. Chem. 2009, 74, 5683-5686.

(120) Wadhwa, K.; Chintareddy, V. R.; Verkade, J. G. P$\left(\mathrm{PhCH}_{2} \mathrm{NCH}_{2} \mathrm{CH}_{2}\right)_{3} \mathrm{~N}$ : an efficient lewis base catalyst for the synthesis of propargylic alcohols and Morita-Baylis-Hillman adducts via aldehyde alkynylation. J. Org. Chem. 2009, 74, 6681-6690.

(121) Raders, S. M.; Verkade, J. G. An electron-rich proazaphosphatrane for isocyanate trimerization to isocyanurates. J. Org. Chem. 2010, $75,5308-5311$.

(122) Chintareddy, V. R.; Wadhwa, K.; Verkade, J. G. P$\left(\mathrm{PhCH}_{2} \mathrm{NCH}_{2} \mathrm{CH}_{2}\right)_{3} \mathrm{~N}$ catalysis of Mukaiyama aldol reactions of aliphatic, aromatic, and heterocyclic aldehydes and trifluoromethyl phenyl ketone. J. Org. Chem. 2009, 74, 8118-8132.

(123) Raytchev, P. D.; Martinez, A.; Gornitzka, H.; Dutasta, J.-P. Encaging the Verkade's superbases: thermodynamic and kinetic consequences. J. Am. Chem. Soc. 2011, 133, 2157-2159.

(124) Chatelet, B.; Gornitzka, H.; Dufaud, V.; Jeanneau, E.; Dutasta, J.-P.; Martinez, A. Superbases in confined space: control of the basicity and reactivity of the proton transfer. J. Am. Chem. Soc. 2013, 135, 18659-18664.

(125) Payet, E.; Dimitrov-Raytchev, P.; Chatelet, B.; Guy, L.; Grass, S.; Lacour, J.; Dutasta, J.-P.; Martinez, A. Absolute configuration and enantiodifferentiation of a hemicryptophane incorporating an azaphosphatrane moiety. Chirality 2012, 24, 1077-1081.

(126) Makita, Y.; Furuyoshi, K.; Ikeda, K.; Fujita, T.; Fujiwara, S.-i.; Ehara, M.; Ogawa, A. Synthesis and characterization of a cyclotriveratrylene-capped azaphosphatrane. Tetrahedron Lett. 2011, 52, 4129-4131.

(127) Wilcox, J. L.; Bevilacqua, P. C. A simple fluorescence method for $\mathrm{p} K_{\mathrm{a}}$ determination in RNA and DNA reveals highly shifted $\mathrm{p} K_{\mathrm{a}}$ 's. J. Am. Chem. Soc. 2013, 135, 7390-7393.

(128) Wiester, M. J.; Ulmann, P. A.; Mirkin, C. A. Enzyme mimics based upon supramolecular coordination chemistry. Angew. Chem., Int. Ed. 2011, 50, 114-137.

(129) Yoshizawa, M.; Klosterman, J. K.; Fujita, M. Functional molecular flasks: new properties and reactions within discrete, selfassembled hosts. Angew. Chem., Int. Ed. 2009, 48, 3418-3438.

(130) Shinoda, S. Dynamic cyclen-metal complexes for molecular sensing and chirality signaling. Chem. Soc. Rev. 2013, 42, 1825-1835.

(131) Fabbrizzi, L.; Poggi, A. Anion recognition by coordinative interactions: metal-amine complexes as receptors. Chem. Soc. Rev. 2013, 42, 1681-1699.

(132) Ngo, H. T.; Liu, X.; Jolliffe, K. A. Anion recognition and sensing with $\mathrm{Zn}$ (II)-dipicolylamine complexes. Chem. Soc. Rev. 2012, 41, 4928-4965.

(133) Mercer, D. J.; Loeb, S. J. Metal-based anion receptors: an application of second-sphere coordination. Chem. Soc. Rev. 2010, 39, $3612-3620$

(134) Steed, J. W. Coordination and organometallic compounds as anion receptors and sensors. Chem. Soc. Rev. 2009, 38, 506-519.

(135) Beer, P. D.; Hayes, E. J. Transition metal and organometallic anion complexation agents. Coord. Chem. Rev. 2003, 240, 167-189.

(136) Verkade, J. G. Atranes: New examples with unexpected properties. Acc. Chem. Res. 1993, 26, 483-489.

(137) Kim, Y.; Verkade, J. G. The first example of a monomeric alumatrane. Inorg. Chem. 2003, 42, 4804-4806.

(138) Schrock, R. R. Transition metal complexes that contain a triamidoamine ligand. Acc. Chem. Res. 1997, 30, 9-16.

(139) Martinez, A.; Guy, L.; Dutasta, J.-P. Reversible, Solventinduced chirality switch in atrane structure: control of the unidirectional motion of the molecular propeller. J. Am. Chem. Soc. 2010, 132, $16733-16734$.

(140) Zhang, D.; Jamieson, K.; Guy, L.; Gao, G.; Dutasta, J.-P.; Martinez, A. Tailored oxido-vanadium(V) cage complexes for selective sulfoxidation in confined space. Chem. Sci. 2017, 8, 789-794.

(141) Santoni, G.; Mba, M.; Bonchio, M.; Nugent, W. A.; Zonta, C.; Licini, G. Stereoselective control by face-to-face versus edge-to-face aromatic interactions: the case of $C_{3}-\mathrm{Ti}(\mathrm{IV})$ amino trialkolate sulfoxidation catalysts. Chem. - Eur. J. 2010, 16, 645-654.

(142) Bonchio, M.; Licini, G.; Furia, F. D.; Mantovani, S.; Modena, G.; Nugent, W. A. The first chiral zirconium(IV) catalyst for highly stereoselective sulfoxidation. J. Org. Chem. 1999, 64, 1326-1330.

(143) Zhang, D.; Gao, G.; Guy, L.; Robert, V.; Dutasta, J.-P.; Martinez, A. A fluorescent heteroditopic hemicryptophane cage for the selective recognition of choline phosphate. Chem. Commun. 2015, 51, 2679-2682.

(144) Makita, Y.; Sugimoto, K.; Furuyoshi, K.; Ikeda, K.; Fujita, T.; Fujiwara, S.-I.; Ogawa, A. Zinc(II)-included hemicryptophane: coordination of an acetonitrile guest within the cavity. Supramol. Chem. 2011, 23, 269-272.

(145) Makita, Y.; Fujita, T.; Danno, T.; Inoue, M.; Ueshima, M.; Fujiwara, S.; Ogawa, A. Selective oxidation of alcohols catalyzed by a hemicryptophane-Ruthenium complex. Supramol. Catal. 2012, 1, 911.

(146) Perraud, O.; Tommasino, J.-B.; Robert, V.; Albela, B.; Khrouz, L.; Bonneviot, L.; Dutasta, J.-P.; Martinez, A. Hemicryptophane- 
assisted electron transfer: a structural and electronic study. Dalton Trans. 2013, 42, 1530-1535.

(147) Uhlenheuer, D. A.; Petkau, K.; Brunsveld, L. Combining supramolecular chemistry with biology. Chem. Soc. Rev. 2010, 39, $2817-2826$

(148) Ma, X.; Zhao, Y. Biomedical applications of supramolecular systems based on host-guest interactions. Chem. Rev. 2015, 115, 7794-7839.

(149) Yu, G.; Zhou, J.; Shen, J.; Tang, G.; Huang, F. Cationic pillar[6]arene/ATP host-guest recognition: selectivity, inhibition of ATP hydrolysis, and application in multidrug resistance treatment. Chem. Sci. 2016, 7, 4073-4078.

(150) Yu, G.; Zhao, R.; Wu, D.; Zhang, F.; Shao, L.; Zhou, J.; Yang, J.; Tang, G.; Chen, X.; Huang, F. Pillar[5]arene-based amphiphilic supramolecular brush copolymers: fabrication, controllable selfassembly and application in self-imaging targeted drug delivery. Polym. Chem. 2016, 7, 6178-6188.

(151) Schmitt, A.; Chatelet, B.; Collin, S.; Dutasta, J. P.; Martinez, A. Chiral discrimination of ammonium neurotransmitters by $C_{3-}$ symmetric enantiopure hemicryptophane hosts. Chirality 2013, 25, 475-479.

(152) Perraud, O.; Lefevre, S.; Robert, V.; Martinez, A.; Dutasta, J.-P. Hemicryptophane host as efficient primary alkylammonium ion receptor. Org. Biomol. Chem. 2012, 10, 1056-1059.

(153) Perraud, O.; Robert, V.; Martinez, A.; Dutasta, J.-P. The cooperative effect in ion-pair recognition by a ditopic hemicryptophane host. Chem. - Eur. J. 2011, 17, 4177-4182.

(154) Perraud, O.; Robert, V.; Martinez, A.; Dutasta, J.-P. A designed cavity for zwitterionic species: selective recognition of taurine in aqueous media. Chem. - Eur. J. 2011, 17, 13405-13408.

(155) Perraud, O.; Martinez, A.; Dutasta, J.-P. Exclusive enantioselective recognition of glucopyranosides by inherently chiral hemicryptophanes. Chem. Commun. 2011, 47, 5861.

(156) Martinez, A.; Robert, V.; Gornitzka, H.; Dutasta, J.-P. Controlling helical chirality in atrane structures: solvent-dependent chirality sense in hemicryptophane-oxidovanadium $(\mathrm{V})$ complexes. Chem. - Eur. J. 2010, 16, 520-527.

(157) Kim, S.-G.; Kim, K.-H.; Jung, J.; Shin, S. K.; Ahn, K. H. Unprecedented chiral molecula recognition in a $C_{3}$-symmetric environment. J. Am. Chem. Soc. 2002, 124, 591-596.

(158) Schnopp, M.; Haberhauer, G. Highly selective recognition of $\alpha$-chiral primary organoammonium ions by $C_{3}$-symmetric peptide receptors. Eur. J. Org. Chem. 2009, 2009, 4458-4467.

(159) Haberhauer, G.; Oeser, T.; Rominger, F. Molecular scaffold for the construction of three-armed and cage-like receptors. Chem. - Eur. J. 2005, 11, 6718-6726.

(160) Lohr, H.-G.; Vogtle, F. Chromo- and fluoroionophores. A new class of dye reagents. Acc. Chem. Res. 1985, 18, 65-72.

(161) Moberg, C. Can $C_{3}$-symmetric receptors differentiate enantiomers? Angew. Chem., Int. Ed. 2006, 45, 4721-4723.

(162) Pradhan, T.; Jung, H. S.; Jang, J. H.; Kim, T. W.; Kang, C.; Kim, J. S. Chemical sensing of neurotransmitters. Chem. Soc. Rev. 2014, 43, 4684-4713.

(163) Frassineti, C.; Ghelli, S.; Gans, P.; Sabatini, A.; Moruzzi, M. S.; Vacca, A. Nuclear magnetic resonance as a tool for determining protonation constants of natural polyprotic bases in solution. Anal. Biochem. 1995, 231, 374-382.

(164) Alkorta, I.; Rozas, I.; Elguero, J. An attractive interaction between the $\pi$-cloud of $\mathrm{C}_{6} \mathrm{~F}_{6}$ and electron-donor atoms. J. Org. Chem. 1997, 62, 4687-4691.

(165) Hibbs, D. E.; Austin-Woods, C. J.; Platts, J. A.; Overgaard, J.; Turner, P. Experimental and theoretical charge density study of the neurotransmitter taurine. Chem. - Eur. J. 2003, 9, 1075-1084.

(166) Zajac, M.; Peters, R. Catalytic asymmetric synthesis of betasultams as precursors for taurine derivatives. Chem. - Eur. J. 2009, 15, $8204-8222$

(167) Mecozzi, S.; Rebek, J., Jr The 55\% solution: a formula for molecular recognition in the liquid state. Chem. - Eur. J. 1998, 4, $1016-1022$
(168) Pluth, M. D.; Johnson, D. W.; Szigethy, G.; Davis, A. V.; Teat, S. J.; Oliver, A. G.; Bergman, R. G.; Raymond, K. N. Structural consequences of anionic host-cationic guest interactions in a supramolecular assembly. Inorg. Chem. 2009, 48, 111-120.

(169) Hynes, M. J. EQNMR: a computer program for the calculation of stability constants from nuclear magnetic resonance chemical shift data. J. Chem. Soc., Dalton Trans. 1993, 311-312.

(170) Zhao, Y. H.; Abraham, M. H.; Zissimos, A. M. Fast calculation of van der Waals volume as a sum of atomic and bond contributions and its application to drug compounds. J. Org. Chem. 2003, 68, 73687373.

(171) Davis, A. P. Synthetic lectins. Org. Biomol. Chem. 2009, 7, 3629-3638.

(172) Dong, J.; Zhou, Y.; Zhang, F.; Cui, Y. A highly fluorescent metallosalalen-based chiral cage for enantioselective recognition and sensing. Chem. - Eur. J. 2014, 20, 6455-6461.

(173) Sookcharoenpinyo, B.; Klein, E.; Ferrand, Y.; Walker, D. B.; Brotherhood, P. R.; Ke, C.; Crump, M. P.; Davis, A. P. High-affinity disaccharide binding by tricyclic synthetic lectins. Angew. Chem., Int. Ed. 2012, 51, 4586-4590.

(174) Ke, C.; Destecroix, H.; Crump, M. P.; Davis, A. P. A simple and accessible synthetic lectin for glucose recognition and sensing. Nat. Chem. 2012, 4, 718-723.

(175) Ferrand, Y.; Klein, E.; Barwell, N. P.; Crump, M. P.; JimenezBarbero, J.; Vicent, C.; Boons, G. J.; Ingale, S.; Davis, A. P. A synthetic lectin for O-linked $\beta$ - $N$-acetylglucosamine. Angew. Chem., Int. Ed. 2009, 48, 1775-1779.

(176) Barwell, N. P.; Crump, M. P.; Davis, A. P. A synthetic lectin for $\beta$-glucosyl. Angew. Chem., Int. Ed. 2009, 48, 7673-7676.

(177) Ferrand, Y.; Crump, M. P.; Davis, A. P. A synthetic lectin analog for biomimetic disaccharide recognition. Science 2007, 318, 619-622.

(178) Bonar-Law, R. P.; Sanders, J. K. M. Polyol recognition by a steroid-capped porphyrin. Enhancement and modulation of misfit guest binding by added water or methanol. J. Am. Chem. Soc. 1995, 117, 259-271.

(179) López de la Paz, M.; Ellis, G.; Perez, M.; Perkins, J.; JimenezBarbero, J.; Vicent, C. Carbohydrate hydrogen-bonding cooperativity intramolecular hydrogen bonds and their cooperative effect on intermolecular processes - binding to a hydrogen-bond acceptor molecule. Eur. J. Org. Chem. 2002, 2002, 840-855.

(180) Erbas-Cakmak, S.; Leigh, D. A.; McTernan, C. T.; Nussbaumer, A. L. Artificial molecular machines. Chem. Rev. 2015, 115, 10081-10206.

(181) Mavroidis, C.; Dubey, A.; Yarmush, M. L. Molecular machines. Annu. Rev. Biomed. Eng. 2004, 6, 363-395.

(182) Harvey, E. C.; Feringa, B. L.; Vos, J. G.; Browne, W. R.; Pryce, M. T. Transition metal functionalized photo- and redox-switchable diarylethene based molecular switches. Coord. Chem. Rev. 2015, 282$283,77-86$.

(183) Collin, J.-P.; Dietrich-Buchecker, C.; Gavina, P.; JimenezMolero, M. C.; Sauvage, J.-P. Shuttles and muscles: linear molecular machines based on transition metals. Acc. Chem. Res. 2001, 34, 477487.

(184) Marsella, M. J.; Rahbarnia, S.; Wilmot, N. Molecular springs, muscles, rheostats, and precessing gyroscopes: from review to preview. Org. Biomol. Chem. 2007, 5, 391-400.

(185) Bruns, C. J.; Stoddart, J. F. Rotaxane-based molecular muscles. Acc. Chem. Res. 2014, 47, 2186-2199.

(186) Zhang, Z.; Han, C.; Yu, G.; Huang, F. A solvent-driven molecular spring. Chem. Sci. 2012, 3, 3026-3031.

(187) Gao, L.; Zhang, Z.; Zheng, B.; Huang, F. Construction of muscle-like metallo-supramolecular polymers from a pillar[5]arenebased [c2] daisy chain. Polym. Chem. 2014, 5, 5734-5739.

(188) Niess, F.; Duplan, V.; Sauvage, J.-P. Molecular muscles: from species in solution to materials and devices. Chem. Lett. 2014, 43, 964-974. 
(189) Xue, M.; Yang, Y.; Chi, X.; Yan, X.; Huang, F. Development of pseudorotaxanes and rotaxanes: from synthesis to stimuli-responsive motions to applications. Chem. Rev. 2015, 115, 7398-7501.

(190) Karlen, S. D.; Garcia-Garibay, M. A. Amphidynamic crystals: structural blueprints for molecular machines. Top. Curr. Chem. 2005, 262, 179-227.

(191) Canary, J. W. Redox-triggered chiroptical molecular switches. Chem. Soc. Rev. 2009, 38, 747-756.

(192) Canary, J. W.; Mortezaei, S.; Liang, J. Transition metal-based chiroptical switches for nanoscale electronics and sensors. Coord. Chem. Rev. 2010, 254, 2249-2266.

(193) Barboiu, M.; Stadler, A.-M.; Lehn, J.-M. Controlled folding, motional, and constitutional dynamic processes of polyheterocyclic molecular strands. Angew. Chem., Int. Ed. 2016, 55, 4130-4154.

(194) Wang, S.; Sawada, T.; Ohara, K.; Yamaguchi, K.; Fujita, M. Capsule-capsule conversion by guest encapsulation. Angew. Chem., Int. Ed. 2016, 55, 2063-2066.

(195) Arroyave, F. A.; Ballester, P. Reversible light-controlled cargo release in hydrogen-bonded dimeric capsules. J. Org. Chem. 2015, 80, 10866-10873.

(196) Mough, S. T.; Goeltz, J. C.; Holman, K. T. Isolation and structure of an "imploded" cryptophane. Angew. Chem., Int. Ed. 2004, 43, 5631-5635.

(197) Wadhwa, K.; Verkade, J. G. P(i-PrNCH$\left.{ }_{2} \mathrm{CH}_{2}\right)_{3} \mathrm{~N}$ : efficient catalyst for synthesizing $\beta$-hydroxyesters and $\alpha, \beta$-unsaturated esters using $\alpha$-trimethylsilylethylacetate (TMSEA). J. Org. Chem. 2009, 74, $4368-4371$.

(198) Chatelet, B.; Dufaud, V.; Dutasta, J. P.; Martinez, A. Catalytic activity of an encaged Verkade's superbase in a base-catalyzed DielsAlder reaction. J. Org. Chem. 2014, 79, 8684-8688.

(199) In Carbon dioxide as chemical feedstock; Aresta, M., Ed.; WileyVCH: Weinheim, Germany, 2010.

(200) Sakakura, T.; Choi, J. C.; Yasuda, H. Transformation of carbon dioxide. Chem. Rev. 2007, 107, 2365-2387.

(201) Omae, I. Aspects of carbon dioxide utilization. Catal. Today 2006, 115, 33-52.

(202) Chatelet, B.; Joucla, L.; Dutasta, J.-P.; Martinez, A.; Szeto, K. C.; Dufaud, V. Azaphosphatranes as structurally tunable organocatalysts for carbonate synthesis from $\mathrm{CO}_{2}$ and epoxides. J. Am. Chem. Soc. 2013, 135, 5348-5351.

(203) Chatelet, B.; Joucla, L.; Dutasta, J.-P.; Martinez, A.; Dufaud, V. Azaphosphatrane organocatalysts in confined space: cage effect in $\mathrm{CO}_{2}$ conversion. Chem. - Eur. J. 2014, 20, 8571-8574.

(204) Martinez, A.; Dutasta, J.-P. Hemicryptophane-oxidovanadium(V) complexes: Lead of a new class of efficient supramolecular catalysts. J. Catal. 2009, 267, 188-192.

(205) Makita, Y.; Ikeda, K.; Sugimoto, K.; Fujita, T.; Danno, T.; Bobuatong, K.; Ehara, M.; Fujiwara, S.-i.; Ogawa, A. Enhancement of catalytic reactivity of zinc(II) complex by a cyclotriveratrylene-capped structure. J. Organomet. Chem. 2012, 706-707, 26-29.

(206) Shul'pin, G. B. In Transition metals for organic synthesis, 2nd ed.; Beller, M., Bolm, C., Eds.; Wiley-VCH: Weinheim, New York, 2004; Vol. 2, pp 215-242.

(207) Olah, G. A.; Molnár, Á. Hydrocarbon Chemistry; Wiley: Hoboken, NJ, 2003.

(208) Crabtree, R. H. Organometallic alkane $\mathrm{CH}$ activation. J. Organomet. Chem. 2004, 689, 4083-4091.

(209) Shilov, A. E.; Shul'pin, G. B. Activation of CH bonds by metal complexes. Chem. Rev. 1997, 97, 2879-2932.

(210) Schuchardt, U.; Cardoso, D.; Sercheli, R.; Pereira, R.; da Cruz, R. S.; Guerreiro, M. C.; Mandelli, D.; Spinace, E. V.; Pires, E. L. Cyclohexane oxidation continues to be a challenge. Appl. Catal., A 2001, 211, 1-17.

(211) Whyman, R. Applied Organometallic Chemistry and Catalysis; Oxford University Press: Oxford, 2001.

(212) Mears, D. E.; Eastman, A. D. In Kirk-Othmer Encyclopedia of Chemical Technology, 5th ed.; Seidel, A., Ed.; Wiley, 2004; Vol. 13, p 706.
(213) Ullmann's, Encyclopedia of Industrial Chemistry, 6th ed.; Wiley-VCH: Weinheim, 2002.

(214) Perraud, O.; Sorokin, A. B.; Dutasta, J.-P.; Martinez, A. Oxidation of cycloalkanes by $\mathrm{H}_{2} \mathrm{O}_{2}$ using a copper-hemicryptophane complex as a catalyst. Chem. Commun. 2013, 49, 1288-1290.

(215) Cougnon, F. B. L.; Sanders, J. K. M. Evolution of dynamic combinatorial chemistry. Acc. Chem. Res. 2012, 45, 2211-2221.

(216) Lehn, J. M. Perspectives in chemistry - aspects of adaptive chemistry and materials. Angew. Chem., Int. Ed. 2015, 54, 3276-3289.

(217) Otto, S. Dynamic molecular networks: from synthetic receptors to self-replicators. Acc. Chem. Res. 2012, 45, 2200-2210.

(218) Yin, J.; Hu, Y.; Yoon, J. Fluorescent probes and bioimaging: alkali metals, alkaline earth metals and pH. Chem. Soc. Rev. 2015, 44, 4619-4644.

(219) Guo, Z.; Park, S.; Yoon, J.; Shin, I. Recent progress in the development of near-infrared fluorescent probes for bioimaging applications. Chem. Soc. Rev. 2014, 43, 16-29.

(220) Yang, Y.; Zhao, Q.; Feng, W.; Li, F. Luminescent chemodosimeters for bioimaging. Chem. Rev. 2013, 113, 192-270.

(221) Zhang, M.; Yan, X.; Huang, F.; Niu, Z.; Gibson, H. W. Stimuliresponsive host-guest systems based on the recognition of cryptands by organic guests. Acc. Chem. Res. 2014, 47, 1995-2005.

(222) Chatelet, B.; Joucla, L.; Dutasta, J.-P.; Martinez, A.; Dufaud, V. Immobilization of a $\mathrm{N}$-substituted azaphosphatrane in nanopores of SBA-15 silica for the production of cyclic carbonates. J. Mater. Chem. A 2014, 2, 14164-14172. 